\title{
The MacroScreen Platform
}

Citation for published version (APA):

Fontaine, M. A. C. (2020). The MacroScreen Platform: Capturing Cardiovascular Disease Inflammation In Vitro. [Doctoral Thesis, Maastricht University]. Maastricht University.

https://doi.org/10.26481/dis.20200514mf

Document status and date:

Published: 01/01/2020

DOI:

10.26481/dis.20200514mf

Document Version:

Publisher's PDF, also known as Version of record

\section{Please check the document version of this publication:}

- A submitted manuscript is the version of the article upon submission and before peer-review. There can be important differences between the submitted version and the official published version of record.

People interested in the research are advised to contact the author for the final version of the publication, or visit the DOI to the publisher's website.

- The final author version and the galley proof are versions of the publication after peer review.

- The final published version features the final layout of the paper including the volume, issue and page numbers.

Link to publication

\footnotetext{
General rights rights.

- You may freely distribute the URL identifying the publication in the public portal. please follow below link for the End User Agreement:

www.umlib.nl/taverne-license

Take down policy

If you believe that this document breaches copyright please contact us at:

repository@maastrichtuniversity.nl

providing details and we will investigate your claim.
}

Copyright and moral rights for the publications made accessible in the public portal are retained by the authors and/or other copyright owners and it is a condition of accessing publications that users recognise and abide by the legal requirements associated with these

- Users may download and print one copy of any publication from the public portal for the purpose of private study or research.

- You may not further distribute the material or use it for any profit-making activity or commercial gain

If the publication is distributed under the terms of Article $25 \mathrm{fa}$ of the Dutch Copyright Act, indicated by the "Taverne" license above, 


\section{The MacroScreen Platform \\ Capturing Cardiovascular Disease Inflammation In Vitro}


(C) Margaux A. C. Fontaine, Maastricht 2020

All rights reserved. No part of this book may be reproduced, stored in a retrieval system of any nature, or transmitted in any form of by any means (electronic, mechanical, photocopying, recording or otherwise) without prior written permission of the author, or when appropriate, by the publishers of the publications.

ISBN

Author

Layout and figure design

Cover design

Printed by
978-94-6375-838-3

Margaux A. C. Fontaine

Margaux A. C. Fontaine

Margaux A. C. Fontaine

Ridderprint 


\title{
The MacroScreen Platform \\ Capturing Cardiovascular Disease Inflammation In Vitro
}

\author{
DISSERTATION
}

to obtain the degree of Doctor at Maastricht University, on the authority of the Rector Magnificus, Prof. dr. Rianne M. Letschert in accordance with the decision of the Board of Deans, to be defended in public

On Thursday, May $14^{\text {th }} 2020,10.00$ hours

By

Margaux Anne Charlotte Fontaine 


\section{Supervisor}

Prof. Dr. E.A.L. Biessen

\section{Co-supervisors}

Dr. J.C. Sluimer

Dr. L. Temmerman

Members of the assessment committee

Prof. dr. L.J. Schurgers (Chairman)

Prof. Dr. S. Kersten (University of Wageningen, the Netherlands)

Prof. Dr. E. Lutgens (University of Amsterdam, the Netherlands)

Dr. N. van den Akker

Dr. S.L.M. Steinbusch - Coort

Financial support by the Dutch Heart Foundation for the publication of this thesis is gratefully acknowledged.

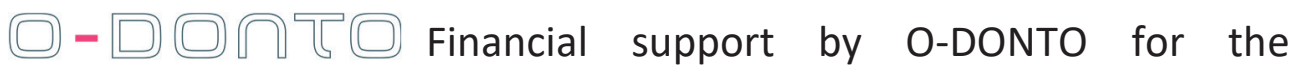
publication of this thesis is gratefully acknowledged. 


\section{Table of contents}

Chapter 1 General introduction and outline of this thesis

Chapter 2 Towards a function-based model of macrophage 31 plasticity: the MacroScreen platform

Chapter 3 The systemic acute myocardial infarction environment reprograms human macrophages

Chapter 4 Low human and murine Mcl-1 expression leads to 101 a pro-apoptotic plaque phenotype enriched in giant-cells

Chapter 5 Cardiovascular event prediction by machine 133 learning: identification of a blood-based lipid signature to stratify obese subjects.

Chapter 6 General discussion

Chapter 7 Summary | Samenvatting | Résumé 201

Chapter 8 Valorization

Appendices List of abbreviations

Acknowledgements 



\section{Chapter 1}

General introduction and outline of this

thesis 



\section{Cardiovascular disease}

Cardiovascular disease (CVD) is currently the number one cause of death worldwide ${ }^{1}$. Over the last decade, CVD-related death has increased by $12.5 \%^{2}$ and in fact, one out of three deaths worldwide is now attributable to $C V D^{1,3}$. Globally, most CVD deaths can be explained by ischemic heart disease $(49.8 \%)$ and stroke (35.3\%), followed by hypertensive heart disease, atrial fibrillation and peripheral vascular disease ${ }^{1}$. The major underlying cause for the development of CVD is atherosclerosis, the buildup of lipid-loaded plaques in the inner lining of an artery ${ }^{4}$. Atherosclerotic plaques can ultimately rupture and lead to the formation of a blood clot, resulting in the obstruction of blood flow in heart (ischemic heart disease), brain (stroke) or peripheral tissue (peripheral artery disease). CVD has become an obvious economic burden, as the European Heart Network has estimated the total CVD-related costs to be $€ 210$ billion per year ${ }^{5}$. Next to the costs generated by the healthcare of CVD patients (healthcare, medication, hospitalization) and indirect costs (patient work productivity loss), there are also costs associated with cardiovascular disease research ${ }^{6}$. Between 2010 and 2012, around $€ 876$ million was attributed to CVD research projects ${ }^{6}$, all trying to better understand and predict the development of CVD. However, current prediction models often underestimate and overestimate CVD risk in high-risk profiles and low-risk profiles, respectively?.

In the below paragraphs we will address on the main CVD risk factors and risk predictors/calculators. Next, we will discuss the ontogenesis of atherosclerosis, the main cause of CVD, with special emphasis on the role of the immune system in this disease. Lastly, we will address the use of a new high throughput analytical technique to study the immune system (mainly focusing on macrophages) in the development and prediction of CVD.

\section{CVD risk factors}

Before the $20^{\text {th }}$ century, there was no clear way to predict the clinical consequences of plaque rupture and the only focus of CVD research was the treatment options. From 1950 onwards, several epidemiological studies have enabled a change in the research focus, aiming for better definition of accurate risk factors to use in risk prediction and disease prevention, rather than only treatment ${ }^{1,8,9}$. Nine main risk factors, including age, gender, dyslipidemia, blood pressure, smoking pattern, obesity, diabetes mellitus ${ }^{10}$ and accounting for more than $90 \%$ of myocardial infarction (MI) and stroke, have been described by the INTERHEART ${ }^{1,11}$ and the 
INTERSTROKE ${ }^{1,12}$ case-control studies, respectively. The Framingham heart study, which started in 1948, investigated the life-time risk of coronary heart disease (CHD) and established the Framingham Risk Score, reflecting the 10-year risk of developing CHD based on several risk factors, including age, sex, cholesterol levels, blood pressure and smoking pattern. In the INTERHEART study, dyslipidemia was the main individual predictor for the development of $\mathrm{MI}^{11}$, whereas hypertension was the most important risk factor for stroke in the INTERSTROKE study ${ }^{12}$. Most individuals in the general population have at least one CHD risk factor, and CHD event risk score increases greatly in individuals having more than one risk factor ${ }^{13-}$ 15. Of all CVD risk factors, the five leading modifiable ones (dyslipidemia, hypertension, smoking pattern, obesity, and diabetes) account for around $50 \%$ of CVD-related death ${ }^{16}$. Below the latter risk factors will be discussed in more detail.

\section{Dyslipidemia}

Dyslipidemia is defined as an abnormal blood lipid concentration, including high triglycerides (TG) level, low high-density lipoproteins cholesterol (HDL) and elevated total (TC) or low-density lipoprotein (LDL) associated cholesterol ${ }^{17}$. To be transportable in blood, TG and LDL bind to apolipoproteins to form lipoproteins. Increased levels of TC, LDL and Apolipoprotein B have all been associated with high CVD risk and reducing LDL levels with statin treatment was repeatedly shown to reduce the risk for CVD development ${ }^{1,18-20}$. More recently, treatment with proprotein convertase subtilisin/kexin type 9 (PCSK9) antibodies showed a 60\% reduction of $\mathrm{LDL}$ concentration, resulting in a $15 \%$ decrease in cardiovascular events on top of statins ${ }^{19,20}$. Furthermore, there is genetic evidence that elevated blood LDL concentration associates with CVD. Indeed, familial hypercholesterolemia $(\mathrm{FH})$ is a genetic condition where LDL levels are abnormally high due to mutations in genes such as APOB, LDLR or PCSK9 ${ }^{21}$. Patients suffering from $\mathrm{FH}$ have a higher risk for the development of $C \mathrm{CV}^{21}$. On the other hand, $\mathrm{HDL}$ is strongly and inversely correlated to CVD but clinical trials raising plasma HDL concentration so far failed to reduce CVD burden ${ }^{22}$. Next to the conventional aforementioned lipids measured to determine CVD risk, novel analytical techniques have allowed the identification and measurement of other lipid species that are potentially more specific for the prediction of $\mathrm{CVD}^{23}$. The lipidomics field has allowed the detection of other lipid classes independently linked to the development of $C V D^{24,25}$, as well as the total lipidome profile ${ }^{26-29}$. 


\section{Hypertension}

High blood pressure is widely accepted to be one of the strongest risk factor for $\mathrm{CVD}^{2,30}$. Hypertension accounts for $54 \%$ of stroke and $47 \%$ of ischemic heart disease worldwide $^{31}$. Elevated systolic blood pressure is the best predictor of CVD in individuals over 50 years old ${ }^{32}$, while both high systolic and diastolic blood pressure can be used as predictors in youngers individuals ${ }^{33}$. Furthermore, the benefit of antihypertensive therapies have been extensively acknowledged in several randomized controlled trials ${ }^{34,35}$. Indeed, reduction of $10 \mathrm{~mm} \mathrm{Hg}$ by five different blood pressure lowering drug led to $20 \%$ risk reduction for major CVD events ${ }^{36}$.

\section{Smoking pattern}

Smoking is a strong, modifiable risk factor for CVD. According to the WHO, 1.1 billion people worldwide were smoking in $2015^{37}$. In the INTERHEART study, current smoking was one of the strongest risk factors for the development of acute myocardial infarction (MI), accounting for $36 \%$ of the risk ${ }^{11}$. Moreover, there was a linear relationship between the number of cigarettes smoked per day and the odds of developing $\mathrm{MI}^{11}$. Duration of smoking is also an important determinant for CVD risk. Smoking fewer cigarettes/day for a longer time is associated with higher CVD risk than smoking more cigarettes/day for shorter time ${ }^{38}$. Smoking is a stronger risk predictor in women than in men, increasing CVD risk by six-fold versus three-fold, respectively when compared to never-smokers ${ }^{39}$. Moreover, cessation of smoking for one year already leads to a $50 \%$ risk reduction, which is further decreased after two years, to reach risk levels of non-smokers ${ }^{40,41}$.

\section{Obesity}

Over the last 40 years, the prevalence of hypertension, smoking behavior and blood lipid levels have substantially reduced worldwide (31 to $15 \%, 39$ to $26 \%$ and 34 to $17 \%$, respectively $)^{42-44}$. On the other hand, obesity prevalence almost tripled since $1975^{45,46}$ and this increase was associated with a rise in (diagnosed) type 2 diabetes mellitus (T2DM) prevalence ${ }^{42}$. Obesity is defined as a Body Mass Index (BMI) $\geq 30$ $\mathrm{kg} / \mathrm{m}^{2}$ and is subdivided in three classes, class I (BMI=30-34.9, mild obesity), class II (BMI=35-39.9, moderate obesity) and class III (BMI $\geq 40$, severe obesity). According to the World Health Organization (WHO) in 2016, 39\% of adults were overweight (BMI 25 ), of which $13 \%$ were obese, reaching 650 million individuals ${ }^{45}$. Since 1975 , obesity prevalence has nearly tripled and is expected to reach $21 \%$ by 2025 if this trend continues ${ }^{45}$. Obesity has been repeatedly shown to be an 
independent risk factor for the development of CVD, as judged its correlation to CVD in absence of any other CVD risk factor ${ }^{47}$.

Obesity has direct and indirect effects on CVD risk, mediated by a functional adaptation of the fat mass and the effects on other CVD risk factors. Regarding the former, obese individuals have excessive fat mass, also known as adipose tissue, and this accumulation of fat mass is directly linked to the development of atherosclerosis ${ }^{48}$. In lean individuals, a series of hormones, most commonly known as adipokines, are secreted by adipose tissue ${ }^{47,49}$. Adipokines are involved in glucose and lipid metabolism, inflammation and coagulation pathways and can either be pro- or anti-atherogenic ${ }^{50}$. During obesity, this adipose tissue secretion pattern is dysregulated and shifts toward a pro-atherogenic phenotype, where adipokines such as leptin, TNF- $\alpha$, IL- 6 and MCP- 1 are overexpressed and contribute to the low-grade inflammatory state observed in obesity ${ }^{49,51}$. These proinflammatory adipokines have been positively associated to the development of $\mathrm{CVD}^{52}$. On the other hand, major cardioprotective adipokines including adiponectin, omentin and apelin, are downregulated during obesity and hence negatively correlated to the development of $\mathrm{CVD}^{50,52}$. Apart from this direct association, obesity is also indirectly linked to CVD due to its strong relationship with other CVD risk factors, such as dyslipidemia, hypertension and T2DM ${ }^{53}$. In 2017, more than $80 \%$ of T2DM cases were overweight or obese ${ }^{54}$.

\section{Diabetes}

Diabetes Mellitus (DM) is a well-known risk factor for CVD, as it is independently associated with a two to four-fold increased risk for $C V D^{55}$. DM prevalence keeps on increasing, affecting 382 million individuals in $2014^{56}$. The relationship between DM and CVD is complicated, as other CVD risk factors, such as obesity, hypertension and dyslipidemia, are often observed in patients with DM. Diabetes is closely linked to obesity, as one kilogram weight gain increases the risk to develop diabetes by 4,5 to $9 \%{ }^{57,58}$. Furthermore, the prevalence of obese among T2DM patients ranges from $60 \%$ to $90 \%$ of all T2DM patients ${ }^{54}$. Glycemic control drugs have shown to help reduce $C V D^{59}$, however this effect was reported to be modest and mostly due the consequences on other risk factors ${ }^{56,59,60}$.

\section{Cardiovascular risk assessment}

To assess the most effective treatment for high risk CVD patients, clinicians often use CVD risk calculators. To date, there are over 100 cardiovascular risk calculators Page | 12 
available ${ }^{61}$ which are all based on the aforementioned traditional CVD risk factors. However, only 25 of these CVD risk prediction models have been externally validated in an independent cohort ${ }^{61,62}$. The most widely known CVD risk calculator is the Framingham risk score, derived from the Framingham study (FRS) in 1991. The FRS has been validated in 35 US cohorts, with area under the curve (AUC, or prediction power value) ranging from 0.60 to 0.83 and in 68 European populations with an AUC ranging from $0.53-0.88^{62}$. However, comparison between 25 different risk calculators in a similar population only revealed a $67 \%$ agreement between models ${ }^{63}$. This shows that the output of risk calculators markedly differs, depending on the population used to generate the score, but also on the clinical endpoints and the length of the calculated risk. Together, this emphasizes that CVD risk assessment for every individual patient should be done with a risk calculator, derived from a representative population, matching with the patient in question.

\section{Atherosclerosis: definition}

Atherosclerosis is the main underlying cause for $\mathrm{CVD}^{8}$, and it is defined as a chronic, progressive disease typified by the accumulation of inflammatory cells, lipids and fibrous tissue in the inner wall of a medium to large sized artery. This so-called atherosclerotic plaque can ultimately rupture and lead to the formation of a blood clot, which in turn will restrict blood flow to a specific organ, such as the brain or the heart. Atherosclerosis is not a modern disease, as it has been observed in 4000 year-old mummies ${ }^{64,65}$. It was recognized for the first time in the beginning of the $19^{\text {th }}$ century, by the French pathologist Jean Lobstein ${ }^{66}$. Initially, atherosclerosis was thought to be a lipid-driven disease, as cholesterol was observed in the plaques ${ }^{67}$. However, the presence of inflammatory cells in the lesion led to the hypothesis that atherosclerosis was not only a cholesterol storage disease ${ }^{68}$. Rudolf Virchow was the first one to explain the role of inflammatory cells in atherogenesis ${ }^{66}$. The implication of inflammation in the development of atherosclerosis was recently demonstrated in the Canakinumab Anti-Inflammatory Thrombosis Outcome Study (CANTOS). The CANTOS trial is a double-blind trial including patients who already suffered a $\mathrm{Ml}$ and with elevated levels of systemic inflammation (CRP> $2 \mathrm{mg} / \mathrm{ml}$ ), despite statin therapy ${ }^{69}$. Patient groups who received $150 \mathrm{mg}$ of canakinumab, an interleukin-1 Beta (IL-1 $\beta$ ) monoclonal antibody, on top of statin treatment and every three months had a significant lower risk for CVD ${ }^{69}$. However, these patients had higher incidence of infection and there was no significant difference in all-cause mortality ${ }^{69}$. 


\section{Atherosclerosis development}

The endothelium, the inner cellular layer of blood vessels, is an almost impermeable barrier between blood vessels and tissues. Upon stress (e.g. lowshear stress, hyperglycemia or inflammation), endothelial cells (ECs) become dysfunctional and the barrier integrity is weakened, leading to leakage, amongst others ${ }^{70}$. The process of atherosclerosis begins with excessive retention of lowdensity lipoprotein (LDL) in the artery's sub-endothelial space ${ }^{8}$. LDL is in turn biochemically modified within the arterial wall and activates the ECs. Activated ECs attract and capture blood monocytes via the expression of adhesion and chemoattractant molecules (such as vascular cell adhesion molecules (VCAMs) and chemokines) in attempt to clear the modified LDL. These monocytes enter the subendothelial space and differentiate into macrophages, which take up the modified LDL and enhance the inflammatory response ${ }^{71}$. These lipid-laden macrophages, called foam cells, accumulate in the lesion and undergo programmed cell-death, apoptosis, due to this lipid overload. One of the main functions of the macrophage is to clear dead cells under physiological conditions, a process called efferocytosis ${ }^{72}$. However, in more advanced lesions, the efferocytosis process is defective and the non-cleared apoptotic cells will become necrotic. Together this leads to the formation of the plaque necrotic core, which consists of apoptotic cell debris and lipids ${ }^{73}$.

In addition, smooth muscle cells (SMCs), normally located in the medial layer of arteries, migrate to the intima and proliferate around the plaque in response to cytokines secreted by activated plaque macrophages. They form the fibrous cap by secreting extracellular matrix protein, such as collagen and proteoglycans ${ }^{74}$. The fibrous cap stabilizes the plaque and protects it from rupturing; however, as disease progresses, the fibrous cap becomes thinner and can ultimately rupture. Indeed, plaque macrophages secrete matrix metallo-proteases (MMPs) which degrade collagen, and subsequently the fibrous cap. Furthermore, SMCs undergo cell death due to the plaque inflammation and uptake of oxidized lipids and rupture-prone regions are often observed where there is a reduced number of SMCs and fibrosis, accompanied by an increased number of macrophages.

\section{Immune cells in atherosclerosis}

Next to macrophages, SMCs and ECs, plaques contain a broad range of immune cell types, which are involved in the initiation and progression of atherosclerosis, such 
as neutrophils, dendritic cells and lymphocytes ${ }^{75}$. The onset of the disease is characterized by stimulation/activation of the innate immune system, which is subsequently followed by adaptive immune responses. The innate immune system is the first line of defense against pathogens such as viruses and bacteria. It acts rapidly and is non-specific. Micro-organisms express pathogen associated molecular pattern (PAMPs), which are recognized by surface receptors on innate immune cells (e.g. macrophages, neutrophils and dendritic cells) and engulfed. However, the innate immune system is not always able to eliminate the pathogens and, in that case, the adaptive immune response is activated. The adaptive immune response is slower but target-specific and involves antigen-presenting cells. These cells will activate several effector T-cell and B-cell types. In turn, the effector cells will produce specific "antigen receptors" or antigen specific antibodies, to clear the pathogens.

In atherosclerosis, both the innate and the adaptive immune responses play pivotal roles. Next to macrophages, other innate immune cell types are recruited to the atherosclerotic lesion, including neutrophils and dendritic cells ${ }^{76}$. Neutrophils accumulate in the lesions and their number positively correlates to plaque size ${ }^{77,78}$. They have been described to produce Neutrophil Extracellular Traps (NETs) to prime macrophages to produce inflammatory cytokines, resulting in increased atherogenesis ${ }^{79}$. Dendritic cells, on the other hand, act as bridge between the innate and the adaptive immune response by presenting antigens to adaptive immune cells. In healthy tissues, DCs are found in atherosclerotic-prone lesions and their number increases during the development and progression of the disease ${ }^{80}$. Furthermore, in advanced lesions, DCs localize to rupture-prone regions ${ }^{81}$.

Similarly, $\mathrm{T}$ and $\mathrm{B}$ lymphocytes, as part of the adaptive immune response, have been observed in the plaque ${ }^{82}$. There are different kind of T-cell and B-cell subsets and this is reflected in their respective role during atherosclerosis. Indeed, the high heterogeneity of $\mathrm{T}$ - and $\mathrm{B}$ - cells allows them to have both pro- and anti-atherogenic phenotypes ${ }^{83}$.

Furthermore, mast cells are also found in atherosclerotic plaques ${ }^{84,85}$. In vivo studies have shown that activation of mast cells led to an exacerbation of atherosclerosis formation and, inversely, inhibition of mast cells activation showed a reduction of atherosclerosis formation ${ }^{85}$. 
Lastly, Natural Killer (NK) and NK T cells have also been implicated in atherosclerosis. NK cells are mostly observed in unstable plaque, where they have been shown to induce apoptosis and hence associate with plaque progression and rupture $^{86}$. In addition, NKT cells also show a pro-atherogenic function, as mice lacking NKT type I and type II cells have a reduction in atherosclerotic plaque formation ${ }^{87}$.

\section{Macrophages in acute myocardial infarction, and post-infarct repair}

Aside from their important role in atherosclerosis, macrophages are also instrumental to another aspect of cardiovascular inflammation: post myocardial infarction repair. Following $\mathrm{MI}$, cardiac remodelling takes place and can be divided into two phases, including an acute inflammatory reaction, followed by fibrosis and scar formation ${ }^{88,89}$. Both processes of the disease are tightly regulated by macrophages. In response to $\mathrm{MI}$, monocytes infiltrate the myocardium, where they differentiate into macrophages and closely collaborate with cardiac resident macrophages to regulate cardiac repair ${ }^{90}$. In the early post-infarct phase, cardiac macrophages were observed to influence the pro-inflammatory response, by releasing a broad range of pro-inflammatory cytokines, such as IL- 6 and TNF- $\alpha^{91}$. Contrarily, in the later post-infarct phases, cardiac macrophages were shown to enter a pro-repair phase, exhibiting increased phagocytic and proliferative capacity and this was further followed by a scar formation phenotype, where macrophages increased their expression of extracellular matrix remodelling genes ${ }^{88}$.

\section{Macrophages heterogeneity}

As mentioned previously, macrophages are the most abundant cell type in atherosclerosis and play a central role in ischemia-reperfusion injury and healing in the heart. Currently, macrophages are divided into two main species: tissue resident macrophages, which are primarily of embryonic origin, and inflammatory macrophages, which are derived from blood monocytes and recruited to sites of inflammation/infection ${ }^{92,93}$. All macrophages share one important characteristic: they are extremely plastic and adapt extraordinarily well to their microenvironment. This high plasticity results in multiple macrophage phenotypes exerting a large variety of functions ${ }^{94-96}$, such as controlling tissue homeostasis, as well as driving inflammatory processes, including phagocytosis, apoptosis, etc ${ }^{94,97}$. In addition, tissue-resident macrophages can exhibit tissue-maintenance functions 
such as cellular debris clearance or immune surveillance, generally upon instruction by their microenvironments ${ }^{92,94,96,98}$.

Over the last years, extensive research has been conducted to understand how macrophages respond to various stimuli. It was first believed that macrophages can polarize into two main phenotypes, M1 or the pro-inflammatory subtype and M2 or the anti-inflammatory subtype. However, recent evidence suggests that this $\mathrm{M} 1 / \mathrm{M} 2$ paradigm is an oversimplification of macrophage polarization ${ }^{99}$. Indeed, the M1/M2 scheme is now seen as the two extremes of a multi-dimensional macrophage polarization spectrum ${ }^{100}$. Inflammatory stimuli, such as interferon- $\gamma$ (IFN $\gamma$ ) or lipopolysaccharide (LPS), can induce a pro-inflammatory response in macrophages (classically activated/M1-macrophages), resulting in production and secretion of pro-inflammatory cytokines, such as IL-1 1 IL-6, IL-12 or tumour necrosis factor (TNF). On the other hand, cytokines such as interleukin-4 (IL-4) or IL-13 will polarize macrophages towards an anti-inflammatory phenotype (alternatively activated-/ M2-macrophages) and the macrophages will, in turn, produce anti-inflammatory molecules, such as IL-10 ${ }^{101}$.

Macrophage transcriptional plasticity has been widely studied; however, the functional implications of macrophage heterogeneity have been barely touched upon. Several key questions remain unanswered. To mention a few: (1) Do macrophages have distinct functions depending on the mode of activation? (2) Do they sense and respond differently to the surrounding micro-environment in disease and is this reflected by their functions? (3) Is the transcriptional plasticity of the macrophages mirrored by their functional phenotype? and (4) Can we build a functional map of macrophage plasticity that could serve as reference to interpret macrophages functional profile?

Using recent technological advances, it is now possible to study the macrophage heterogeneity at the functional level. The next section will discuss how high content analysis can help in understanding macrophage functions in atherosclerosis and CVD risk assessment.

\section{High content analysis of cell function}

The term high-content analysis (HCA) defines a technique used to image and measure complex cellular activity. It combines automated microscopy with advanced analytic tools to extract multi-parametric data of single cells. HCA is based 
on fluorescent microscopy; generally, fluorescent probes are added to cells in culture and subsequent biological activity can be measured ${ }^{102}$. HCA technology provides multiple advantages over conventional functional screening. The latter were generally done in single tube format, and hence were labour intensive, slow and required large volumes of cell culture medium. Furthermore, the data analysis using HCA technologies allows rapid extraction of numerous features at the singlecell level. HCA makes it possible to simultaneously screen numerous variables in a semi-high throughput manner, at up to 384 (or even 1536) well plate format. Moreover, need for cell culture media, probes, cells and compounds/stimuli are therefore minimized, and thus costs. Also, all live measurements over time will not only give quantitative, but also spatiotemporal information, often not considered in functional analysis.

Over the last years, HCA technology has evolved, and imaging software solutions and microscopes nowadays enable automation and contain a robotic system. The development of easy-to-use image analysis tools have allowed scientists to extract a high number of features. HCA workflow is typically composed of the following standardized steps: (1) (Un)stimulated cells are stained for a special functional phenotype, the 96/384-well format plate is then placed in an automated fluorescent microscope that will measure in each well the exact same parameters, without changing the settings. (2) Once the acquiring is done, the data analysis starts. (3) Images are transferred in an image analysis tool, where each picture containing thousands of cells will be segmented. Digital segmentation algorithms detect and locate each cell or sub-cellular component and turn them into one single digital data point. (4) Following segmentation, interesting features are extracted. Features range from fluorescent signal intensity or percentage of positive cells, to shape/morphology of the signal.

HCA usually generates large data files of extracted features and the files are subsequently analysed using machine learning. Unsupervised and supervised machine learning help to extract phenotypic appreciations that were not necessarily referring to the first experimental question. Furthermore, machine learning algorithms help at integrating HCA data with other kind of data, such as phenotypic, proteomics or transcriptomics data, to build in silico models of cellular functions (Figure 1). 


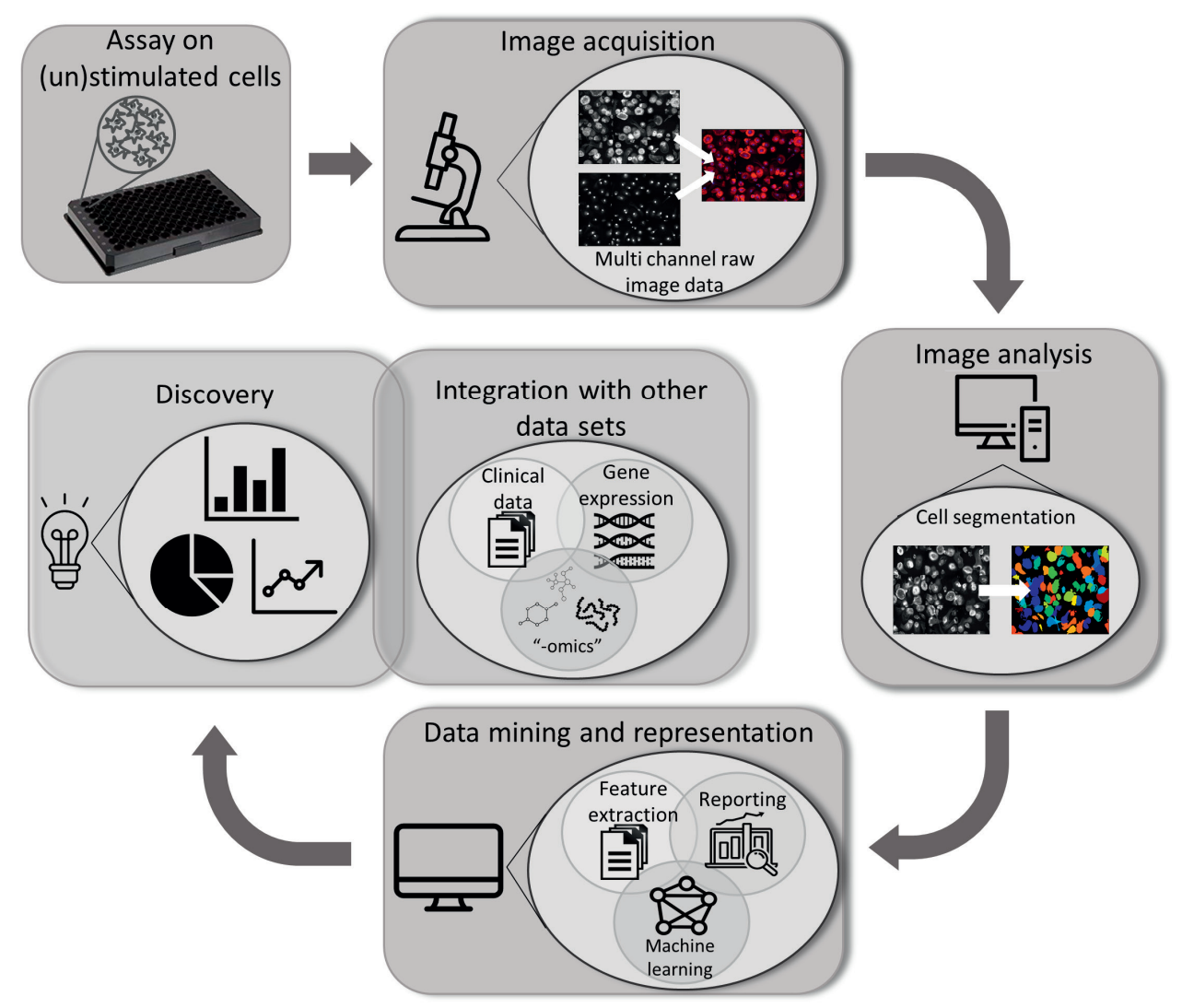

Figure 1. Standardized HCA pipeline

Fluorescent functional assays are performed on (un)stimulated cells, which are imaged with an automated microscope. Each cell will become an individual data point during the cell segmentation step. Data will be extracted using powerful computational software solutions. Relevant information will be analysed, represented and integrated to other types of data sets.

HCA was first developed in the 1980s by Pfizer for a drug screening purpose, generating new antibiotics ${ }^{103}$. Nowadays, it is not only used for high-throughput drug screening purpose, but also to image and analyse, in an unbiased way, general or specific cellular functions. In the past 15 years, biomedical research has increasingly embraced the use of HCA technologies and several genomic studies made use of HCA, where thousands of genes were knocked-out (KO) in a specific cell type and the subsequent morphological changes were analysed ${ }^{104}$. In 2005, Ohya et al. studied the yeast morphological phenotypes of 4,718 KO genes and were able to identify 2,378 candidate genes showing morphological differences in 
at least one of the 254 parameters measured ${ }^{105}$. In the years that followed, HCA technologies were further applied to study the link between genes and functional profiles in several cell types and to build genomic atlases for a variety of functions, such as cell division ${ }^{106}$, cell migration ${ }^{107}$, or endocytosis ${ }^{108}$. More recently, technological advances in cell culture and imaging methods enabled us to study three-dimensional (3D) structures, also known as organoids, using HCA. Organoids are made of stem cells, organ progenitor cells or tissue derived cell suspensions grown with extracellular matrix material. By enabling cell-cell interaction, spatial organization of cells, organ-like functional diversity, they mimic the in vivo situation better than classical 2D cell monolayers ${ }^{109}$ and have been commonly used in HCA cancer research ${ }^{110-112}$. Furthermore, HCA can be combined with confocal microscopy to provide a better resolution and image contrast during 2D/3D screening. Altogether, HCA technologies are great tools to accurately study cellular functions at single cell level. The next section will define the specific aim and hypothesis of this thesis and will explain how we plan to use HCA techniques to study macrophage functions in the context of atherosclerosis and AMI repair.

\section{Aim and hypothesis of this thesis}

Summarizing the above, macrophages are the most abundant cell type in atherosclerotic plaque and are implicated in its development at all stages of disease. Furthermore, they play a pivotal role in AMI repair. They are well known to be transcriptionally and phenotypically plastic and will respond profoundly to their (micro-)environment. In this thesis, we aim to build a functional map of macrophages by using a high content analysis system in vitro to study macrophage functions in CVD inflammation, including atherosclerosis, acute myocardial infarction and cardiometabolic disorders. This map could help to understand the role of macrophage in health and disease.

We hypothesize that macrophage transcriptional plasticity is reflected in their functional profile and that macrophages can sense their micro-environment and respond accordingly.

To test this, we will:

(1) Build a high content analyser platform (the MacroScreen platform) using human primary macrophages to define a macrophage functional profile map in vitro (chapter 2) 
(2) Use the platform to analyse the response of macrophages to a cardiovascular disease environment, using two cohorts of acute myocardial infarction (chapter 3)

(3) Validate the platform in a mouse study focusing on apoptosis and atherosclerosis (chapter 4 )

(4) Use the platform to study the effect of newly discovered biomarkers (bioactive lipids) for the development of obesity-related CVD (chapter 5).

\section{Outline of the thesis}

Macrophages are the most abundant cell type in atherosclerosis. Their transcriptional heterogeneity has been widely studied; however, a systematic study of their phenotypical plasticity is lacking. In chapter 2, we set out to build a "functionomics" platform (the MacroScreen), enabling us to detect several macrophage functions relevant for atherosclerosis and to generate a functionbased atlas of human monocyte derived macrophage responses to a variety of established stimuli in vitro.

This functional map served as reference for a subsequent study, where we mapped the functional impact of the systemic status of patients that suffered an acute myocardial infarction (AMI), on human monocyte derived macrophages. Such study could be particularly relevant as macrophages are key players not only in atherosclerosis but also in AMI repair ${ }^{90,113}$, and disease compromised functions may thus have direct implications for disease prognosis after infarct. Chapter 3 investigates whether our functionomics platform can pick up any functional changes in macrophages exposed to the serum environment of AMI patients, whether these functional changes are reflected in their transcriptional profile, and if specific functional or transcriptional patterns are associated with a poor prognosis.

Chapter 4 describes the use of the MacroScreen platform for dissection of causal mechanisms in mouse studies of atherosclerosis. Macrophage apoptosis is an important process during atherosclerosis at all stages of the disease but this process can be beneficial or detrimental, depending on plaque stage ${ }^{114,115}$. In this HCA valorization study, we investigated the effects of a key regulator of myeloid apoptosis, the anti-apoptotic protein $\mathrm{Mcl}-1$, on macrophage functions, including apoptosis, underpinning the benefits of the HCA platform for mechanistic in vitro studies. 
In chapter $\mathbf{5}$ the MacroScreen platform is deployed in a different setting. As described in the introduction, obesity is associated with CVD events, however not all obese individuals will develop CVD overtime. Conventional classifiers for CVD risk lack precision, and are generally not accurate at all within the obese population, thus more predictive biomarkers to stratify the obese individuals are eagerly awaited. In this chapter, we explored lipids for their potential to predict CVD risk in the obese population. After the discovery of novel biomarkers, we studied their causal relationship with macrophage function using our functionomics platform.

A general discussion of the main findings of this thesis is presented in chapter 6 , also including future perspective and applications of our functionomics platform. 


\section{References}

1. Joseph, P. et al. Reducing the Global Burden of Cardiovascular Disease, Part 1. The Epidemiology and Risk Factors. Circ. Res. 121, 677-694 (2017).

2. Wang, H. et al. Global, regional, and national life expectancy, all-cause mortality, and cause-specific mortality for 249 causes of death, 1980-2015: a systematic analysis for the Global Burden of Disease Study 2015. Lancet 388, 1459-1544 (2016).

3. LIPIDS MAPS, Lipidomics Gateway. (2019). Available at: https://www.lipidmaps.org/.

4. Benjamin, E. J. et al. Heart Disease and Stroke Statistics - 2019 Update. A Report From the American Heart Association. Circulation 139, 56-528 (2019).

5. (EHN), E. H. N. European Cardiovascular Disease Statistics 2017 edition. (2017).

6. Sankyo, D., Zeneca, A. \& Bayer, S.-A. Funding cardiovascular research in Europe. doi:10.1093/eurheartj/ehy817

7. Kakadiaris, I. A. et al. Machine Learning Outperforms ACC/AHA CVD Risk Calculator in MESA. J. Am. Heart Assoc. 7, e009476 (2018).

8. $\quad$ Lusis, A. J. Atherosclerosis. Nat. 20004076801 407, 233 (2000).

9. Mahmood, S. S., Levy, D., Vasan, R. S. \& Wang, T. J. The Framingham Heart Study and the epidemiology of cardiovascular disease: a historical perspective. Lancet 383, 999-1008 (2014).

10. Viera, A. J. \& Sheridan, S. L. Global Risk of Coronary Heart Disease: Assessment and Application. Am. Fam. Physician 91, 538-543 (1970).

11. Yusuf, S. et al. Effect of potentially modifiable risk factors associated with myocardial infarction in 52 countries (the INTERHEART study): case-control study. Lancet 364, 937-952 (2004).

12. O'donnell, M. J. et al. Global and regional eff ects of potentially modifi able risk factors associated with acute stroke in 32 countries (INTERSTROKE): a case-control study. www.thelancet.com 388, 761 (2016).

13. Vasan, R. S. et al. Relative importance of borderline and elevated levels of coronary heart disease risk factors. Ann. Intern. Med. 142, 393-402 (2005).

14. Stamler, J. et al. Low risk-factor profile and long-term cardiovascular and noncardiovascular mortality and life expectancy: findings for 5 large cohorts of young adult and middle-aged men and women. JAMA 282, 2012-8 (1999).

15. Lowe, L. P. et al. Impact of major cardiovascular disease risk factors, particularly in combination, on 22-year mortality in women and men. Arch. Intern. Med. 158, 2007-14 (1998).

16. Patel, S. A., Winkel, M., Ali, M. K., Narayan, K. M. V. \& Mehta, N. K. Cardiovascular Mortality Associated With 5 Leading Risk Factors: National and State Preventable Fractions Estimated From Survey Data. Ann. Intern. Med. 163, 245 (2015).

17. Chait, A. \& Eckel, R. H. Lipids, Lipoproteins, and Cardiovascular Disease: Clinical Pharmacology Now and in the Future. J. Clin. Endocrinol. Metab. 101, 804-814 (2016).

18. Collins, R. et al. Interpretation of the evidence for the efficacy and safety of statin therapy. Lancet 388, 2532-2561 (2016). 
19. van Kuijk, K., Baker, A. H. \& Sluimer, J. C. Atherosclerosis development: lipoproteins and beyond. Curr. Opin. Lipidol. 28, 520-521 (2017).

20. Cupido, A. J., Reeskamp, L. F. \& Kastelein, J. J. P. Novel lipid modifying drugs to lower LDL cholesterol. Curr. Opin. Lipidol. 28, 367-373 (2017).

21. Youngblom, E., Pariani, M. \& Knowles, J. W. Familial Hypercholesterolemia. GeneReviews ${ }^{\circledR}$ (University of Washington, Seattle, 1993).

22. Barter, P. J. et al. Effects of Torcetrapib in Patients at High Risk for Coronary Events. N. Engl. J. Med. 357, 2109-2122 (2007).

23. Laaksonen, R. Identifying new Risk Markers and Potential Targets for Coronary Artery Disease: The Value of the Lipidome and Metabolome. Cardiovasc. Drugs Ther. 30, 19-32 (2016).

24. Fernandez, C. et al. Plasma Lipid Composition and Risk of Developing Cardiovascular Disease. PLoS One 8, e71846 (2013).

25. Aki S. Havulinna,* Marko Sysi-Aho,* Mika Hilvo, Dimple Kauhanen, R. H. \& Kim Ekroos, Veikko Salomaa, * Reijo Laaksonen. Circulating Ceramides Predict Cardiovascular Outcomes in the Population-Based FINRISK 2002 Cohort. Arter. Thromb Vasc Biol 36, 2024-2430 (2016).

26. Holčapek, M. et al. Lipidomic analysis of plasma, erythrocytes and lipoprotein fractions of cardiovascular disease patients using UHPLC/MS, MALDI-MS and multivariate data analysis. J. Chromatogr. B 990, 52-63 (2015).

27. Meikle, P. J. et al. Plasma Lipidomic Analysis of Stable and Unstable Coronary Artery Disease. Arterioscler. Thromb. Vasc. Biol. 31, 2723-2732 (2011).

28. Stegemann, C. et al. Lipidomics Profiling and Risk of Cardiovascular Disease in the Prospective Population-Based Bruneck Study. Circulation 129, 1821-1831 (2014).

29. Cirulli, E. T. et al. Profound Perturbation of the Metabolome in Obesity Is Associated with Health Risk. Cell Metab. 29, 488-500.e2 (2019).

30. Kjeldsen, S. E. Hypertension and cardiovascular risk: General aspects. Pharmacol. Res. 129, 95-99 (2018).

31. Lawes, C. M., Hoorn, S. Vander \& Rodgers, A. Global burden of blood-pressurerelated disease, 2001. Lancet 371, 1513-1518 (2008).

32. Franklin, S. S. et al. Hemodynamic patterns of age-related changes in blood pressure. The Framingham Heart Study. Circulation 96, 308-15 (1997).

33. Staessen, J. A. et al. Risks of untreated and treated isolated systolic hypertension in the elderly: meta-analysis of outcome trials. Lancet 355, 865-72 (2000).

34. Fretheim, A. et al. Comparative effectiveness of antihypertensive medication for primary prevention of cardiovascular disease: systematic review and multiple treatments meta-analysis. BMC Med. 10, 33 (2012).

35. Julius, S. et al. Outcomes in hypertensive patients at high cardiovascular risk treated with regimens based on valsartan or amlodipine: the VALUE randomised trial. Lancet 363, 2022-2031 (2004).

36. Ettehad, D. et al. Blood pressure lowering for prevention of cardiovascular disease and death: a systematic review and meta-analysis. Lancet (London, England) 387, 957-967 (2016).

37. WHO | Prevalence of tobacco smoking. WHO (2015). 
38. Lubin, J. H. et al. Risk of Cardiovascular Disease from Cumulative Cigarette Use and the Impact of Smoking Intensity. Epidemiology 27, 395-404 (2016).

39. Njølstad, I., Arnesen, E. \& Lund-Larsen, P. G. Smoking, Serum Lipids, Blood Pressure, and Sex Differences in Myocardial Infarction. Circulation 93, 450-456 (1996).

40. Wilhelmsson, C., Elmfeldt, D., Vedin, J. ., Tibblin, G. \& Wilhelmsen, L. SMOKING AND MYOCARDIAL INFARCTION. Lancet 305, 415-420 (1975).

41. Rose, G., Hamilton, P. J., Colwell, L. \& Shipley, M. J. A randomised controlled trial of anti-smoking advice: 10 -year results. J. Epidemiol. Community Health 36, 102-8 (1982).

42. Gregg, E. W. Secular Trends in Cardiovascular Disease Risk Factors According to Body Mass Index in US Adults. JAMA 293, 1868 (2005).

43. Danaei, G. et al. National, regional, and global trends in systolic blood pressure since 1980: systematic analysis of health examination surveys and epidemiological studies with 786 country-years and 5.4 million participants. Lancet 377, 568-577 (2011).

44. Farzadfar, F. et al. National, regional, and global trends in serum total cholesterol since 1980: systematic analysis of health examination surveys and epidemiological studies with 321 country-years and 3.0 million participants. Lancet 377, 578-586 (2011).

45. WHO O Obesity. WHO (2016). Available at: https://www.who.int/topics/obesity/en/.

46. Anand, S. S. \& Yusuf, S. Stemming the global tsunami of cardiovascular disease. Lancet (London, England) 377, 529-32 (2011).

47. Carbone, S. et al. Obesity paradox in cardiovascular disease: where do we stand? Vasc. Health Risk Manag. Volume 15, 89-100 (2019).

48. Burke, G. L. et al. The impact of obesity on cardiovascular disease risk factors and subclinical vascular disease: the Multi-Ethnic Study of Atherosclerosis. Arch. Intern. Med. 168, 928-35 (2008).

49. Blüher, M. Adipose Tissue Dysfunction in Obesity. Exp Clin Endocrinol Diabetes 117, 241-250 (2009).

50. Smekal, A. \& Vaclavik, J. Adipokines and cardiovascular disease: A comprehensive review Ales Smekal, Jan Vaclavik. doi:10.5507/bp.2017.002

51. Zhang, H., Cui, J. \& Zhang, C. Emerging role of adipokines as mediators in atherosclerosis. World J. Cardiol. 2, 370 (2010).

52. mattu, H. S. \& Randeva, H. S. Role of adipokines in cardiovascular disease. J. Endocrinol. 216, 17-36 (2013).

53. Koliaki, C., Liatis, S. \& Kokkinos, A. Obesity and cardiovascular disease: revisiting an old relationship. Metabolism 92, 98-107 (2019).

54. Malone, J. I. \& Hansen, B. C. Does obesity cause type 2 diabetes mellitus? Or is it the opposite? Pediatr. Diabetes 20, 5-9 (2019).

55. The Emerging Risk Factors Collaboration. Diabetes mellitus, fasting blood glucose concentration, and risk of vascular disease: a collaborative meta-analysis of 102 prospective studies. Lancet 375, 2215-2222 (2010). 
56. Leon, B. M. \& Maddox, T. M. Diabetes and cardiovascular disease: Epidemiology, biological mechanisms, treatment recommendations and future research. World $\mathrm{J}$. Diabetes 6, 1246-58 (2015).

57. Ford, E. S., Williamson, D. F. \& Liu, S. Weight Change and Diabetes Incidence: Findings from a National Cohort of US Adults. Am. J. Epidemiol. 146, 214-222 (1997).

58. Golay, A. \& Ybarra, J. Link between obesity and type 2 diabetes. Best Pract. Res. Clin. Endocrinol. Metab. 19, 649-663 (2005).

59. King, P., Peacock, I. \& Donnelly, R. The UK Prospective Diabetes Study (UKPDS): clinical and therapeutic implications for type 2 diabetes. Br. J. Clin. Pharmacol. 48, 643-648 (2001).

60. Riddle, M. C. Effects of Intensive Glucose Lowering in the Management of Patients With Type 2 Diabetes Mellitus in the Action to Control Cardiovascular Risk in Diabetes (ACCORD) Trial. Circulation 122, 844-846 (2010).

61. Allan, G. M., Garrison, S. \& McCormack, J. Comparison of cardiovascular disease risk calculators. Curr. Opin. Lipidol. 25, 254-65 (2014).

62. Matheny, M. et al. Systematic Review of Cardiovascular Disease Risk Assessment Tools. (2011).

63. Allan, G. M. et al. Agreement Among Cardiovascular Disease Risk Calculators. Circulation 127, 1948-1956 (2013).

64. Thompson, R. C. et al. Atherosclerosis across 4000 years of human history: the Horus study of four ancient populations. Lancet 381, 1211-1222 (2013).

65. Ruffer, M. A. On arterial lesions found in Egyptian mummies (1580B.C. - 525A.D.). J. Pathol. Bacteriol. 15, 453-462 (1911).

66. Mayerl, C. et al. Atherosclerosis research from past to present-on the track of two pathologists with opposing views, Carl von Rokitansky and Rudolf Virchow. Virchows Arch. 449, 96-103 (2006).

67. McMillan, G. C. Historical Review of Research on Atherosclerosis. in 1-6 (Springer, Boston, MA, 1995). doi:10.1007/978-1-4615-1957-7_1

68. Libby, P. Inflammation in atherosclerosis. Arterioscler. Thromb. Vasc. Biol. 32, 2045-51 (2012).

69. Ridker, P. M. et al. Antiinflammatory Therapy with Canakinumab for Atherosclerotic Disease. N. Engl. J. Med. 377, 1119-1131 (2017).

70. Linton, M. F. et al. The Role of Lipids and Lipoproteins in Atherosclerosis. Science (80-. ). 111, (1950).

71. Bobryshev, Y. V, Ivanova, E. A., Chistiakov, D. A., Nikiforov, N. G. \& Orekhov, A. N. Macrophages and Their Role in Atherosclerosis: Pathophysiology and Transcriptome Analysis. Biomed Res. Int. 2016, 9582430 (2016).

72. Kojima, Y., Weissman, I. L. \& Leeper, N. J. The Role of Efferocytosis in Atherosclerosis. Circulation 135, 476-489 (2017).

73. Seimon, T. \& Tabas, I. Mechanisms and consequences of macrophage apoptosis in atherosclerosis. J. Lipid Res. 50 Suppl, S382-7 (2009).

74. Bennett, M. R., Sinha, S. \& Owens, G. K. Vascular Smooth Muscle Cells in Atherosclerosis. Circ. Res. 118, 692-702 (2016). 
75. Taleb, S. Inflammation in atherosclerosis. Arch. Cardiovasc. Dis. 109, 708-715 (2016).

76. Winkels, H. et al. Atlas of the Immune Cell Repertoire in Mouse Atherosclerosis Defined by Single-Cell RNA-Sequencing and Mass Cytometry. Circ. Res. 122, 16751688 (2018).

77. Ionita, M. G. et al. High Neutrophil Numbers in Human Carotid Atherosclerotic Plaques Are Associated With Characteristics of Rupture-Prone Lesions. Arterioscler. Thromb. Vasc. Biol. 30, 1842-1848 (2010).

78. Soehnlein, O. Multiple Roles for Neutrophils in Atherosclerosis. Circ. Res. 110, 875888 (2012).

79. Warnatsch, A., loannou, M., Wang, Q. \& Papayannopoulos, V. Neutrophil extracellular traps license macrophages for cytokine production in atherosclerosis. Science (80-. ). 349, 316-320 (2015).

80. Gil-Pulido, J. \& Zernecke, A. Antigen-presenting dendritic cells in atherosclerosis. Eur. J. Pharmacol. 816, 25-31 (2017).

81. Yilmaz, A. et al. Emergence of dendritic cells in rupture-prone regions of vulnerable carotid plaques. Atherosclerosis 176, 101-110 (2004).

82. Ketelhuth, D. F. J. \& Hansson, G. K. Adaptive Response of T and B Cells in Atherosclerosis. Circ. Res. 118, 668-678 (2016).

83. Lahoute, C., Herbin, O., Mallat, Z. \& Tedgui, A. Adaptive immunity in atherosclerosis: mechanisms and future therapeutic targets. Nat. Rev. Cardiol. 8, 348-358 (2011).

84. Sun, J. et al. Mast cells promote atherosclerosis by releasing proinflammatory cytokines. (2007). doi:10.1038/nm1601

85. Bot, I. \& Biessen, E. A. L. Mast cells in atherosclerosis. (2011). doi:10.1160/TH1105-0291

86. Kyaw, T., Tipping, P., Toh, B.-H. \& Bobik, A. Killer cells in atherosclerosis. Eur. J. Pharmacol. 816, 67-75 (2017).

87. van Puijvelde, G. H. M. \& Kuiper, J. NKT cells in cardiovascular diseases. Eur. J. Pharmacol. 816, 47-57 (2017).

88. Mouton, A. J. et al. Mapping macrophage polarization over the myocardial infarction time continuum. Basic Res. Cardiol. 113, (2018).

89. Gombozhapova, A. et al. Macrophage activation and polarization in post-infarction cardiac remodeling. J. Biomed. Sci. 24, 1-11 (2017).

90. van der Laan, A. M. et al. Monocyte subset accumulation in the human heart following acute myocardial infarction and the role of the spleen as monocyte reservoir. Eur. Heart J. 35, 376-385 (2014).

91. Rienks, M. et al. Sema3A promotes the resolution of cardiac inflammation after myocardial infarction. Basic Res. Cardiol. 112, (2017).

92. Ginhoux, F., Schultze, J. L., Murray, P. J., Ochando, J. \& Biswas, S. K. New insights into the multidimensional concept of macrophage ontogeny, activation and function. Nat. Immunol. 17, 34-40 (2016).

93. Davies, L. C. \& Taylor, P. R. Tissue-resident macrophages: then and now. Immunology 144, 541-548 (2015). 
94. Mosser, D. M. \& Edwards, J. P. Exploring the full spectrum of macrophage activation. Nat. Rev. Immunol. 8, 958-969 (2008).

95. Edwards, J. P., Zhang, X., Frauwirth, K. A. \& Mosser, D. M. Biochemical and functional characterization of three activated macrophage populations. J. Leukoc. Biol. 80, 1298-307 (2006).

96. Martinez, F. O. \& Gordon, S. The M1 and M2 paradigm of macrophage activation: time for reassessment. F1000Prime Rep. 6, 13 (2014).

97. Wynn, T. A., Chawla, A. \& Pollard, J. W. Macrophage biology in development, homeostasis and disease. Nature 496, 445-455 (2013).

98. Aschenbrenner, A. C. \& Schultze, J. L. New "programmers" in tissue macrophage activation. Pflugers Arch. Eur. J. Physiol. 469, 375-383 (2017).

99. Nagenborg, J., Goossens, P., Biessen, E. A. L. \& Donners, M. M. P. C. Heterogeneity of atherosclerotic plaque macrophage origin, phenotype and functions: Implications for treatment. Eur. J. Pharmacol. 816, 14-24 (2017).

100. Xue, J. et al. Transcriptome-Based Network Analysis Reveals a Spectrum Model of Human Macrophage Activation. Immunity 40, 274-288 (2014).

101. Hill Charles D Mills, A. M., Kincaid, K. \& Alt, J. M. Paradigm M-1/M-2 Macrophages and the Th1/Th2. J Immunol Ref. 164, 6166-6173 (2018).

102. Usaj, M. M. et al. High-Content Screening for Quantitative Cell Biology. Trends Cell Biol. 26, 598-611 (2016).

103. Pereira, D. A. \& Williams, J. A. Origin and evolution of high throughput screening. Br. J. Pharmacol. 152, 53-61 (2007).

104. Chessel, A. \& Salas, R. E. C. From observing to predicting single-cell structure and function with high-throughput/high-content microscopy. Essays Biochem. 63, 197208 (2019).

105. Ohya, Y. et al. High-dimensional and large-scale phenotyping of yeast mutants. Proc. Natl. Acad. Sci. 102, 19015-19020 (2005).

106. Neumann, B. et al. Phenotypic profiling of the human genome by time-lapse microscopy reveals cell division genes. Nature 464, 721-727 (2010).

107. Williams, S. P. et al. Systematic high-content genome-wide RNAi screens of endothelial cell migration and morphology. Sci. Data 4, 170009 (2017).

108. Pelkmans, L. et al. Genome-wide analysis of human kinases in clathrin- and caveolae/raft-mediated endocytosis. Nature 436, 78-86 (2005).

109. Kriston-Vizi, J. \& Flotow, H. Getting the whole picture: High content screening using three-dimensional cellular model systems and whole animal assays. Cytom. Part $A$ 91, 152-159 (2017).

110. Sirenko, O. et al. High-Content Assays for Characterizing the Viability and Morphology of 3D Cancer Spheroid Cultures. Assay Drug Dev. Technol. 13, 402414 (2015).

111. Stefanovski, D. et al. Prostate cancer diagnosis using epigenetic biomarkers, 3D high-content imaging and probabilistic cell-by-cell classifiers. Oncotarget 8, 5727857301 (2017).

112. Gobeil, S., Zhu, X., Doillon, C. J. \& Green, M. R. A genome-wide shRNA screen identifies GAS1 as a novel melanoma metastasis suppressor gene. Genes Dev. 22, 2932-2940 (2008). 
113. Prabhu, S. D. \& Frangogiannis, N. G. The Biological Basis for Cardiac Repair After Myocardial Infarction. Circ. Res. 119, 91-112 (2016).

114. Hansson, G. K., Libby, P. \& Tabas, I. Inflammation and plaque vulnerability. J. Intern. Med. 278, 483-93 (2015).

115. Gonzalez, L. \& Trigatti, B. L. Macrophage Apoptosis and Necrotic Core Development in Atherosclerosis: A Rapidly Advancing Field with Clinical Relevance to Imaging and Therapy. Can. J. Cardiol. 33, 303-312 (2017). 



\section{Chapter 2}

Towards a function-based model of macrophage plasticity: the MacroScreen

platform

MAC Fontaine, H Jin, J Huckriede, P Goossens, M Rousch, E Wijnands, L Dubois, MPH van de Waarenburg, J Schultze, JC Sluimer, T Ulas*, L Temmerman*, EAL Biessen*

*Shared authorship In preparation 


\section{Chapter 3}

The systemic acute myocardial infarction environment reprograms human macrophages

MAC Fontaine, H Jin, M Gagliardi, M Rousch, E Wijnands, M Stoll, C Reutelingsperger, C Schalkwijk, D Molin, J Eritsland, P Hoffman, G Andersen, P Aukrust, B Halvorsen, EAL Biessen, L Temmerman 


\section{Chapter 4}

\section{Low human and murine $\mathrm{Mcl}-1$ expression leads to a pro-apoptotic plaque phenotype enriched in giant-cells.}

MAC Fontaine ${ }^{\dagger}, \mathrm{MM} \mathrm{Westra}^{\dagger}$, I Bot, $\mathrm{H}$ Jin, AJPM Franssen, M Bot, SCA de Jager, I Dzhagalov, Y-W He, BJM van Vlijmen, MJJ Gijbels, CP Reutelingsperger, TJC van Berkel, JC Sluimer, L Temmerman, EAL Biessen

'These authors contributed equally Modified from Scientific Reports. 2019 Oct 9:14547 



\section{Abstract}

The anti-apoptotic protein myeloid cell leukemia 1 (Mcl-1) plays an important role in survival and differentiation of leukocytes, more specifically of neutrophils. Here, we investigated the impact of myeloid Mcl-1 deletion in atherosclerosis. Western type diet fed LDL receptor-deficient mice were transplanted with either wild-type (WT) or LysMCre Mcl-1 ${ }^{\mathrm{fl} / \mathrm{fl}}\left(\mathrm{Mcl}^{-1 /-}\right)$ bone marrow. Mcl-1 myeloid deletion resulted in enhanced apoptosis and lipid accumulation in atherosclerotic plaques. In vitro, Mcl-1 deficient macrophages also showed increased lipid accumulation, resulting in increased sensitivity to lipid-induced cell death. However, plaque size, necrotic core and macrophage content were similar in $\mathrm{Mcl}-1{ }^{-/}$compared to WT mice, most likely due to decreased circulating and plaque-residing neutrophils. Interestingly, Mcl1 $\%$ peritoneal foam cells formed up to $45 \%$ more multinucleated giant cells (MGCs) in vitro compared to WT, which concurred with an increased MGC presence in atherosclerotic lesions of $\mathrm{Mcl}^{-/}$mice. Moreover, analysis of human unstable atherosclerotic lesions also revealed a significant inverse correlation between MGC lesion content and $\mathrm{Mcl}-1$ gene expression, coinciding with the mouse data. Taken together, these findings suggest that myeloid Mcl-1 deletion leads to a more apoptotic, lipid and MGC-enriched phenotype. These potentially pro-atherogenic effects are however counteracted by neutropenia in circulation and plaque. 


\section{Introduction}

Antiapoptotic $\mathrm{Mcl}-1$ is a member of the apoptosis regulating $\mathrm{Bcl}-2$ family ${ }^{1}$. It directly interacts with pro-apoptotic BH3-only proteins Bim and Bid and multidomain proapoptotic $\mathrm{Bad}^{2-4}$, thereby inhibiting apoptosis. $\mathrm{Mcl}-1$ is expressed in various tissues including hematopoietic cells ${ }^{5}$, in which its overexpression delays cell death in response to various stimuli ${ }^{6}$. Indeed Mcl-1 is critical for neutrophil survival ${ }^{7-10}$ at all differentiation stages ${ }^{11}$. Survival of macrophages lacking Mcl-1 does not seem to be impacted ${ }^{9}$, albeit that $\mathrm{Mcl}-1$ deficient macrophages were observed to be more sensitive to apoptosis induced either by phagocytosis ${ }^{10}$, or infection ${ }^{12}$.

While monocytes and macrophages have been the subject of extensive studies in the atherosclerosis field for years ${ }^{13}$, neutrophils were only more recently investigated due to their scarce presence in atherosclerotic plaque. Nevertheless, it is now believed that neutrophils are instrumental in plaque development and later destabilization, as we and others have shown ${ }^{14-16}$. Warnatch et al. demonstrated that Neutrophil Extracellular Traps (NETs) prime macrophages to produce inflammatory cytokines, resulting in increased atherogenesis ${ }^{17}$. Dissection of the contribution of neutrophils to atherosclerotic plaque progression has however remained difficult, since other cell populations are also affected when neutrophils are experimentally manipulated. Deletion of Interferon Regulatory Factor 8 (IRF8) for example results in neutrophilia which exacerbates atherosclerosis in $\mathrm{IRF}^{-/-} \mathrm{ApoE}^{-/}$chimeric mice, but was at the same time accompanied by changes in monocytes and several dendritic cell populations ${ }^{18,19}$. In addition, neutrophils have thus far not been depleted during the complete course of atherosclerosis. Neutrophil depleting antibodies such as the antipolymorphonuclear leukocyte (PMN) antibody cannot be sustained for more than 4 weeks in mice without affecting monocyte counts ${ }^{16}$.

As Mcl-1 is vital for neutrophil survival, whilst presumably having mild effects on macrophage apoptosis, we hypothesized that myeloid Mcl-1 deletion could serve as an efficient neutropenia model during the full pathogenesis of atherosclerosis. Moreover, although several $\mathrm{Bcl}-2$ family members have been investigated in the context of atherosclerosis ${ }^{20-23}$, the role of $\mathrm{Mcl}-1$ in disease progression has not been assessed thus far. To this end, we studied effects of specific deletion of Mcl-1 in the lysozyme $M$ expressing myeloid subsets neutrophils and macrophages on early and advanced atherosclerosis using bone marrow transplantation of $\mathrm{Mcl}-1^{\mathrm{fl} / \mathrm{fl}} \mathrm{LysMCre}$ or wild-type (WT) bone marrow into low density lipoprotein receptor-null ( $\mathrm{LDLr}^{-/}$) Page | 104 
mice. Our study shows that myeloid $\mathrm{Mcl}-1$ deletion indeed has a profound impact on neutrophil survival. However, Mcl-1 deficient macrophages were seen to accumulate more lipids in vitro and in vivo and were subsequently more sensitive to apoptosis. Moreover, we show that Mcl-1 is implicated in the fusion of macrophages. These combined effects however counteracted each other affecting only viable cell plaque composition, but not plaque growth. 


\section{Material and methods}

Animals

All animal work was approved by animal regulatory authority of Leiden University and performed in compliance with Dutch national guidelines. Low density lipoprotein receptor-null $\left(\mathrm{LDLr}^{-/}\right)$mice were obtained from the local animal breeding facility. $\mathrm{Mcl}-1^{\mathrm{fl} / \mathrm{fl}}$ LysMcre mice were obtained from the Department of Immunology, Duke University Medical Center, USA and were backcrossed to C57BL/6J.

\section{Mcl-1 gene expression during atherogenesis}

Twenty male $\mathrm{LDLr}^{-/-}$mice were fed a Western-type diet (WTD) two weeks prior to surgery and throughout the experiment. Atherosclerotic carotid artery lesions were induced by perivascular collar placement ${ }^{24}$. Carotid $\mathrm{Mcl}-1$ gene expression was analysed prior to and two, four, six and eight weeks after collar placement ( $n=4$, per timepoint). The mice were anaesthetized and perfused with phosphate buffered saline (PBS) after which both common carotid arteries were isolated. After dissection of the adventitia, plaque containing segments were excised based on macroscopic examination, snapfrozen and stored at $-80^{\circ} \mathrm{C}$. Two to three atherosclerotic plaques were pooled per sample and total RNA was isolated using Trizol reagent (Invitrogen). Gene expression was analysed by real time PCR (qPCR) using ABI PRISM 7700 Sequence Detector (Applied Biosystems) with SYBR-Green technology. Mcl-1 and housekeeping gene Hprt primers used are listed in supplementary table 1 .

\section{Mcl-1 gene expression in different cell types}

Murine 3 T3 fibroblasts, smooth muscle cells (SMCs), cardiac endothelial cells (MCECs), and BMDMs stimulated with either lipopolysaccharide $(10 \mathrm{ng} / \mathrm{ml})$ and Interferon- $\gamma$ (IFN- $\gamma, 100 \mathrm{U} / \mathrm{ml}$ ) (M1 macrophage) or Interleukin-4 (IL-4, $20 \mathrm{ng} / \mathrm{ml}$ ) (M2 macrophage) were cultured. Total RNA was extracted and gene expression was analysed by qPCR. Mcl-1 and housekeeping gene $18 \mathrm{~S}$ primers used are listed in supplementary table 1.

Bone marrow transplantation and atherosclerosis induction

Male recipient $\mathrm{LDLr}^{-/}$mice were housed in sterile ventilated cages with food (RM3, Special Diet Services) and water ad libitum. Antibiotics ( $83 \mathrm{mg} / \mathrm{l}$ ciprofloxacin, 67 $\mathrm{mg} / \mathrm{l}$ Polymixin B and $5 \mathrm{~g} / \mathrm{l}$ sugar) were supplied in the drinking water. Mice were 
exposed to a single dose of $9 \mathrm{~Gy}$ total body irradiation (0.19Gy/min, $200 \mathrm{kV}, 4 \mathrm{~mA}$ ) using an Andrex Smart 225 Röntgen source (YXLON International) one day before transplantation. Bone marrow was extracted from femur and tibia of male $\mathrm{Mcl}-1^{\mathrm{fl} / \mathrm{fl}}$ LysMcre (hereafter $\mathrm{Mcl}^{-{ }^{-1}}$ ) donors and wild type (WT) littermates. Irradiated LDLr /- mice received $2.5 \times 10^{6} \mathrm{BM}$ cells of either $\mathrm{Mcl}^{-1 /-}(n=17)$ or WT $(n=15)$ via tail vein injection. After a recovery period of eight weeks mice were put on a WTD containing $\mathbf{0 . 2 5 \%}$ cholesterol and $15 \%$ cacao butter (Diet W, Special Diet Services) for an additional five (plaque initiation) or ten weeks (advanced plaque).

\section{Blood cell analysis and flow cytometry}

Blood samples were taken by tail bleeding immediately before BMT, prior to (week 0 ) and after four weeks of WTD feeding (week 4) and at the time of sacrifice (week 5 or week 10). Peritoneal leukocytes were isolated at the time of sacrifice by peritoneal lavage with $10 \mathrm{ml}$ PBS. Whole blood and peritoneal lavage samples were analysed using a Sysmex blood cell analyser (XT-2000i). For flow cytometry, white blood cells (WBC) and peritoneal leukocytes were stained with fluorescently labelled antibodies against F4/80, CD19, CD4, CD71 and CD11b (eBioscience) and Gr1, CD8 and CXCR4 (BD Pharmingen). Fluorescence-activated cell sorting (FACS) analysis was performed on a FACSCalibur with CellQuest software (BD Biosciences).

\section{Tissue harvesting and analysis}

Two hours before sacrifice, $\mathrm{Mcl}-1^{-1}$ or WT mice $(n=5)$ received intraperitoneal injections of CXCL1 $(200 \mathrm{ng} / \mathrm{ml}$ in $1 \mathrm{ml} \mathrm{PBS})$ or PBS control. The mice were anesthetized and perfused with PBS. Cryosections of the aortic root tissue were stained with hematoxylin and eosin (HE) or Oil Red O (ORO). Lesion size was quantified using a Leica DMRE microscope with camera and Leica Qwin Imaging software (Leica Ltd). MGCs were defined as macrophages with two or more round nuclei on the HE slides and quantified by an animal pathologist. Immunohistochemical stainings were performed for macrophage (MOMA-2, Sigma) and VSMC ( $\alpha$-smooth muscle actin, Sigma) content. Apoptotic cell content was quantified using terminal deoxytransferase dUTP nick-end labeling (TUNEL) kit (Roche Diagnostics).

\section{$L D L$ and VLDL isolation and ox LDL preparation}

LDL and very low-density lipoprotein (VLDL) were isolated from human plasma by density gradient ultracentrifugation for $20 \mathrm{~h}$ at $4^{\circ} \mathrm{C}^{25}$. LDL concentration was adjusted to $0.5 \mathrm{mg} / \mathrm{ml}$ with PBS and oxidized by incubation with $0.32 \mathrm{mM} \mathrm{CuSO}_{4}$ 
overnight at $37^{\circ} \mathrm{C}$ after which the oxidation reaction was terminated by addition of $50 \mu \mathrm{M}$ EDTA. OxLDL was then dialyzed against PBS containing $10 \mu \mathrm{M}$ EDTA for 24h. Final oxLDL and VLDL concentration were measured using the bicinchoninic acid protein kit (Thermo Fisher Scientific).

\section{BMDMs and peritoneal macrophages}

Bone marrow cells were isolated by flushing femurs and tibia with PBS and single cell suspensions were obtained by passing the suspension through a $70 \mu \mathrm{m}$ nylon cell strainer (BD Falcon). Bone marrow cells were differentiated into macrophages by culturing in RPMI-1640 medium (GIBCO Invitrogen), supplemented with $10 \%$ (vol/vol) heat inactivated fetal calf serum (FCS) (GIBCO, Invitrogen), glutamine (2 $\mathrm{mM})$, penicillin $(100 \mathrm{U} / \mathrm{ml})$, streptomycin $(100 \mu \mathrm{g} / \mathrm{ml})$ and 15\% (vol/vol) L929conditioned medium for seven days. After differentiation, BMDMs were harvested with lidocaine and replated at $0.5 \times 10^{5}$ cells/well in a 96 well imaging plate (BD \#353219, Corning Life Sciences) for apoptosis, lipid uptake and fusion assay. Peritoneal leukocytes were isolated from $\mathrm{Mcl}^{-1-}$ and WT mice following an i.p. injection of PBS before sacrifice. Cells were pooled from 2-3 mice per genotype and plated at $0.25 \times 10^{6}$ cells/well in 8 chamber culture slides or 24 -well plates (BD Falcon) and non-adherent peritoneal macrophages were removed.

Lipid loading of BMDMs and peritoneal macrophages

Adherent peritoneal macrophages were stimulated with $20 \mu \mathrm{g} / \mathrm{ml}$ oxLDL or 50 $\mu \mathrm{g} / \mathrm{ml} \mathrm{VLDL}$ for $24 \mathrm{~h}$, after which slides were washed with PBS and stained with ORO. Lipid loading was quantified as the ratio between the ORO stained area and total cell surface. BMDMs were loaded with $20 \mu \mathrm{g} / \mathrm{ml}$ oxLDL or $50 \mu \mathrm{g} / \mathrm{ml} \mathrm{VLDL} \mathrm{combined}$ with $5 \mu \mathrm{g} / \mathrm{ml}$ and $12.5 \mu \mathrm{g} / \mathrm{ml}$ Topfluor cholesterol (Avanti Polar Lipids) respectively for $2.5 \mathrm{~h}$ (D0) and 120h (D5). Cell nuclei were stained with Hoechst (Sigma Aldrich) at $15 \mu \mathrm{g} / \mathrm{ml}$.

\section{Apoptosis of peritoneal macrophages and BMDMs}

Adherent peritoneal macrophages were stimulated with $40 \mu \mathrm{g} / \mathrm{ml}$ oxLDL for $24 \mathrm{~h}$. The macrophages were detached with Accutase (PAA Laboratories $\mathrm{GmbH}$ ), stained with FITC-labeled Annexin-V (ImmunoTools) and propidium iodide (Sigma Aldrich) and subsequently analysed by flow cytometry (FACSCalibur, BD Biosciences). For the BMDM apoptosis assay, cells were loaded with $20 \mu \mathrm{g} / \mathrm{ml}$ oxLDL or $50 \mu \mathrm{g} / \mathrm{ml}$ VLDL for $6 \mathrm{~h}$ (D0) or $120 \mathrm{~h}$ (D5) and subsequently stained with Hoechst and Oregongreen or Alexa-647 labelled Annexin-V for 15 minutes ${ }^{26}$. 


\section{Fusion assay}

BMDMs were loaded with $20 \mu \mathrm{g} / \mathrm{ml}$ oxLDL or $50 \mu \mathrm{g} / \mathrm{ml} \mathrm{VLDL} \mathrm{for} \mathrm{either} \mathrm{24h} \mathrm{(D1)} \mathrm{or}$ 120h (D5). Macrophage fusion was measured by co-staining with calcein-AM (ThermoFisher Scientific) at $1 \mu \mathrm{g} / \mathrm{ml}$ and Hoechst. MGCs were defined as having two or more nuclei per calcein-segmented cell.

\section{Image analysis}

For all 96-well plate immunofluorescence assays (apoptosis, lipid loading and cell fusion), nine images per well were taken using the high content analyser (HCA) BD pathway 855 (BD Biosciences) with 10x objective and further analysed using Attovision and DIVA software (BD Biosciences).

\section{Human atherosclerotic plaque collection}

Stable and unstable human carotid atherosclerotic plaques segments (classified according to Virmani et al. $^{27}$ ) were collected from the same symptomatic patient $(n=22 / 23)$ undergoing carotid endarterectomy in Maastricht University Medical Centre (MUMC, The Netherlands) and Zuyderland Medical Center (Sittard, the Netherlands). Collection, storage, and use in the Maastricht Pathology Tissue Collection (MPTC) were approved by medical ethical committee (16-4-181) and in accordance with the "Code for Proper Secondary Use of Human Tissue in the Netherlands" (http://www.fmwv.nl). Atherosclerotic plaque segments were alternatively snap-frozen for RNA and microarray analysis, or formalin-fixed for paraffin-embedding.

\section{Human atherosclerotic plaque histology}

The human plaque sections adjacent to the snapfrozen segment were classified to determine plaque type according to Virmani et al. ${ }^{27}$. HE staining was used to quantify plaque size, lipid core size and hemorrhage. Alizarin red staining was done to measure the percentage of calcification.

\section{Human atherosclerotic plaque immunohistochemistry}

All stainings were performed on adjacent plaque sections for vascular endothelial marker CD31 (Dako), macrophage marker CD68 (Dako), T-cell marker CD3 (Dako) and MGC marker (cathepsin $\mathrm{K}^{28}$ ). MGCs were defined as cathepsin-K positive cells having two or more round nuclei. MGC were quantified in all sections and averaged per patient. Relative abundance of MGCs was calculated by dividing the number of MGCs by that of $\mathrm{CD} 68$ positive cells. 
Human atherosclerotic plaque RNA extraction and transcriptomics

RNA was isolated by Guanidium Thiocyanate lysis followed by Cesium Chloride gradient centrifugation, and then purified using the Nucleospin RNAll kit. 750 ng of biotinylated cRNA per sample was hybridized to Illumina Human Sentrix-8 V2.0 BeadChip ${ }^{\circledR}$ and washed according to the Illumina standard procedure. Scanning was performed on the Illumina BeadStation 500. Raw expression data were extracted from the images using default settings and without normalization.

\section{Statistics}

Values are expressed as mean \pm standard error of the mean (SEM). All statistical analyses were performed using Prism (GraphPad Software). Statistically significant differences $(p<0.05)$ were evaluated using the Student's t-test unless stated otherwise. Pearson correlation analysis was performed to assess the association between Mcl-1 gene expression or MGCs presence and clinical plaque traits. ${ }^{*} p<0.05, * * p<0.01$ and ${ }^{* * *} p<0.001$. 


\section{Results}

Mcl-1 deletion altered neutrophil levels and characteristics

We first quantified $\mathrm{Mcl}-1$ gene expression during atherogenesis. Mcl-1 levels in collar-induced carotid artery lesions of $\mathrm{LDLr}^{-/}$mice gradually increased during lesion development and in particular in advanced plaques, six weeks after collar induction (Figure 1A). Of note, this increase was not validated at the protein level. Mcl-1 was mostly expressed in activated macrophages (M1- or M2-macropahges), as compared to other cell types (Figure 1B). Mcl-1 was also detectable in human atherosclerotic plaques, and its expression did not differ between stable and unstable plaque (Figure 1C). However, Pearson correlation analysis revealed that Mcl-1 expression did correlate with pathogenic plaque traits, with more traits in unstable plaques, suggesting an involvement in the disease process (Figure 1D). To verify whether $\mathrm{Mcl}-1$ deletion indeed resulted in an efficient neutropenia model in the context of atherosclerosis, Ldlr $^{-/}$recipient mice were transplanted with LysMCre Mcl-1 ${ }^{\mathrm{fl} / \mathrm{fl}}$ (hereafter $\mathrm{Mcl}-1^{--}$) or wild type (WT) bone marrow (Figure 1E). $\mathrm{Mcl}-1^{--}$mice showed similar serum cholesterol and triglyceride levels, and body weight (Supplementary Figure 1A-C). 
A

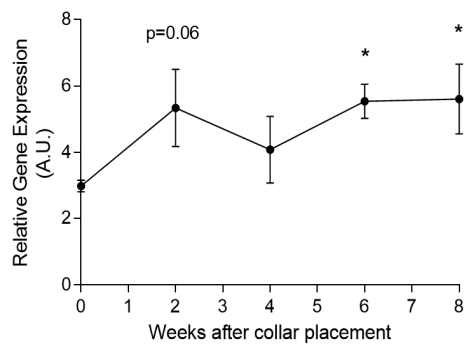

C

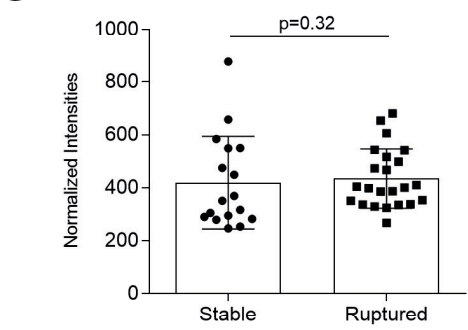

$\mathbf{E}$

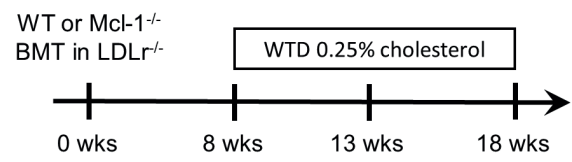

B

D
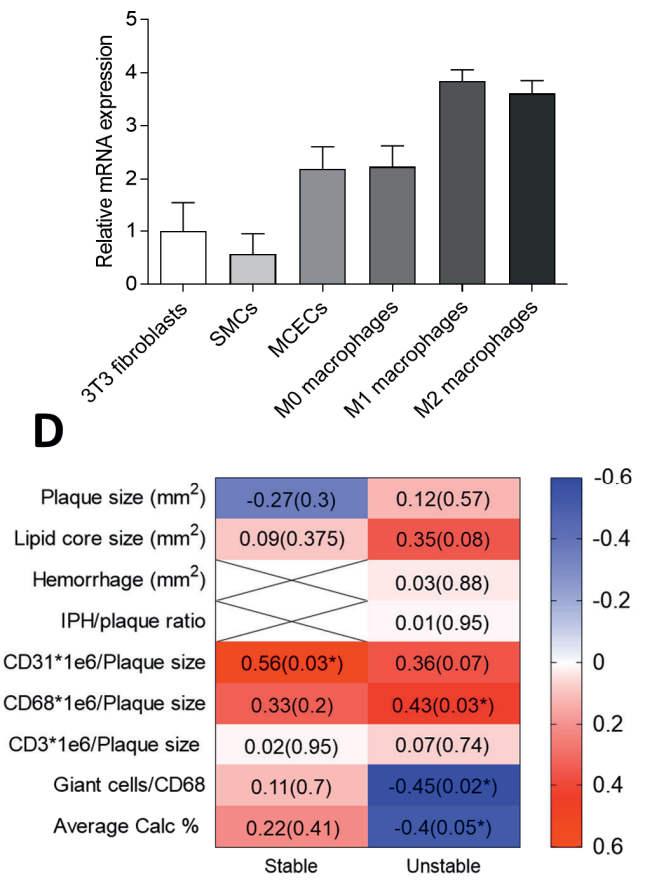

Figure 1. Regulation of $\mathrm{Mcl}-1$ expression in atherosclerosis

A, B and C. Mcl-1 gene expression measured by RT-qPCR. A. Vascular Mcl-1 expression corrected for HPRT housekeeping gene in a model of collar induced carotid artery atherogenesis in $\mathrm{LDLr}^{-1-}$ mice. B. Mcl-1 expression corrected for $18 \mathrm{~S}$ housekeeping gene in different mouse cell types. SMCs: smooth muscle cells, MCECs: mouse cardiac endothelial cells. C. Mcl-1 gene expression in human atherosclerotic plaques, represented by microarray normalized intensities. D. Heatmap showing Pearson correlation coefficient ( $p-$ values) of $\mathrm{Mcl}-1$ human plaque gene expression correlation with clinical plaque traits. $\mathrm{N}=22 / 23$ (stable/unstable). E. Lethally irradiated $\mathrm{LDLr}^{-/-}$mice were reconstituted with WT or $\mathrm{Mcl}-1 \%$ bone marrow, and after 8 weeks of recovery, put on a Western Type Diet (WTD) containing $0.25 \%$ cholesterol for 5 weeks $(n=17)$ or 10 weeks $(n=19)$. All data is presented as mean \pm SEM. ${ }^{*} p<0.05$

Compatible with the notion that $\mathrm{Mcl}-1$ is essential for neutrophil survival ${ }^{7}$, circulating and splenic neutrophil numbers were sharply reduced by $80 \%$ and $86 \%$, respectively in $\mathrm{Mcl}^{-1 \mathrm{fl} / \mathrm{fl}}$ LysMcre mice ${ }^{9}$. Circulating neutrophils were depressed in $\mathrm{Mcl}-1^{-/}$chimeras both at baseline (82\% depletion) and even more so under hyperlipidemic conditions (91\% depletion) (Figure 2A). Likewise, neutrophil 
content in $\mathrm{Mcl}-1^{1-}$ atherosclerotic lesions was decreased, albeit to a lower extent than in blood (Figure 2B and C), hinting to an enhanced adhesive capacity or faster turnover of residual neutrophils in circulation. Considering that an elevated CXCR4/CXCR2 balance is associated with regress to the bone marrow and that CXCR4 is an established measure of neutrophil ageing ${ }^{16}$, we examined neutrophil phenotype. CXCR4 expression on circulating and peritoneal residual neutrophils was increased (Figure 2D and $\mathbf{E}$ respectively), suggesting hyperactivation and increased SDF1 migratory capacity. Moreover, responsiveness of remaining neutrophils to the potent neutrophil chemokine CXCL1 was blunted, concordant with the reduced CXCR2 expression by pre-apoptotic neutrophils ${ }^{16}$. Peritoneal neutrophil influx $2 \mathrm{~h}$ after i.p. injection of CXCL1 was prominent in WT transplanted mice, whereas $\mathrm{Mcl}-1^{-/}$transplanted mice only showed a minor, non-significant, increase in peritoneal neutrophils (Figure $\mathbf{2 F}$ and $\mathbf{G}$ ). Of note, neutrophil recruitment was paralleled by stromal egress of neutrophils into circulation in WT, but not $\mathrm{Mcl}^{-1-}$ mice (data not shown). Taken together, these results confirm $\mathrm{Mcl}-1$ as a crucial neutrophil survival factor, also under hyperlipidemic conditions, and demonstrate that $\mathrm{Mcl}-1$ myeloid deletion can be used as a genetic tool to induce a long-lasting, severe neutropenia in atherosclerosis. 

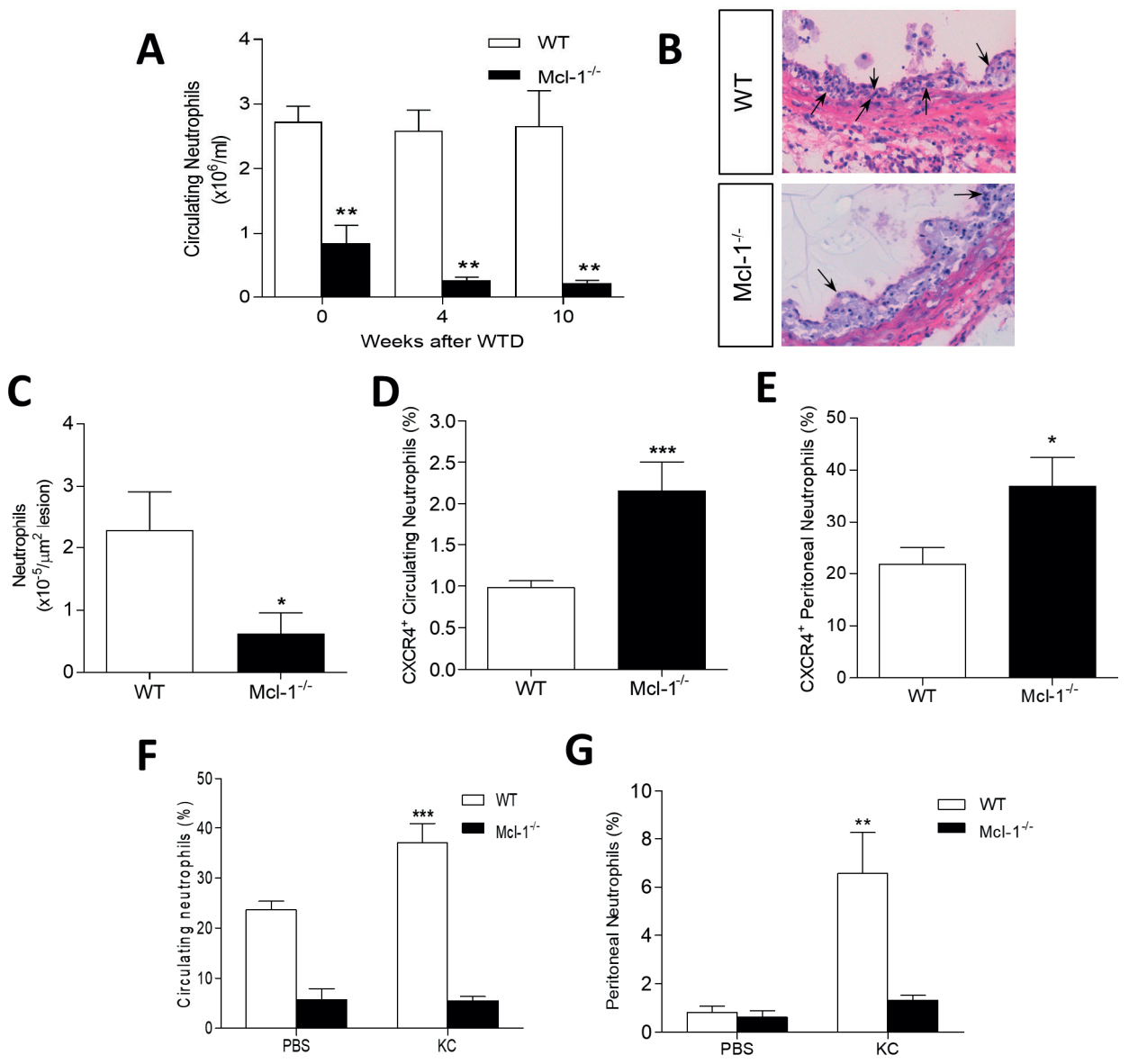

Figure 2. $\mathrm{Mcl}-1^{-/}$chimeric mice have altered neutrophil levels and characteristics

A. Circulating neutrophils were defined as $\mathrm{Gr} 1+$ and measured by flow cytometry in blood samples obtained from tail vein of WT and $\mathrm{Mcl}^{-1}$ bone marrow chimeras. B. Representative H\&E pictures of WT and $\mathrm{Mcl}-1^{-/-}$atherosclerotic plaques $(n=19)$. Neutrophils are indicated by the arrow. $\mathbf{C}$. in aortic root atherosclerotic lesions of BM transplanted LDLr /- after 10 weeks of WTD ( $n=19)$. D. and E. CXCR4 expression in circulating and peritoneal neutrophils respectively assessed by flow cytometry (CXCR4 positive cells within the neutrophil gate of A). F. and G. Circulating and peritoneal neutrophil levels respectively $2 \mathrm{~h}$ after CXCL1 injection measured by flow cytometry (CXCR4 positive cells within the neutrophil gate of $A)$. Data is presented as mean \pm SEM. ${ }^{* * *} p<0.001,{ }^{* *} p<0.01$ and ${ }^{*} p<0.05$. 
Myeloid Mcl-1 deletion increased plaque apoptotic cell content but did not affect atherosclerotic lesion size

Despite its profound effects on circulating neutrophils, and on plaque neutrophil content, myeloid Mcl-1 deletion did neither alter early nor advanced plaque area, necrotic core size, or plaque macrophage content as compared to controls (Figure 3A-D). We did observe an increase in plaque apoptosis by $71 \%$ and $77 \%$ in atherosclerotic lesions of $\mathrm{Mcl}^{-/}$mice fed a WTD for 5 and 10 weeks, respectively, compared to WT mice (Figure $3 \mathrm{E}$ ), suggesting that $\mathrm{Mcl}-1$ not only plays an important role in the survival of neutrophils, but also of other myeloid plaqueresident cells, such as plaque macrophages and foam cells.
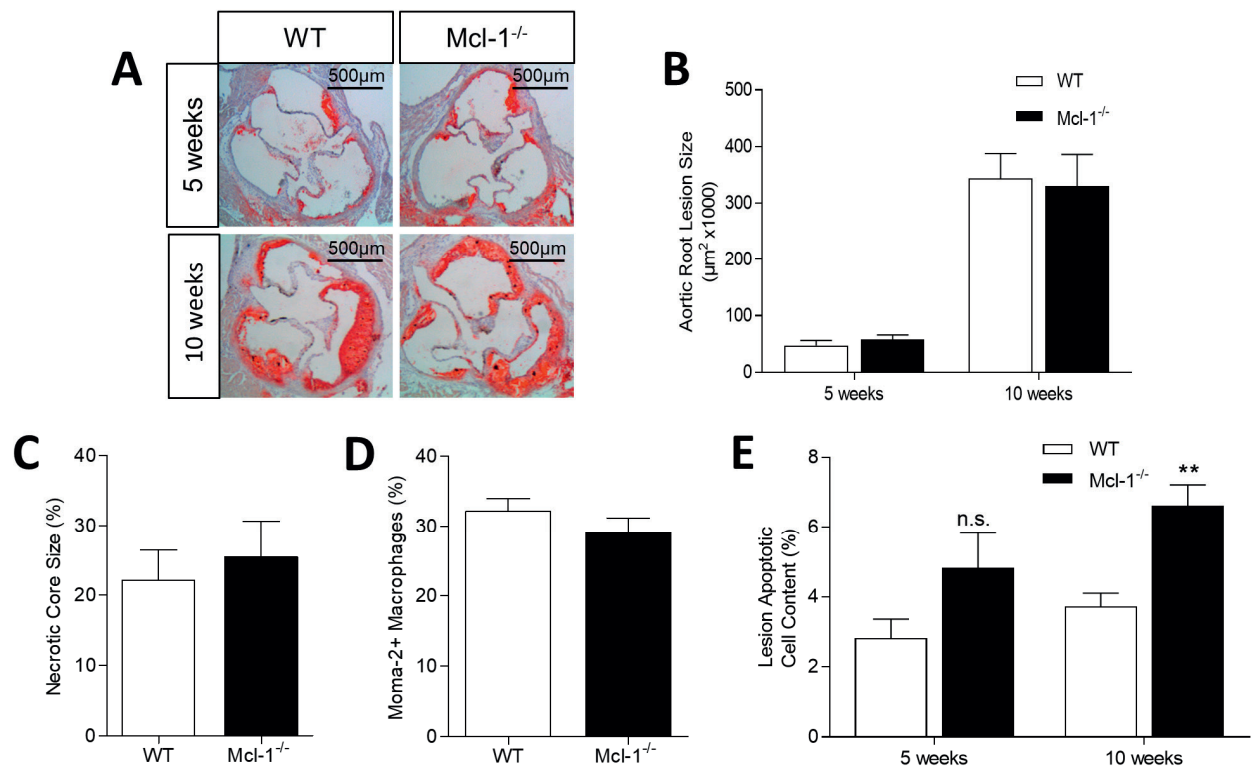

Figure 3. Effect of myeloid Mcl-1 deficiency on atherosclerotic lesion size and composition.

A. Representative micrographs of Oil Red O stained aortic root sections in WT and Mcl1\% mice after 5 and 10 weeks of WTD. B. Atherosclerotic lesion size after 5 weeks or 10 weeks of WTD quantified on Oil Red $\mathrm{O}$ staining using Leica image analysis system. C. Plaque necrotic core size after 10 weeks of WTD. D. Plaque macrophage content after 10 weeks of WTD assessed on Moma-2 positive staining. E. Plaque apoptotic cell content after 5 weeks or 10 weeks of WTD, measured by TUNEL staining. Data is presented as mean \pm SEM. $* * p<0.01$. 
Mcl-1 myeloid deletion enhanced lipid-induced apoptosis sensitivity and lipid loading capacity of macrophages

We next investigated the role of $\mathrm{Mcl}-1$ in macrophages and foam cells in atherosclerosis, reasoning that hyperlipidemia could unleash a role for Mcl-1 in plaque macrophage biology, as has been described for macrophages undergoing infection ${ }^{12}$. $\mathrm{Mcl}-1^{-/}$peritoneal macrophages displayed a higher level of apoptosis already at baseline, confirming that the hyperlipidemic environment by itself triggered the $\mathrm{Mcl}-1$ survival program (Figure 4A). Moreover, $\mathrm{Mcl}^{-1-}$ peritoneal macrophages, as well as $\mathrm{Mcl}-1^{--}$BMDMs (Supplementary Figure $2 \mathrm{~A}$ and $\mathrm{B}$ ), displayed an increased sensitivity towards oxLDL-induced cell death compared to WT macrophages (Figure $4 A$ and $B$ and Supplementary Figure 3A-E online). Interestingly, peritoneal foam cell numbers were increased by 2.5 -fold in $\mathrm{Mcl}^{-1 /-}$ compared to WT transplanted mice (Figure 4C), whereas total peritoneal macrophage numbers were unchanged (data not shown). This finding led us to examine the lipid loading capacity of peritoneal macrophages in vitro. In agreement with the elevated peritoneal foam cell counts in vivo, lipid accumulation in nonstimulated $\mathrm{Mcl}^{-1-}$ BMDMs in vitro was markedly increased (Figure 4D). Lipid loading in WT macrophages remained unchanged after incubation with oxLDL for 24h but was substantially enhanced in $\mathrm{Mcl}^{-1 /-}$ macrophages (Figure 4D). While incubation with VLDL increased lipid content in both WT and $\mathrm{Mcl}-1^{-}$- macrophages, this increase was considerably higher in the latter cells (Figure 4D). In keeping with what is observed in peritoneal macrophages, $\mathrm{Mcl}-1^{--}$BMDMs also showed an increased lipid uptake capacity (Figure 4E). Thus, under conditions of hyperlipidemia $\mathrm{Mcl}-1$ appears to be an active regulator of macrophage survival as well as of macrophage lipid loading. 

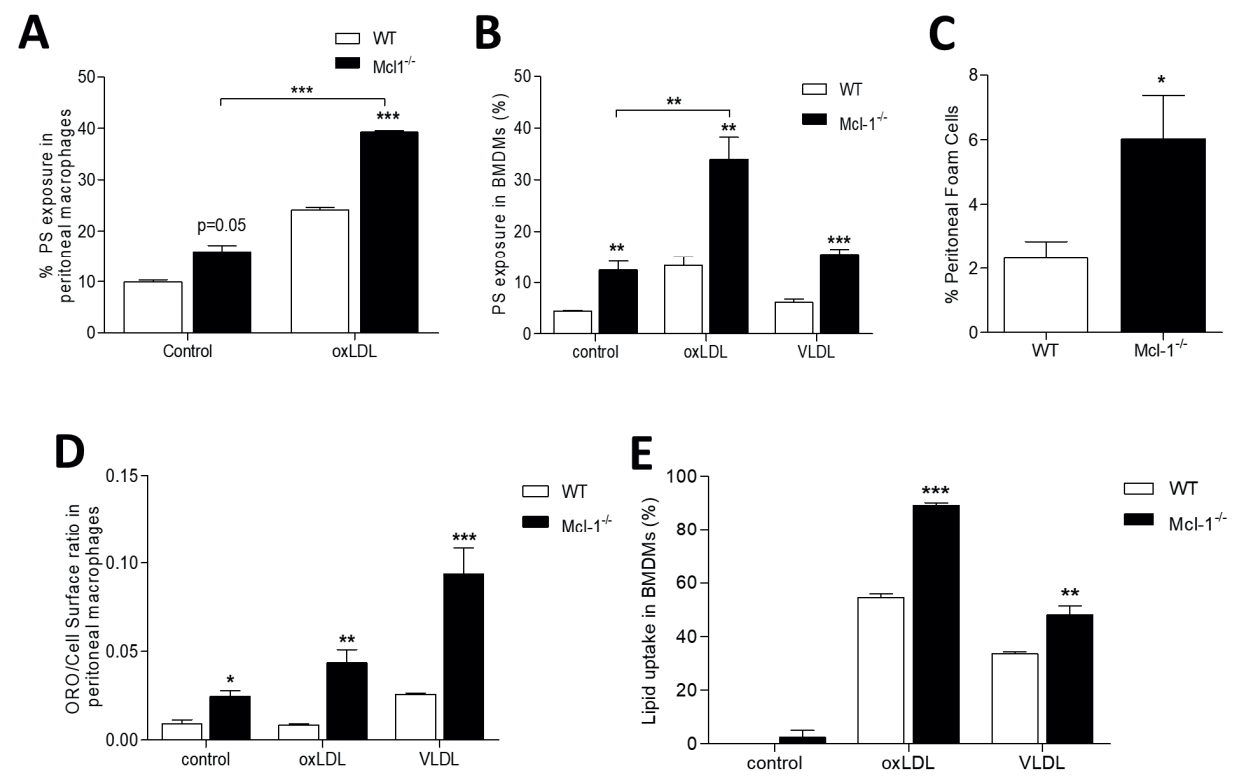

Figure 4. Effect of Mcl-1 myeloid deletion on macrophage apoptosis and lipid loading.

A. PS exposure of unstimulated or oxLDL $(40 \mu \mathrm{g} / \mathrm{ml})$ stimulated peritoneal macrophages measured by Annexin-V-OG staining. B. PS exposure of unstimulated or oxLDL/VLDL stimulated bone marrow derived macrophages (BMDMs) measured by Annexin-V-OG staining. C. Peritoneal foam cell presence of WT and $\mathrm{Mcl}-1^{--}$mice after 10 weeks of WTD assessed by Oil Red O staining in vitro. D. Lipid loading capacity of peritoneal macrophages after oxLDL $(20 \mu \mathrm{g} / \mathrm{ml})$ and $\mathrm{vLDL}(50 \mu \mathrm{g} / \mathrm{ml})$ exposure. E. Lipid uptake capacity of BMDMs after oxLDL $(20 \mu \mathrm{g} / \mathrm{ml})$ and VLDL $(50 \mu \mathrm{g} / \mathrm{ml})$ incubation. Data is presented as mean $\pm \mathrm{SEM}$. $* * * p<0.001, * * p<0.01$ and $* p<0.05$.

\section{Mcl1 deletion induces multinucleated giant cell formation}

Much to our surprise, we noticed the abundant presence of multinucleated giant cells (MGCs) in plaques of $\mathrm{Mcl}-1^{-/}$transplanted animals after 10 weeks on WTD. Indeed, MGC content per plaque was increased by $118 \%$ in the $\mathrm{Mcl}-1^{-/}$transplanted animals as compared to WT (Figure 5A and B), suggesting that Mcl-1 myeloid deficiency leads to the formation of MGCs. In addition, Mcl-1 myeloid deficiency increased MGCs formation by peritoneal macrophages in vitro both in control conditions and after incubation with oxLDL and VLDL (Figure 5C and D). To further investigate the Mcl1-dependent changes underlying MGC formation, we incubated WT BMDMs with IL-4 and GM-CSF, two known cytokines to induce giant cells ${ }^{29,30}$, and compared them to $\mathrm{Mcl}-1 \%$ BMDMs. While giant cell formation was unaffected after one week of culture (data not shown), it was significantly increased in $\mathrm{Mcl}^{-} \mathbf{1}^{-}$ 
1- BMDMs compared to WT BMDMs at 13 days of culture ( $P$ value $=0.002$, Figure 5E). Mechanistically, the effect was partially mediated by hyperlipidemia, as oxLDL or VLDL increased MGC formation in BMDM-derived cells to a larger extent (Figure 5E). Of note, after 13 days in culture, $\mathrm{Mcl}-1^{-1-}$ BMDMs had partially lost their increased capacity of lipid uptake and subsequent lipid-induced apoptosis (Figure $5 F$ and $\mathbf{G}$, respectively).

\section{A}

B
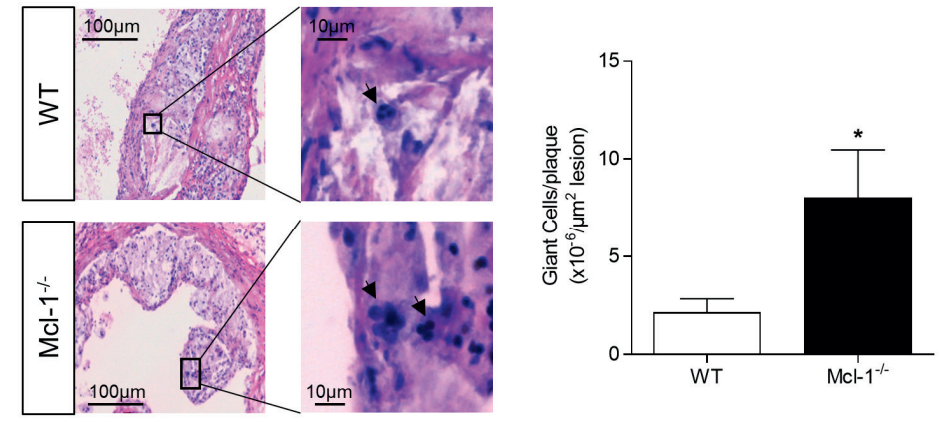

C

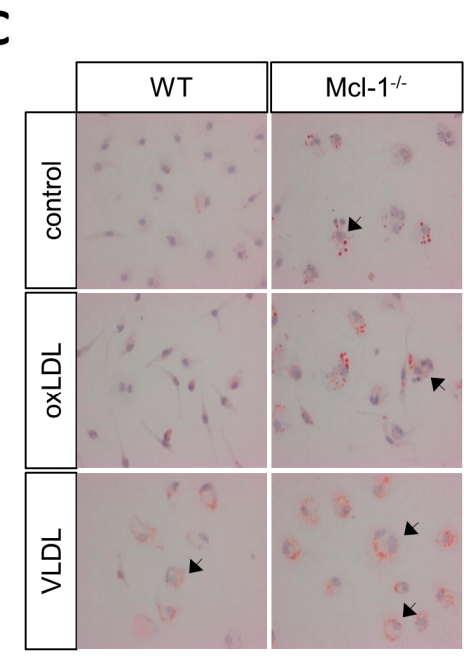

D

$\mathbf{E}$
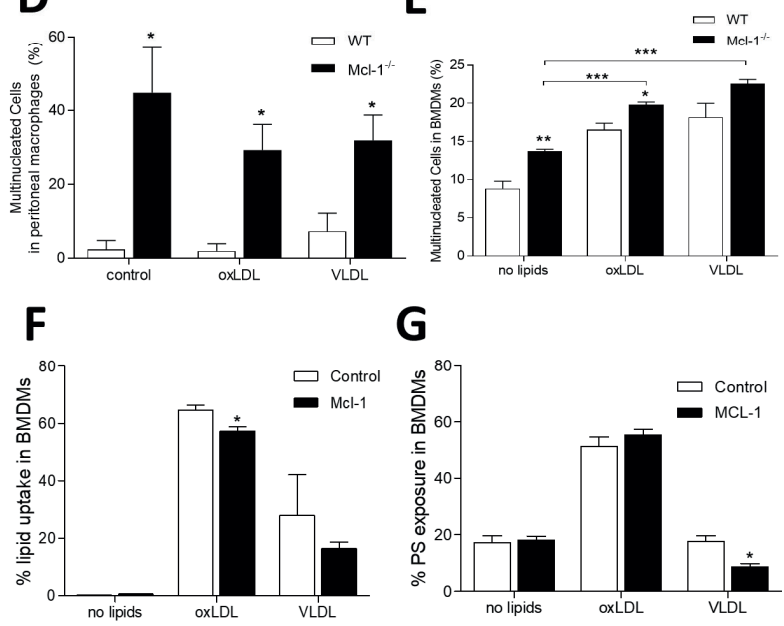

\section{G}

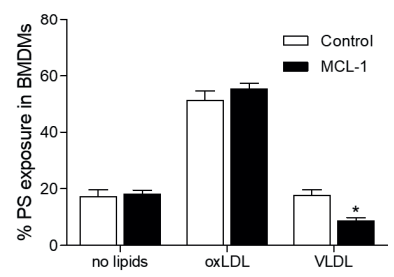

Figure 5. Effect of $\mathrm{Mcl}-1$ deletion on macrophage fusion

A. Representative pictures of mouse aortic root sections stained with H\&E. Multinucleated Giant Cells are indicated by the arrow. MGCs were quantified as cells containing two or more round nuclei. B. MGCs quantification in the atherosclerotic lesions of WT and $\mathrm{Mcl}^{-1-}$ chimeras after 10 weeks of WTD. C. Representative pictures of Oil Red $O$ stained unstimulated, oxLDL or VLDL stimulated peritoneal macrophages. Multinucleated Giant Cells are indicated by the arrow D. Quantification of Giant Cell population in peritoneal 
macrophages depicted in C. E. MGC in BMDMs after $6 \mathrm{~d}$ of culture in the presence of either oxLDL, VLDL or nothing. F. Lipid loading capacity of MGCs after $13 \mathrm{~d}$ in culture. G. PS exposure in MGC population after $13 \mathrm{~d}$ in culture. Data is presented as mean \pm SEM. $* * * p<0.001, * * p<0.01$ and $* p<0.05$

To assess the relevance of Mcl-1-dependent MGC formation in human atherosclerosis, we quantified MGCs in human plaques. Cathepsin $\mathrm{K}^{+}$ multinucleated cells were frequently found in both stable and unstable plaques (Figure 6A and B). Interestingly, their presence inversely correlated with $\mathrm{Mcl}-1$ gene expression in unstable plaque, and only in unstable lesions associated significantly with lesion hemorrhages and calcifications ( $P$ value $=0.044$ and 0.055 , respectively, Figure $6 \mathrm{C}$ and $\mathrm{D}$ ). Thus, our results unveil a hitherto unknown link between $\mathrm{Mcl}-1$ and MGC formation, which is influenced by hyperlipidemia, an association potentially preserved in human atherosclerotic lesions as well.

A
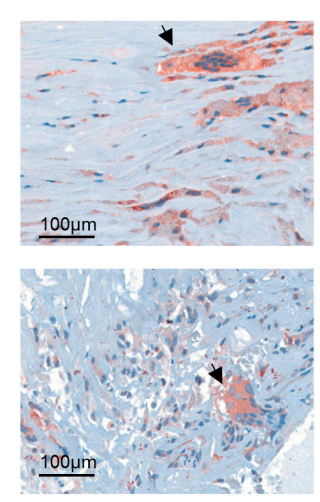

B

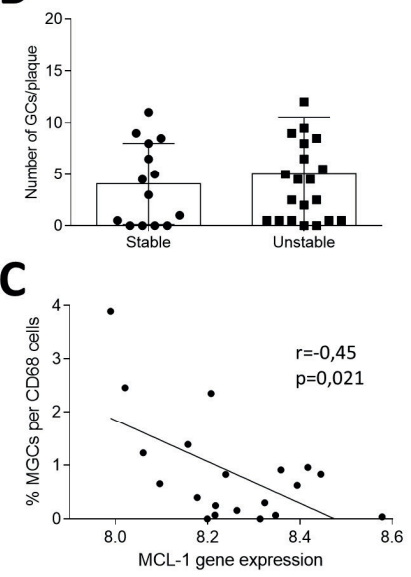

D

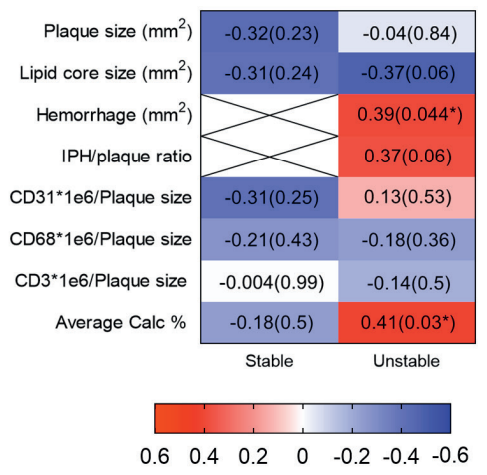

Figure 6. Presence of Multinucleated Giant Cells in human atherosclerotic plaques.

A. Representative pictures of cathepsin K stained human unstable plaques. Multinucleated Giant Cells are indicated by the arrow B. MGCs are quantified as cells positive for cathepsin $\mathrm{K}$ and containing two or more round nuclei. C. Pearson correlation analysis showing coefficient ( $p$-values) between MGCs presence and MCL-1 gene expression levels in human unstable plaque segments ( $n=18$ ). D. Heatmap showing Pearson's correlation coefficient/pvalues between the presence of MGCs and other clinical plaque traits. $N=22 / 23$ (stable/unstable). * indicates significant correlation. 


\section{Discussion}

In this study, we evaluated the effects of myeloid Mcl-1 deletion and its accompanying neutropenia on atherosclerosis progression. In addition to extreme neutropenia, Mcl-1 deficiency resulted in increased macrophage apoptosis and lipid handling, and triggered multinucleated giant cell formation. First, we found that myeloid $\mathrm{Mcl}-1$ deletion dramatically reduced neutrophil numbers both in circulation and in atherosclerotic lesions. This is in keeping with extensive data on the vital role of $\mathrm{Mcl}-1$ in neutrophil survival ${ }^{9,10,31,32}$ which as we now demonstrated remains valid in a hyperlipidemic environment. On the other hand, Mcl-1 overexpression $\mathrm{n}^{33,34}$ and Bim deletion ${ }^{23}$, a pro-apoptotic $\mathrm{Bcl}-2$ family member and Mcl-1 antagonist, do not affect circulating myeloid cell numbers, suggesting that physiological Mcl-1 levels are sufficient for normal cell function. Our work thus provides a mouse model for continuous neutropenia, an important advantage to models used in earlier studies addressing neutrophil contribution to atherogenesis. Though Zernecke et al. demonstrated that CXCR4 blockade aggravated atherosclerosis due to increased neutrophil recruitment to the plaque, they were unable to extend the neutrophil depletion beyond a 4 week period ${ }^{16}$. They did show that plaques of neutrophil-depleted mice were smaller and had a lower neutrophil and macrophage content, but did not evaluate plaque apoptosis or necrotic core size. Similarly so, $\mathrm{CCL3}^{-/-} \mathrm{LDLr}^{-/-}$bone marrow chimeras with $50 \%$ less neutrophils, developed smaller atherosclerotic lesions ${ }^{35}$. Consequently, we were highly surprised by the unaffected atherosclerotic lesion burden in neutropenic LysMCre $\mathrm{Mcl}-1^{-/-}$mice.

Apparently the atheroprotective effects of Mcl-1 deletion in neutrophils in LDLr-mice are counteracted by potentially pro-atherogenic effects on other cell types targeted by the LysM conditional $\mathrm{Mcl}-1$ deletion, we therefore examined in greater detail the role of $\mathrm{Mcl}-1$ in atherosclerotic $\mathrm{LysM}^{+}$monocytes and macrophages.

Although Mcl-1 loss was previously shown to have no effect on monocyte and

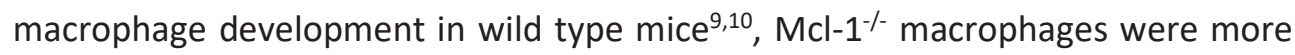
sensitive to apoptosis upon an infection ${ }^{12}$ or phagocytic challenge ${ }^{10}$. We found that the apoptotic cell content in advanced aortic root lesions (10 weeks of WTD) was increased by $44 \%$ in mice with myeloid Mcl-1 deficiency. As neutrophils are only scarcely present in advanced lesions ${ }^{14}$ and most apoptotic cells were located in the central atheroma (data not shown), the high apoptotic cell density is likely to reflect dying LysM $^{+}$plaque macrophages. Our work thus identifies $\mathrm{Mcl}-1$ as a major survival Page | 120 
protein in atherosclerotic lesions. Atherosclerotic lesion burden was however unaltered in $\mathrm{Mcl}-1 \%$ BM recipients, as were necrotic core, macrophage and collagen content. Similar results were obtained when studying plaque initiation five weeks after WTD. Our results correspond with those from Thorp et al. ${ }^{21}$, who showed increased macrophage apoptosis, but unchanged lesion burden in Bcl-2 $2^{\text {flox }}-\mathrm{LysMCre}$ $\mathrm{ApoE}^{-/}$mice that are deficient in macrophage and neutrophil $\mathrm{Bcl}-2^{21}$. In turn, hematopoietic Bim deficiency, a pro-apoptotic Bcl-2-family member, had no impact on macrophage apoptosis and lesion burden in $\mathrm{LDLr}^{-/}$mice ${ }^{23}$. Thus, $\mathrm{Mcl}^{-1 /}$ deletion in macrophages led to higher apoptosis level in advanced plaques, however it is clear from the above that this not always translates into a pro-atherogenic plaque progression.

In addition to an increased sensitivity to oxLDL induced cell death, $\mathrm{Mcl}^{-1}{ }^{-1}$ macrophages showed augmented lipid accumulation after incubation with oxLDL and VLDL. In keeping, we observed elevated foam cell levels in vivo in the peritoneal cavity of $\mathrm{Mcl}-1^{-} \mathrm{BM}$ compared to WT BM recipients. These findings seem to contrast with those of Halvorsen et al. ${ }^{36}$, who reported reduced IL-10 induced oxLDL loading by THP-1 macrophages in vitro after siRNA mediated silencing of Mcl-1 and Bfl-1 expression. The authors did not assess effects of Mcl-1 inhibition alone, without IL-10 stimulation. Based on our data we hypothesize that the apoptosisprone phenotype of $\mathrm{Mcl}^{-1 /}$ macrophages is at least partly caused by the increased uptake of lipids.

Another remarkable characteristic was the high propensity of $\mathrm{Mcl}-1^{--}$cells to form multinucleated giant cells (MGCs). MGCs, a hallmark of several chronic inflammatory diseases ${ }^{37,38}$, originate from monocyte-macrophage lineage and result from cell fusion ${ }^{37,39}$. Giao et al. have illustrated the presence of TRAP-positive (osteoclast like giant) cells in close relation to calcified regions and TRAP-negative MGCs in advanced human atherosclerotic plaques ${ }^{40}$. In addition, Samokhin et al. ${ }^{41}$ showed that mice fed a Paigen diet displayed a 4-fold increase in MGC number in atherosclerotic lesions ${ }^{41}$. In our study, we observed a higher macrophage fusion capacity in both $\mathrm{Mcl}-1^{-/}$peritoneal and BMDMs, which increased even more upon oxLDL or VLDL stimulation. Furthermore, $\mathrm{Mcl}-1^{-1}$ deficiency in BMDMs seemed to promote MGC formation, independently of lipid uptake. In line with our in vitro findings, $\mathrm{Mcl}^{-1}$ - atherosclerotic plaques had a 4-fold increase in MGC presence as compared to WT lesions. Additionally, the presence of MGCs in human unstable plaques correlated negatively with $\mathrm{Mcl}-1$ gene expression and significantly 
associated with hemorrhages and calcifications in the lesion. The exact role of MGCs in atherosclerosis is not yet fully understood, however it was previously shown that MGCs facilitate vascular smooth muscle cell migration in the context of atherosclerosis by producing cathepsin $\mathrm{K}$ and destroying the elastin fibers ${ }^{41}$. Although not providing conclusive evidence, our findings support such proatherogenic role of MGCs. To our knowledge, we are the first to implicate Mcl-1 in the fusion of macrophages. Possibly, this is related to increased oxidative phosphorylation capacity for energy production in $\mathrm{Mcl}-1^{-1}$ deficient BMDMs (data not shown), however the exact mechanism by which Mcl-1 induces MGC formation remains to be investigated.

In summary, myeloid Mcl-1 deficiency led to a profound and sustained neutropenia in hyperlipidemic $\mathrm{LDLr}^{-/}$mice accompanied by enhanced oxLDL induced macrophage death in vitro, as well as increased atherosclerotic lesion apoptosis. Furthermore, Mcl-1 deficiency was shown to enhance lipid uptake and induce the formation of MGCs in vitro and in vivo. In line with the observation in mice, Mcl-1 gene expression negatively correlated with the presence of MGCs in human unstable plaque. Taken together, the markedly lower neutrophil numbers mask the combined effects of a more lipid rich and apoptotic plaque in myeloid Mcl-1 deficient animals, and result in an unchanged lesion development and progression. Our results clearly identify $\mathrm{Mcl}-1$ as a macrophage survival protein under hyperlipidemia and uncover a hitherto unknown role for Mcl-1 in MGC formation. 


\section{Acknowledgements}

This work is part of the research program \#912.02.037 to EB and BV, which is financed by the Netherlands Organization for Scientific Research (NWO). 


\section{References}

1. Kozopas, K. M., Yang, T., Buchan, H. L., Zhou, P. \& Craig, R. W. MCL1, a gene expressed in programmed myeloid cell differentiation, has sequence similarity to BCL2. Proc. Natl. Acad. Sci. U. S. A. 90, 3516-20 (1993).

2. Opferman, J. T. et al. Development and maintenance of B and T lymphocytes requires antiapoptotic MCL-1. Nature 426, 671-676 (2003).

3. Clohessy, J. G., Zhuang, J., de Boer, J., Gil-Gómez, G. \& Brady, H. J. M. Mcl-1 Interacts with Truncated Bid and Inhibits Its Induction of Cytochrome $c$ Release and Its Role in Receptor-mediated Apoptosis. J. Biol. Chem. 281, 5750-5759 (2006).

4. Willis, S. N. et al. Proapoptotic Bak is sequestered by $\mathrm{Mcl}-1$ and $\mathrm{Bcl}-\mathrm{xL}$, but not $\mathrm{Bcl}-$ 2, until displaced by BH3-only proteins. Genes Dev. 19, 1294-1305 (2005).

5. Krajewski, S. et al. Immunohistochemical analysis of $\mathrm{Mcl}-1$ protein in human tissues. Differential regulation of $\mathrm{Mcl}-1$ and $\mathrm{Bcl}-2$ protein production suggests a unique role for $\mathrm{Mcl}-1$ in control of programmed cell death in vivo. Am. J. Pathol. 146, 1309-19 (1995).

6. Zhou, P., Qian, L., Kozopas, K. M. \& Craig, R. W. Mcl-1, a Bcl-2 family member, delays the death of hematopoietic cells under a variety of apoptosis-inducing conditions. Blood 89, 630-43 (1997).

7. Murphy, M. P. \& Caraher, E. Mcl-1 is vital for neutrophil survival. Immunol. Res. 62, 225-233 (2015).

8. Milot, E. \& Filep, J. G. Regulation of neutrophil survival/apoptosis by Mcl-1. ScientificWorldJournal. 11, 1948-62 (2011).

9. Dzhagalov, I., St John, A., He, Y.-W. \& Edwards, S. W. The antiapoptotic protein Mcl1 is essential for the survival of neutrophils but not macrophages. Blood 109, 16206 (2007).

10. Steimer, D. A. et al. Selective roles for antiapoptotic MCL-1 during granulocyte development and macrophage effector function. Blood 113, 2805-15 (2009).

11. Vier, J., Groth, M., Sochalska, M. \& Kirschnek, S. The anti-apoptotic Bcl-2 family protein A1/Bfl-1 regulates neutrophil survival and homeostasis and is controlled via PI3K and JAK/STAT signaling. Cell Death Dis. 7, (2016).

12. Wang, F. et al. Suppression of Mcl-1 induces apoptosis in mouse peritoneal macrophages infected with Mycobacterium tuberculosis. Microbiol. Immunol. 60, 215-227 (2016).

13. Nagenborg, J., Goossens, P., Biessen, E. A. L. \& Donners, M. M. P. C. Heterogeneity of atherosclerotic plaque macrophage origin, phenotype and functions: Implications for treatment. Eur. J. Pharmacol. 816, 14-24 (2017).

14. Hartwig, H., Silvestre Roig, C., Daemen, M., Lutgens, E. \& Soehnlein, O. Neutrophils in atherosclerosis. A brief overview. Hamostaseologie 35, 121-7 (2015).

15. Chistiakov, D. A., Grechko, A. V., Myasoedova, V. A., Melnichenko, A. A. \& Orekhov, A. N. The role of monocytosis and neutrophilia in atherosclerosis. J. Cell. Mol. Med. 22, 1366-1382 (2018).

16. Zernecke, A. et al. Protective Role of CXC Receptor 4/CXC Ligand 12 Unveils the Importance of Neutrophils in Atherosclerosis. Circ. Res. 102, 209-217 (2008). 
17. Warnatsch, A., loannou, M., Wang, Q. \& Papayannopoulos, V. Neutrophil extracellular traps license macrophages for cytokine production in atherosclerosis. Science (80-. ). 349, 316-320 (2015).

18. Doring, Y. et al. Hematopoietic Interferon Regulatory Factor 8-Deficiency Accelerates Atherosclerosis in Mice. Arterioscler. Thromb. Vasc. Biol. 32, 16131623 (2012).

19. Tailor, P., Tamura, T., Morse, H. C. \& Ozato, K. The BXH2 mutation in IRF8 differentially impairs dendritic cell subset development in the mouse. Blood 111, 1942-1945 (2008).

20. $\mathrm{Xu}, \mathrm{W}$. et al. IL-10-producing macrophages preferentially clear early apoptotic cells. Blood 107, 4930-4937 (2006).

21. Thorp, E. et al. Brief Report: Increased Apoptosis in Advanced Atherosclerotic Lesions of Apoe-/- Mice Lacking Macrophage Bcl-2. Arterioscler. Thromb. Vasc. Biol. 29, 169-172 (2009).

22. Liu, J. et al. Reduced Macrophage Apoptosis Is Associated With Accelerated Atherosclerosis in Low-Density Lipoprotein Receptor-Null Mice. Arterioscler. Thromb. Vasc. Biol. 25, 174-9 (2004).

23. Temmerman, L. et al. Leukocyte Bim deficiency does not impact atherogenesis in Idlr -/- mice, despite a pronounced induction of autoimmune inflammation. Sci. Rep. 7, 3086 (2017).

24. von der Thüsen, J. H., van Berkel, T. J. \& Biessen, E. A. Induction of rapid atherogenesis by perivascular carotid collar placement in apolipoprotein Edeficient and low-density lipoprotein receptor-deficient mice. Circulation 103, 1164-70 (2001).

25. Redgrave, T. G., Roberts, D. C. K. \& West, C. E. Separation of plasma lipoproteins by density-gradient ultracentrifugation. Anal. Biochem. 65, 42-49 (1975).

26. van Genderen, H. et al. In vitro measurement of cell death with the annexin A5 affinity assay. Nat. Protoc. 1, 363-367 (2006).

27. Otsuka, F. et al. Natural progression of atherosclerosis from pathologic intimal thickening to late fibroatheroma in human coronary arteries: A pathology study. Atherosclerosis 241, 772-782 (2015).

28. Donners, M. M. P. C. et al. Cathepsin K Deficiency Prevents the Aggravated Vascular Remodeling Response to Flow Cessation in ApoE-/- Mice. PLoS One 11, e0162595 (2016).

29. Helming, L. \& Gordon, S. Macrophage fusion induced by IL-4 alternative activation is a multistage process involving multiple target molecules. Eur. J. Immunol. 37, 3342 (2007).

30. Helming, L., Winter, J. \& Gordon, S. The scavenger receptor CD36 plays a role in cytokine-induced macrophage fusion. J. Cell Sci. 122, 453-9 (2009).

31. Moulding, D. A., Quayle, J. A., Hart, C. A. \& Edwards, S. W. Mcl-1 expression in human neutrophils: regulation by cytokines and correlation with cell survival. Blood 92, 2495-502 (1998).

32. Epling-Burnette, P. K. et al. Cooperative regulation of $\mathrm{Mcl}-1$ by Janus kinase/stat and phosphatidylinositol 3-kinase contribute to granulocyte-macrophage colony- 
stimulating factor-delayed apoptosis in human neutrophils. J. Immunol. 166, 748695 (2001).

33. Campbell, K. J. et al. Elevated Mcl-1 perturbs lymphopoiesis, promotes transformation of hematopoietic stem/progenitor cells, and enhances drug resistance. Blood 116, 3197-207 (2010).

34. Anstee, N. S. et al. Overexpression of $\mathrm{Mcl}-1$ exacerbates lymphocyte accumulation and autoimmune kidney disease in Ipr mice. Cell Death Differ. 24, 397-408 (2017).

35. de Jager, S. C. A. et al. Leukocyte-specific CCL3 deficiency inhibits atherosclerotic lesion development by affecting neutrophil accumulation. Arterioscler. Thromb. Vasc. Biol. 33, e75-83 (2013).

36. Halvorsen, B. et al. Interleukin-10 enhances the oxidized LDL-induced foam cell formation of macrophages by antiapoptotic mechanisms. J. Lipid Res. 46, 211-219 (2005).

37. Anderson, J. M. Multinucleated giant cells. Curr. Opin. Hematol. 7, 40-47 (2000).

38. Vignery, A. Osteoclasts and giant cells: Macrophage-macrophage fusion mechanism. International Journal of Experimental Pathology 81, 291-304 (2000).

39. Helming, L. \& Gordon, S. The molecular basis of macrophage fusion. Immunobiology 212, 785-793 (2008).

40. Qiao, J. H., Mishra, V., Fishbein, M. C., Sinha, S. K. \& Rajavashisth, T. B. Multinucleated giant cells in atherosclerotic plaques of human carotid arteries: Identification of osteoclast-like cells and their specific proteins in artery wall. Exp. Mol. Pathol. 99, 654-662 (2015).

41. Samokhin, A. O. et al. Cholate-containing high-fat diet induces the formation of multinucleated giant cells in atherosclerotic plaques of apolipoprotein E-/-mice. Arterioscler. Thromb. Vasc. Biol. 30, 1166-1173 (2010). 


\section{Supplemental data}

\begin{tabular}{lll}
\hline Gene & Forward primer $\left(5^{\prime}-3^{\prime}\right)$ & Reverse primer $\left(5^{\prime}-3^{\prime}\right)$ \\
\hline Mcl-1 & AAGAGGCTGGGATGGGTTTGT & AGTCCCCTATTGCACTCACAAG \\
HPRT & TTGCTCGAGATGTCATGAAGGA & AGCAGGTCAGCAAAGAACTTATAG \\
18S & GTAACCCGTTGAACCCCATT & CCATCCAATCGGTAGTAGCG
\end{tabular}

Supplementary Table 1: Primer sequences 
A

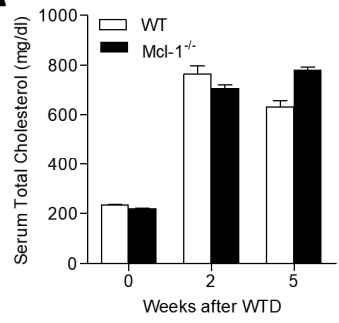

B

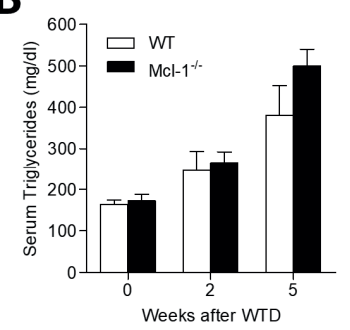

C

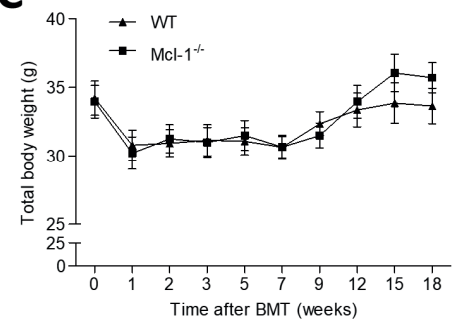

Supplementary Figure 1. Lipid levels and total body weight of $\mathrm{Mcl}^{-1} \%$ chimeras are unchanged.

A. Serum total cholesterol levels at 0,2 and 5 weeks after WTD. B. Serum triglyceride levels at 0,2 and 5 weeks after WTD. Total body weight of WT and $\mathrm{Mcl}^{-1}$ chimeras. Data is presented as mean \pm SEM. ${ }^{*} p<0.05$ 

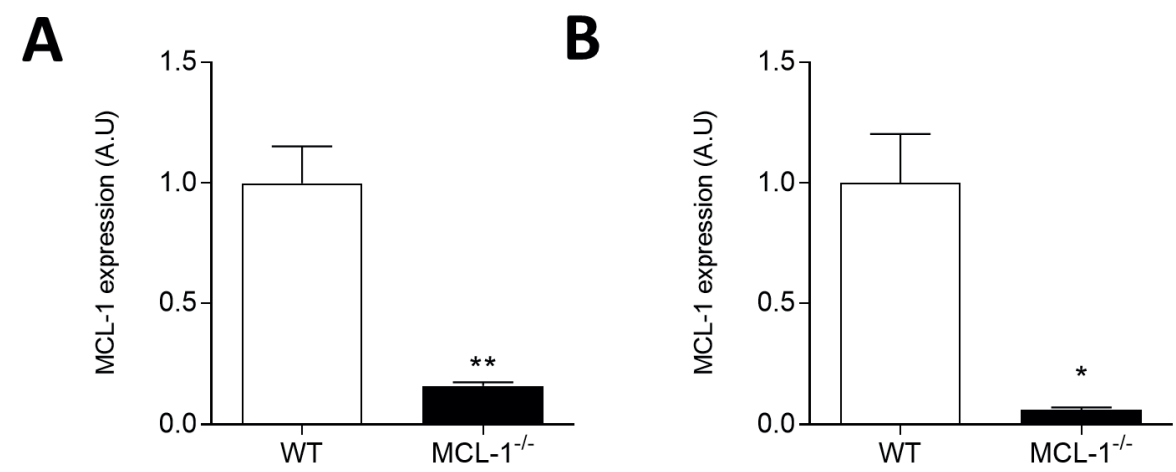

\section{Supplementary Figure 2: Mcl-1 gene knock-out confirmation by qPCR.}

$\mathrm{Mcl}-1$ gene expression in $\mathrm{BMDMs}$ from $\mathrm{Mcl}-1^{-/}$mice is almost blunted as compared to that of WT BMDM at day $7 d(A)$ or $12 d(B)$ of culturing. Data is presented as mean \pm SEM. $* p<0.05 ; * * p<0.01$. 

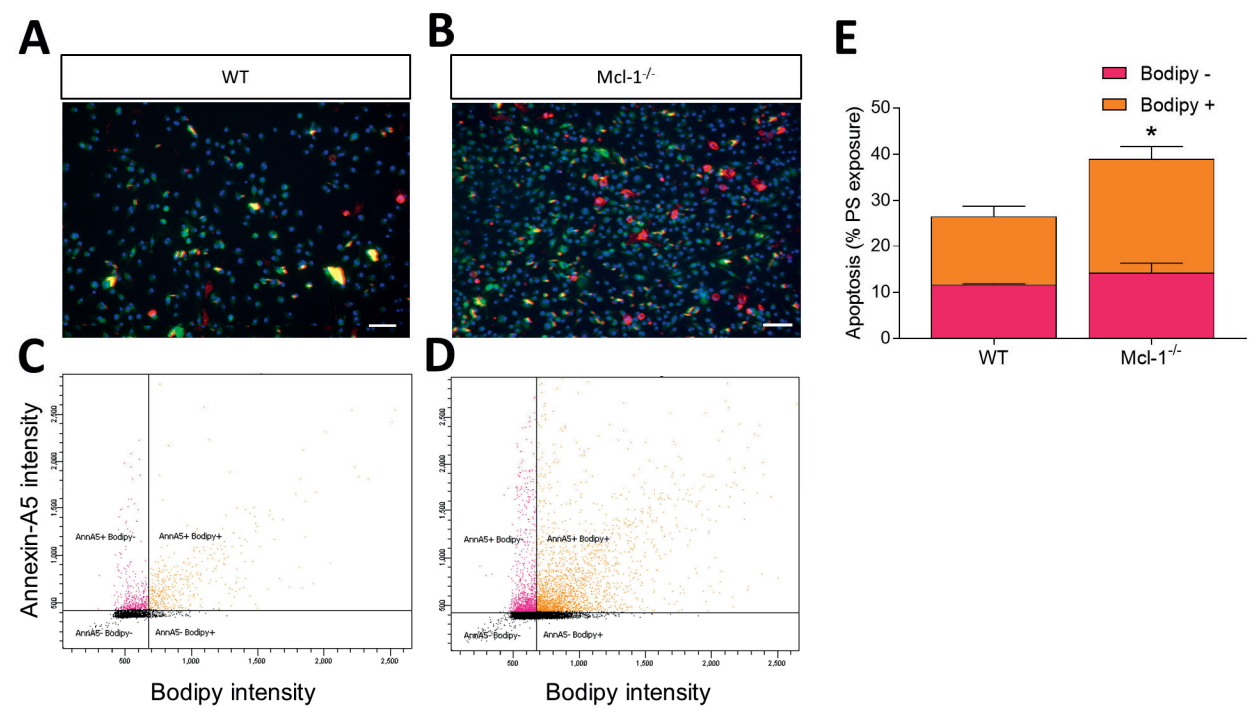

\section{Supplementary Figure 3: Lipid induced-apoptosis in $\mathrm{Mcl}-1^{\%}$ - BMDMs.}

A. WT and B. Mcl-1\% BMDMs were incubated for 2,5h with fluorescently-labeled oxLDL (bodipy, $20 \mu \mathrm{g} / \mathrm{ml}$ ) and subsequently stained for PS exposure using Alexa-647 labelled Annexin-A5 and cell associated fluorescence was measured by using a fluorescent microscope (BD pathway 855; representative image at $10 \mathrm{X}$ magnification). C. and D. show representative analysis performed with the DIVA software and $E$. represents the quantification. Data is presented as mean \pm SEM. $* p<0.05$ 




\section{Chapter 5}

Cardiovascular event prediction by machine learning: identification of a blood-based lipid signature to stratify obese subjects.

MAC Fontaine, T Aliyev, RH Sikkens, J Dehairs, E Waelkens, R Derua, J Swinnen, MMJ van Greevenbroek, CJH van der Kallen, CG Schalkwijk, CDA Stehouwer, M Nauck,' E Hammer, U Völker, A Hannemann, M Dörr, H Völzke, S Zylla, JC Sluimer, Y Mengerink, L Temmerman, EAL Biessen. 


\section{Chapter 6}

General discussion 



\section{Main findings of this thesis}

Macrophages are the most abundant immune cell type in atherosclerosis and their transcriptional plasticity has been widely demonstrated ${ }^{1}$. However, a clear link between transcriptional heterogeneity and the corresponding functional activity was lacking. Therefore, in this thesis we aimed at building a macrophage functional map using a high content analysis system in vitro to study macrophage functions in CVD inflammation, including atherosclerosis, acute myocardial infarction repair and cardiometabolic disorders, and link it to specific transcriptional profiles.

In this chapter, we will discuss the following main findings and deliverables of this thesis:

(1) The successful development of a ready-to-use "functionomics" platform (called the MacroScreen). This platform is able to measure 19 distinct functions of human and mouse macrophages in a semi-automated manner and at microscale (chapter 2 to 5 ).

(2) The identification of a macrophage functional activation map. Macrophages transcriptional plasticity, which cannot be fully captured by the $\mathrm{M} 1 / \mathrm{M} 2$ dichotomy, has direct repercussion on their functional profile (chapter 2).

(3) The functional responses of macrophages to their environment. Systemic changes following acute myocardial infarction (AMI) reprograms human macrophages by dysregulating their functional and transcriptional profile. Furthermore, these transcriptional and functional changes correlate with clinical progression of the patients (chapter $\mathbf{3}$ ).

(4) The discovery of a highly predictive lipid-signature for the development of obesity-related CVD. These lipids not only predict future CVD events but also seem causally implicated in the pathophysiology of atherosclerosis and related CVD, as assessed by our functionomics platform. (chapter 5 ).

In the following, integrative discussion, we will (1) address the use of macrophages as sensors for CVD inflammation and discuss relevant macrophage functions in CVD, macrophage plasticity and the impact of macrophage source that can be used 
in the MacroScreen; (2) compare the MacroScreen to other currently available humanized platforms; and (3) focus on patient systemic environment and its relation to CVD. 


\section{The MacroScreen: a novel tool to study innate immune responses in cardiovascular diseases}

The use of macrophages as sensors in the MacroScreen: Macrophage functions in CVD and their measurement in the Macroscreen

In chapters 2-5, we used human macrophages to assess changes in cellular function associated with cardiovascular inflammation, including atherosclerosis (chapter 4), repair after acute myocardial infarction (AMI, chapter 4 ), and cardiometabolic diseases (chapter 5). Macrophages are innate immune cells implicated in atherosclerosis and AMI repair. First, in atherosclerosis, macrophages are the most abundant immune cells and are involved at all stages of the disease. They derive from blood monocytes that are recruited to the vascular wall where they differentiate into macrophages and ingest oxidized low-density lipoprotein (oxLDL) to become lipid-laden foam cells, forming the atherosclerotic plaque. Second, after an AMI event, macrophages are recruited to the ischemic heart and contribute to cardiac repair by regulating, amongst others, inflammation, apoptosis and extracellular matrix degradation and formation, and angiogenesis ${ }^{2}$. In chapter $\mathbf{2}$, we describe the development of a high content analysis platform able to measure 19 distinct macrophage functions, all relevant for the development of atherosclerosis, associated inflammatory responses, and AMI post injury repair. This platform allows us to understand how certain environmental cues (chapter 2 and 5) or systemic patient environment (chapter 3) can affect macrophage functional profile and subsequently relate to CVD incidence.

In the next paragraphs, we will further discuss the implication of each function included in the MacroScreen in the context of atherosclerosis and AMI repair. Furthermore, we will discuss possible other functions the platform could cover.

\section{Cholesterol metabolism}

Cholesterol metabolism in macrophages is an important player during atherosclerosis, it involves excessive uptake of modified cholesterol and reduced reverse transport of cholesterol to HDL particles ${ }^{3,4}$. Studies in mice have shown that inhibition of lipid uptake by depletion of certain scavenger receptors results in a reduction of atherosclerotic plaque development. Babaev et al. showed that deletion of myeloid class A scavenger receptors in mice reduced the atherosclerotic lesion area by $60 \%{ }^{5}$. A similar reduction in lesion area (76.5\%) was observed after depletion of $\mathrm{CD} 36$, a class $\mathrm{B}$ scavenger receptor, and this was attributed to reduced 
foam cell formation by $60 \%{ }^{6}$. Additionally, increased reverse cholesterol transport, called cholesterol efflux, from macrophages has also shown beneficial effects on atherosclerosis. Stimulation of liver $X$ receptor $\alpha(L X R \alpha)$ in macrophages leads to upregulation of ATP binding cassette A1 (ABCA1), a cholesterol transporter, and was seen to reduce atherosclerotic lesions ${ }^{7-9}$, confirming that regulation of cholesterol metabolism in macrophages is crucial in atherosclerosis. Unsaturated fatty acid, such as palmitic and linoleic acid (included in chapter 2) can downregulate $A B C A 1$ and $A B C G 1$ expression, via inhibition of agonist binding to $L X R \alpha^{10}$. Furthermore, the pro-inflammatory micro-environment of the atherosclerotic plaque is also able to regulate foam cell formation, as interleukin12 (IL-12) and IL-18 were shown to reduce ABCA1 expression, and thus cholesterol efflux by macrophages ${ }^{11}$.

\section{Mitochondrial functions}

During the process of foam cell formation, free cholesterol can disrupt mitochondrial functions in macrophages ${ }^{12}$. Mitochondria are cell organelles exerting a myriad of functions essential for cell homeostasis, including regulation of ATP production, reactive oxygen species (ROS) production or apoptosis signal ${ }^{13}$ and macrophage mitochondrial dysfunction has been associated with inflammation in cardiovascular disease. Yu et al. observed a reduction in mitochondrial oxygen consumption and mitochondrial DNA (mtDNA) copies in human atherosclerotic necrotic cores and fibrous cap. This observation was also made in $\mathrm{ApoE}^{-/-}$mice fed a high-fat diet and increasing mitochondrial respiration by restoring mtDNA copy number through overexpression of Twinkle, a mitochondrial helicase, led to smaller and more stable plaques ${ }^{14}$. In the context of cardiac repair after $\mathrm{Ml}$, three days post infarct, cardiac macrophages have been observed to exhibit dysregulated mitochondrial function, as shown by e.g. upregulation of genes involved in oxidative phosphorylation, hinting to a macrophage metabolic switch ${ }^{15}$.

\section{ROS production}

ROS production is a critical function of macrophages. To combat infection, phagocytes, including macrophages, release massive amounts of reactive oxygen species, a process known as respiratory burst ${ }^{16}$. Macrophage-derived ROS are produced by mitochondria e.g. fatty acid oxidase (NOX4), in endosomes (NOX1), in cytosol, or at the cell membrane (e.g. via NADPH oxidases (NOX4 and 5) and extracellularly (myeloperoxidases etc)). Excessive intra- and extracellular ROS has been repeatedly linked to atherosclerosis development ${ }^{16,17}$. Xu et al. showed that 
deletion of NOX1 and NOX2 leads to reduced ROS macrophage production and defective macrophage differentiation from monocytes ${ }^{18}$. Furthermore, a recent study showed that reduction of atherosclerotic plaque by treatment with the antioxidant flavonoid quercetin in $\mathrm{ApoE}^{-/}$mice was attributable to decreased ROS production by macrophages ${ }^{19}$. Additionally, $\mathrm{LDLR}^{-/}$mice irradiated and transplanted with mitochondrial catalase transgenic mouse bone marrow, known to have reduced mitochondrial oxidative stress, showed less macrophage oxidative stress in atherosclerotic lesions and in turn, smaller plaque size ${ }^{20}$. ROS production is also critical to cardiac repair following $\mathrm{MI}$, as ROS was associated with the amount of necrosis after $\mathrm{Ml}$ and overexpression of superoxide dismutase in mice led to improved cardiac function ${ }^{21}$. In addition, bone marrow derived macrophages were found to be the main source of increasing expression of gp91phox, also known as NOX2, during the first stages of cardiac repair ${ }^{22}$.

\section{Cytokine production}

Next to ROS production, macrophages also produce a broad range of cytokines during cardiovascular disease. Cytokines are effector proteins that will act as pro or anti-inflammatory signals and are abundantly found in atherosclerotic lesions or in the infarcted heart ${ }^{23}$. In atherosclerosis, cytokines are first released by macrophages after oxLDL uptake and this will, in turn, become a vicious circle of inflammation, as cytokines will further activate macrophages and other cell types to release more cytokines progressively. Pro-inflammatory cytokines, such as Interferon- $\gamma$ (IFN $\gamma$ ) and tumor necrosis factor (TNF) have pro-atherogenic properties, as TNF $\alpha$-deficient or IFN $\gamma$-deficient $\mathrm{ApoE}^{-/-}$mice showed reduced atherosclerotic plaque size, mostly attributed to less foam cell formation, expression of other pro-inflammatory markers ${ }^{24}$ and decreased lipid content $\mathrm{t}^{25}$. Contrarily, anti-inflammatory cytokines, such as IL-13 or IL-10, commonly exert anti-atherogenic effects by modulating macrophage phenotype ${ }^{26}$ and lipid metabolism ${ }^{27}$, respectively. Similarly, during cardiac repair following $\mathrm{MI}$, macrophages first release a range of pro-inflammatory cytokines, such as IL-1 $\beta$ and TNF- $\alpha$, and this is followed by a switch to an anti-inflammatory state, mediated by anti-inflammatory cytokines, such as IL- 4 and IL-1028. This switch seems beneficial, as treatment of mice after $\mathrm{MI}$ with IL-10 led to increased polarization to $\mathrm{M} 2$ macrophage and improved cardiac functions, such as ejection fraction and left ventricular dilation ${ }^{29}$. 


\section{Inflammasome activation}

Another key pro-inflammatory cytokine produced by macrophages is IL-1 $\beta$. IL-1 is the result of the macrophage inflammasome activation in response to cholesterol crystals and $\operatorname{oxLDL}^{30,31}$. The inflammasome is a protein complex containing one nucleotide-binding oligomerization domain-like receptors (NLR) protein, an apoptosis-associated speck-like (ASC) protein and a cysteine protease caspase-1 and has widely been reported to play an important role in the progression of atherosclerosis. Indeed, in a LDLR ${ }^{-1-}$ mouse model, Duewell et al. transplanted bone marrow lacking NLRP3, ASC or IL-1 $\beta$ and observed a regression in atherosclerosis development by $69 \%^{32}$. Similarly, mice lacking ASC and subjected to ischemia/reperfusion injury displayed smaller infarct size, and improved cardiac repair ${ }^{33}$. Prior to the secretion of IL- $1 \beta$ in macrophages, the inflammasome complex activates caspases, which will then turn on the programmed cell death machinery or apoptosis.

\section{Apoptosis and phagocytosis}

Apoptosis is another key process in the development of atherosclerotic lesions and after MI. Macrophages have been shown to undergo apoptosis at all stages of atherosclerosis ${ }^{34,35}$, however, macrophage apoptosis will affect lesion progression distinctively depending on plaque stage ${ }^{34,36,37}$. In early mouse and human lesions, macrophage apoptosis is thought to protect against plaque progression, as they are cleared by phagocytosis, preventing the formation of a necrotic core ${ }^{38}$. In contrast to advanced lesions, where apoptotic cell clearance by phagocytosis is defective, leading to the formation of larger necrotic cores consisting mostly of lipids and apoptotic cell debris ${ }^{36,39,40}$. Impairing phagocytosis by depleting phagocytic receptors such as Mertk or Lrp1 has shown to increase apoptosis and plaque size ${ }^{41,42}$. Second, macrophages help at resolving the inflammation in the post-MI response by phagocyting apoptotic myocytes ${ }^{28}$. Impaired macrophage phagocytosis after MI was linked to differed inflammation resolution and disrupted cardiac repair ${ }^{43}$.

\section{Giant cell formation}

Another intriguing and less known macrophage function is the formation of giant cells. Multinucleated giant cells result from the fusion of macrophages and have only been observed in calcified regions of human atherosclerosis ${ }^{44}$. Furthermore, cathepsin $\mathrm{K}$ expressing giant cells, were previously observed in the central atheroma, close to the media, where they cleave elastin fibers and facilitate smooth 
muscle cell migration. In chapter 4 , we have investigated the effect of $\mathrm{Mcl}-1$ myeloid deletion in atherosclerosis and observed a great increase in giant cell formation. However, the exact mechanism and contribution to atherosclerosis remains to be elucidated.

\section{Other functions}

In conclusion, we built a platform able to investigate major macrophage functions in CVD, however macrophages exert some other key functions that are not (yet) included in the platform. First, macrophage foam cell formation also depends on cholesterol efflux. However, our platform does not yet include a cholesterol efflux assay and it would be important to complement our lipid uptake assay with a measure of reverse cholesterol transport, e.g. by micro scaling an existing efflux assay $^{45}$. Second, human macrophages also act as antigen presenting cells and express major histocompatibility complex class II (MHC II), as well as Human Leukocyte Antigen-DR isotype on their surface to elicit an adaptive immune response ${ }^{46}$. Furthermore, macrophage MHC II expression can be regulated by autophagy, a process of self-digestion to maintain energy homeostasis and macrophage autophagy has been shown to be athero-protective in the later stage of the disease ${ }^{47}$. Therefore, measuring macrophage antigen-presentation and autophagy capacity could be indicative of macrophage performance in CVD. Third, macrophage migration to tissue is a key process in CVD. To be able to infiltrate and migrate in tissue, macrophages employ focal proteolysis, secreting several proteases, such as matrix metalloproteinases or cathepsins ${ }^{48}$. Additionally, macrophage metalloproteinases also regulate the extra cellular matrix turnover after $\mathrm{AMI}^{49}$. Therefore, assessment of macrophage migration and proteolytic activity would be an important addition to the MacroScreen. Lastly, hypoxia or the lack of oxygen has been suggested to promote necrotic core formation in atherosclerosis ${ }^{50}$ and is also observed in the heart after AMI. In response to hypoxia macrophages, will stabilize hypoxia-inducible factor 1 , and subsequently polarize to pro-inflammatory macrophage ${ }^{51}$. Measuring macrophage hypoxic response in the MacroScreen would therefore also complement the function panel.

\section{Capturing macrophage functional plasticity with the MacroScreen}

In chapter 2, we have shown that macrophage transcriptional plasticity is reflected in their functional behaviour, resulting in five functional clusters of macrophage activation. At first, macrophages were thought to present in two phenotypes: M1 (pro-) and M2 (anti-inflammatory macrophages). M1 polarization is induced by pro- 
inflammatory cytokines, such as LPS and IFN- $\gamma$ and hence M1 macrophages exert pro-inflammatory functions. On the other hand, macrophages are polarized towards M2 by a broad range of anti-inflammatory cytokines (e.g. IL-4, IL-13, IL-10), to exert tissue remodelling and wound healing functions. Over the years, accumulating evidence suggested that the dichotomous macrophage polarization model was incomplete and, depending on the activating stimulus and functional profile, the M1-M2 bipolar activation was further refined to include M2a, M2b, M2c and $M 2 d$ subgroups and other subtypes (M4, Mox, Mhem and $M(H b))^{52,53}$. All these macrophage subtypes were observed in atherosclerotic lesions, with M1-like macrophages being more abundantly found in rupture-prone plaque regions or unstable plaque segments; whereas M2-like macrophage were found in the adventitia or stable plaque regions ${ }^{54,55}$. Moreover, Mhem and $\mathrm{M}(\mathrm{Hb})$ macrophages were associated with intraplaque haemorrhage ${ }^{56}$, whereas Mox macrophages was suggested to be induced by oxidised phospholipids and showed pro-atherogenic features ${ }^{57}$. Next to their high heterogeneity, plaque macrophages appear to be very plastic and are able to switch phenotypes depending on their environment ${ }^{58}$. Indeed, M1 and M2 macrophages can reverse their phenotype, when exposed to M2 and M1 stimuli, respectively ${ }^{59,60}$. Taken altogether, this shows that macrophages respond differently depending on stimulus and that their polarization profile is complicated. Furthermore, most of the polarization studies are performed in vitro using at most two stimuli and this setting obviously does not reflect the complexity of the in vivo situation. In the infarcted heart environment, there is a great amount of effector molecules able to activate macrophages. Using our platform, we were able to study individual stimuli to identify specific activation pathways related to certain functions, but we also included combinations of stimuli (chapter 2) to reflect chronic inflammation and human diseased serum to reflect the systemic environment (chapter 3 ). This allows better in vitro mimicking of complex activation profiles observed in vivo.

\section{The use of different types of macrophages in the Macroscreen}

In our newly developed functionomics platform (chapter $\mathbf{2}$ to 5), we made use of monocyte-derived macrophages (MDM). However, this is not the only type of human macrophages. In this section, we will discuss source-dependent differences in makeup of macrophages, and repercussions thereof for the MacroScreen application. 


\section{Monocyte-derived vs tissue-resident macrophages}

It is nowadays widely accepted that there are two principal types of macrophages: tissue-resident macrophages, mainly of embryonic origin, and inflammatory macrophages derived from blood monocytes and recruited to the site of inflammation ${ }^{61}$. Tissue-resident macrophages originate from the yolk sac or fetal liver during embryonic development and are seeded into the respective tissues before birth, maintained independently of monocytes ${ }^{61-63}$. Not only do they differ regarding their origin, tissue-resident macrophages and recruited macrophages were also seen to exert different functions. Indeed, embryonic macrophages were shown to exert tissue remodelling and homeostatic functions, whereas MDMs mainly have inflammatory functions, such as pathogen killing and host defence ${ }^{64}$, serving as reservoir for temporary repopulation of macrophage-depleted tissue.

Resident macrophages exert a variety of homeostatic functions under normal conditions, such as phagocytosis of apoptotic cells ${ }^{62}$, lipid homeostasis in the liver ${ }^{65}$ or electric conductance in the heart ${ }^{66}$. Upon infection, but also during cardiac repair after AMI and chronic sterile inflammation (e.g. atherosclerosis), macrophages were initially thought to originate from blood born monocytes ${ }^{67}$, which after recruitment differentiate into (often short-lived) inflammatory macrophages. More recent studies suggest resident macrophage proliferation as main source of macrophage pool maintenance in atherosclerotic plaques ${ }^{68,69}$, and in the heart ${ }^{2,70}$. Accordingly, resident hematopoietic progenitor cells were shown to reside in murine adventitia ${ }^{71,72}$. Furthermore, proliferating macrophages were observed in all stages of atherosclerosis, however, this process was mostly prominent in early lesions where almost $50 \%$ of replicating macrophages derived from resident macrophage proliferation ${ }^{68}$. In addition, resident macrophage proliferation can affect atherosclerosis, as Gage et al. showed that increased atherosclerotic plaque burden after disruption of LXR $\alpha$ phosphorylation was attributed to lesion-resident macrophage proliferation. Yet, these results must be interpreted with caution, as recent doubts were emitted regarding that the clonal expansion of plaque macrophage pool might be overestimated ${ }^{73}$.

Our in vitro functionomics platform described in chapter 2-5 is closely modelling inflammatory macrophages as it focuses on monocyte-derived macrophages isolated from healthy volunteers and differentiated for seven days using macrophage colony-stimulating factor (M-CSF). 
iPSC derived macrophages to mimic tissue-resident macrophages

One could argue that our platform does not mimic the tissue-resident macrophage phenotype. Isolating human tissue-resident macrophages is laborious and the number of isolated cells is usually limited. Furthermore, care should be taken when working with isolated tissue-resident macrophages, as their transcriptional profile is affected by the isolation procedure, as shown by Gosselin et al. with human and mouse microglia, the brain-resident macrophages ${ }^{74}$. One attractive alternative to study the tissue-resident macrophage phenotype would be the use of human induced pluripotent stem cells (iPSC) derived macrophages (iMacs). iMacs are generated in vitro with a protocol that mimics the in vivo situation in the yolk sac ${ }^{75}$. They have been shown to resemble human and mouse yolk sac ${ }^{76,77}$ and fetal liver ${ }^{78}$ derived tissue-resident macrophages, especially in terms of transcription profiles. To program iMacs into specific tissue-resident macrophages, two approaches have been proposed ${ }^{75}$. First, iMacs can be cultured in the presence of effector molecules, such as specific cytokines. For instance, Abud et al. successfully produced brainresident macrophages, a.k.a. microglia cells, by exposing iMacs to CSF1, IL-34 and TGF $\beta$. These iMac-derived microglia cells resembled real microglia, as they expressed microglia-specific genes and proteins and showed increased phagocytotic activity ${ }^{79}$. However, this technique lacks the complex milieu of the in vivo situation and cannot completely mimic real microglia ${ }^{75}$. Second, iMacs can be differentiated to tissue-resident macrophages by culturing them with other cell types in that particular tissue, such as astrocytes and neurons for microglia ${ }^{79}$ or with complete organoids. In the context of cardiovascular inflammation, iMacs could be cultured with cardiomyocytes to recapitulate cardiac-resident macrophage functions or with smooth muscle and endothelial cells in a lipid-rich environment to acquire a plaque phenotype. Alternatively, to mimic the atherosclerotic plaque environment, iMacs could also be cultured in plaque conditioned medium or lysates. However, the functional similarity between iMacs-derived tissue resident macrophages and tissue-resident macrophages remains to be elucidated, and this could be done using the MacroScreen platform.

The use of cell lines in the MacroScreen

Isolating human $\mathrm{CD}_{1} 4^{+}$monocytes from peripheral blood mononuclear cells (PBMCs) for our HCA platform is time consuming and cell yields were usually low, as monocytes only represent three to seven percent of the total $\mathrm{PBMCs}^{80}$. Furthermore, to avoid donor-to-donor variability reflected in cell phenotype, we always pooled five to seven donors per experiment. Another alternative to MDMs Page | 182 
to study in vitro human macrophage functional identity could be the use of immortalized cell lines, such as THP-1. THP-1 cells are monocyte-like cells obtained from acute monocytic leukemia ${ }^{81}$ with stable genetic background, making them an interesting tool to study macrophage functions ${ }^{82}$. However, recent comparison between MDMs and THP-1 cells revealed that THP-1 cells were less sensitive to LPS stimulation $^{81}$, and that gene expression profiles do not fully correlate between THP1 cells and $\mathrm{MDMs}^{83,84}$. This was confirmed at the functional level, as macrophage surface markers were only comparable for $41 \%{ }^{85}$. Therefore, using THP-1 cells to assess cellular functions on our functionomics platform should be tested and compared to MDMs functional profile before switching to cell lines.

In conclusion, the use of MDMs in the MacroScreen does not reflect the full diversity of human macrophages. However, before using other cell types in the platform, such as cell lines to have a more controlled environment, or iMacs to mimic tissue-resident macrophages, these should be functionally tested and compared to MDMs functional signatures.

\section{Humanized test platforms}

The need for humanized test platforms

Biomedical research mainly relies on animal models such as mice, which represent a fast and easy readout for studying, amongst others, CVD inflammation including atherosclerosis, myocardial infarction repair or cardiometabolic disorders. Animal testing was traditionally thought to be an unavoidable step in fundamental research and drug discovery. However, it is increasingly clear that humans are not an inflated, big copy of mice and most results derived from animal testing cannot be directly extrapolated to humans ${ }^{86}$. Indeed, Pasterkamp et al. elegantly showed that the main mouse immune-associated genes and pathways causally associated with murine atherosclerosis had no association with human atherosclerotic plaque traits and subsequent incidence of coronary artery disease (CAD) or stroke ${ }^{87}$. Furthermore, many clinical trials testing drugs have failed due to grave side effects or drug efficacy issues, although the tested drugs were safe and effective in animal models ${ }^{88-90}$. Moreover for ethical reasons, increased efforts are being made to reduce the number of animals used in research (applying the 3R rule; replacement, refinement and reduction) ${ }^{91}$. We believe that our platform could be a good alternative to animal testing of innate immune responses, as it is based on human primary macrophages and it covers the major inflammatory processes involved in 
the pathophysiology of atherosclerosis, including phagocytosis, oxLDL uptake and apoptosis (chapter 2). Furthermore, as we were able to show in chapter 3, our platform can detect changes in blood, which are able to alter macrophage functions relating to poor prognosis after an acute myocardial infarction. In addition, we were able to discover human immune genes directly linked to infarct size, showing the potential of the platform to unravel new mechanistic pathways linked to cardiovascular disease (chapter $\mathbf{3}$ ).

\section{Goals of current humanized test platforms}

In the last two decades, the field of humanized test platforms has gained growing interest and many platforms are currently being developed to serve several purposes in a broad range of research fields ${ }^{92}$. First, humanized test platforms were used to identify specific genes associated with biological processes. For instance, in the context of atherosclerosis, Domschkle et al. discovered four novel genes involved in LDL uptake in monocyte-derived macrophages ${ }^{93}$. Second, humanized test platforms can also be used to assess complex cell phenotypic changes after screening a compound library and to help selecting potential drug candidates, as illustrated by a study of Gao et al. who screened a library of 2,600 compounds and measured their impact on ABCA1 expression in HepG2 cells. They identified and validated 10 compounds that increased ABCA1 gene expression ${ }^{94}$. Third, humanized test platforms can be used as disease models to study mechanistic pathways and discover new potential drugs, e.g. Honarnejad et al. aberrantly expressed a mutant causing Alzheimer's disease in HEK293 cells to discover new drugs $^{95}$.

In this thesis, we developed a humanized high-throughput platform to model innate immune responses relevant to cardiovascular diseases with special emphasis on the functional behaviour of macrophages. The MacroScreen can detect, in a highthroughput and -content manner, 19 distinct functions, in contrast to mostly singular parameters measured by all the platforms described above.

\section{Possible improvements of the MacroScreen}

In the context of CVD, measuring macrophage function in vitro does not fully represent the complexity of the in vivo situation, which for atherosclerotic plaque contains, next to macrophages, smooth muscle and endothelial cells (ECS) and Tlymphocytes amongst others, and for myocardium, cardiomyocytes, fibroblasts and ECs. Therefore, it is important to stress that our platform neither covers cell-cell 
interaction, nor cell-cytokine and cell-matrix interaction. Extracellular matrix components, such as proteoglycans, hyaluronic acid, and collagen deposition are instrumental in tissue remodelling processes in the atherosclerotic plaque or in the post-ischemic heart ${ }^{96,97}$. Thus, to better mimic the complexity of the in vivo pathophysiology of these diseases, some improvements could be made, which will be discussed below.

First, during atherogenesis, the endothelium becomes dysfunctional, leading to a weakened barrier integrity and leakage ${ }^{98}$. Endothelial cell dysfunction leads to the infiltration of blood monocyte to the vascular wall. During atherosclerosis, smooth muscle cells (SMCs), which under normal conditions exhibit a contractile phenotype, will undergo phenotypic switch to migrate from the media to the intima and proliferate, to produce collagen and form a fibrous cap ${ }^{99}$. Therefore, our innate immune platform could be complemented with EC and VSMC functional profiles, to create a humanized model of atherosclerosis cell functionality. Most of the processes included in the MacroScreen are also relevant to ECs and SMCs, such as apoptosis and cytokine production but some cell-specific functions should be added. Human SMCs from advanced atherosclerotic plaques have been shown to decrease proliferation and enter a state of senescence ${ }^{100}$. Furthermore, as explained above, during atherogenesis SMCs migrate to the intima to form a fibrous cap $^{101}$. In addition, vSMCs can differentiate to osteoblast-like cells during the course of atherosclerosis and produce micro-calcification, which are known to promote plaque rupture ${ }^{102}$. Therefore, phenotype, proliferation, senescence, migration and calcification assays are the most obvious functionalities relevant to atherosclerosis and should be added to our functionomics platform to complement the current macrophage functional profile.

A second limitation of our platform is that all of the above described assays are based on two-dimensional (2D) monolayers. Three-dimensional (3D) cell cultures have emerged and offer a great opportunity to integrate cell-cell interaction, cellextra cellular matrix (ECM) interaction, tissue oxygenation and nutrient gradients $^{103}$. Three-D cultures were initially developed by growing single cell lines into spheroids. This was prominently used in the cancer field, where 3D spheroid cultures showed a high potential for drug discovery ${ }^{103,104}$. Later on, the spheroid approach was slowly abandoned in favour of organoids, which offer a better representation of cell heterogeneity as they were directly derived from human tissue or stem cells. Organoids are now widely used in biomedical research to grow 
organs such as brains ${ }^{105}$ and kidneys ${ }^{106}$, but also tumors ${ }^{107}$. Interestingly, organoids have also been used in the field of cardiology to study the cardiac formation during organogenesis $^{108}$ and (congenital) cardiomyopathies ${ }^{109}$. More recently, even more refined multicellular organoid models have been designed such as endothelialized myocardium, consisting of endothelial cells bioprinted in a 3D hydrogel scaffold and seeded with cardiomyocytes to form a contracting myocardium ${ }^{110}$. Another example was established by Wimmer et al., who successfully created a human blood vessel organoid composed of endothelial cells, pericytes, mesenchymal stem-like cells and haematopoietic cells as a model of diabetic vasculopathy ${ }^{111}$. They showed that exposure of blood vessel organoids to high concentration of glucose and cytokines led to the thickening of the basement membrane, a process also observed in diabetic patients, proving that this 3D model was structurally and functionally resembling the in vivo situation. The latter example, however, does not consider biomechanical forces, an important aspect of vascular disease. Recent advances in microfluidics have enabled the development of 3D blood vessels under flow $^{112}$. For instance, van Duinen and colleagues developed a robust highthroughput 3D microvessel to assess barrier function under continuous flow ${ }^{113}$. Another recent example was brought by Poussin et al., who established a human 3D model of endothelial microvessels under flow, able to measure leukocyte adhesion to the lumen ${ }^{114}$.

Summarizing the above, the field of in vitro humanized test models for (diseased) vasculature and myocardium is increasingly growing to allow rapid, cheap and more reliable way to study atherosclerosis and AMI, respectively. The strength of the MacroScreen, compared to other humanized platforms, lies in the development of a multi-parametric platform, able to measure 19 distinct macrophage functions in a high-throughput way, as opposed to the measurement of a single function in current platforms. Our platform is a fast and cheap way to measure cell functionality, as compared to organoids. However, one should realize that the MacroScreen is an in vitro static 2D model and lacks the physiological relevance of the dynamic 3D in vivo situation. To mimic the complexity of the in vivo situation and capture the full spectrum of cellular functions involved in CVD-related innate immunity, co-culture of macrophages with other cell types, such as SMCs and ECs or deployment of cell free (artificial or tissue based) matrices to form a "3D plaque on a chip" and further functional analysis could be performed. 


\section{Patient macro-environment and CVD risk}

Systemic environment and its link to CVD risk

Chapter $\mathbf{3}$ of this thesis highlights the potential of mapping the patient's systemic environment, defined as patient circulating plasma or serum containing a variety of effector molecules, for disease (prognostic) diagnosis, as exposure of macrophages to $20 \%$ serum of AMI patients led to functional as well as transcriptional changes that accurately correlated with infarct size four months after the event. This is probably attributable to all kind of effector molecules, released/contained in patient serum upon such major ischemic event. Currently, patient diagnosis relies on a few molecules or risk factors; however, we further show in chapter 5 that measuring a higher number of features can lead to a great improvement of disease prediction. In chapter 5, we screened circulating lipids to discover new biomarkers for the development of obesity-related cardiovascular disease. The plasma lipid profiles, in particular of cholesterol ester and triglyceride content, have widely been shown to be predictive of cardiovascular event ${ }^{115}$. Lipidic molecules are not the only systemic predictors of CVD. Atherosclerosis is, as previously explained, seen as an inflammatory disease and measurement of systemic inflammatory cytokines has showed its potential in terms of event prediction. High sensitivity C-reactive protein (hs-CRP) and other pro-inflammatory cytokines such as IL-6, serum amyloid A and soluble intercellular adhesion molecule type I and chemokines, such as chemokine ligand 2 or 8 , have been observed as independent predictors of CVD ${ }^{116,117}$. Furthermore, it was recently confirmed that targeting the inflammation by treating high-risk patients with an IL-1 $\beta$ antibody reduced the risk of CVD by $15 \%{ }^{118}$. Since then, many studies are trying to investigate the role of different cytokines, such as IL-5, IL-6 receptor, IFN- $\gamma$ and TNF $\alpha$ in disease prediction ${ }^{119}$. However, these biomarkers assume that patient populations are all similar and that a universal disease mechanism exists that applies to all patients, which can be captured by one single biomarker. In obesity, for example, increase in BMI leads to an increase in the most common lipid predictors (including LDL cholesterol, total cholesterol) and inflammatory markers ${ }^{120,121}$. Therefore, better prediction and subclassification of high-risk population and subsequent therapy tailoring is needed. Our lipid signature, confirmed in two independent cohorts of obesity, could, in the future, serve as new biomarkers for obesity-related cardiovascular disease. 
The need for precision medicine

Obesity is a very heterogenous condition, available diagnosis tests and treatments for obesity-related comorbidities are not efficient in all patients. Thus, there is a need for more precise medicine. Precision medicine is defined as the concept of characterizing each patient separately to select more effective treatment. The recent advances in "-Omics" techniques has greatly helped to deeply characterize patient groups at several levels, such as genes, proteins, metabolites ${ }^{122}$. However, in a recent study, only $2.7 \%$ of gene loci were associated with $\mathrm{BMI}^{123}$. Furthermore, another genome wide association (GWAS) study showed that, in a population of 200,000 individuals, only $10.6 \%$ of coronary artery disease (CAD) could be explained by genetics ${ }^{124}$. This shows the need to integrate environment-derived cues into the characterization of high-risk individuals. Lipidomics, as performed in chapter $\mathbf{5}$, has already been used before to facilitate to reclassification of high-risk patients ${ }^{125}$. For instance, Fan et al. performed a comparison of metabolome profile between distinct subtypes of CAD and identified 89 differential metabolites classifying with an accuracy $>90 \%$ in 2,324 patients ${ }^{125}$. A common limitation to such metabolomics approaches is the lack of causal assessment. Demonstration of causality of a marker in disease will not only facilitate development of specific therapeutic approaches, but it also warrants that any changes in marker level will reflect changes in disease risk. Investigating biomarker causality in disease development and progression can help understand which mechanistic pathways are altered and further design robust treatment. In an ideal situation, novel biomarkers could serve as risk predictors but could also be modifiable by specific therapies and subsequently reduce diseaserisk. These risk factors could have the potential to better stratify risk population, where standard risk factors, such as CRP or LDL, lack precision. In this thesis (chapter 5), we have thoroughly assessed the implication of our lipid-signature in CVD development by investigating their presence in atherosclerotic plaques and their effect on macrophage functions using our "functionomics" platform. Further analyses on our predictive lipid-signature could help understand how these lipids dysregulate phagocytosis, how this is reflected in disease progression and how certain drugs could possibly reverse this phenotype to study risk reduction properties. In the future, biomarker research should be more centered on causality assessment as this allows better and more precise disease prevention. 
Linking systemic inflammation to CVD risk using the MacroScreen: a monocyte centered view

Precision medicine uses many "-omics" platforms to deeply characterize patients, and our functionomics platform developed in chapter 2 could help to further characterize patient phenotype by directly screening functionality of circulating monocytes after a cardiovascular event. In this thesis, we have used monocytesderived macrophages from healthy volunteers, but one could think of adapting the platform to enable monocyte screening. AMI leads to an increased production and release of classical monocytes from the spleen, worsening atherosclerosis and, subsequently, the incidence of secondary CVD events during followup ${ }^{118,126}$. Moreover, the systemic blood environment was demonstrated to influence monocytes; for example, in patients with familial hypercholesterolemia, a genetic disorder leading to high level of circulating LDL, monocytosis was observed ${ }^{127}$. In addition, dyslipidemia also activated monocytes and regulated their adhesion to the endothelium ${ }^{128}$. Therefore, investigating the systemic environment in terms of monocyte functionality and linking it to secondary event would be of great interest. Monocytes represent $3-8 \%$ of total circulating leukocytes and are embedded in plasma, the patient's systemic environment ${ }^{129}$. Human monocytes are divided in three subsets based on their expression of CD14 and CD16. Classical monocytes $\left(\mathrm{CD} 14^{++} \mathrm{CD} 16^{-}\right)$, intermediate monocytes $\left(\mathrm{CD} 14^{+} \mathrm{CD} 16^{+}\right)$and non-classical monocytes $\left(\mathrm{CD} 14^{+} \mathrm{CD} 16^{++}\right.$) have all been linked to CVD. In fact, classical ${ }^{130}$ and intermediate ${ }^{131}$ monocytes have been defined as independent risk predictors of CVD in separate cohorts, whereas $\mathrm{CD} 16^{+}$monocytes have been correlated to mean intima-media thickness ${ }^{130}$. Moreover, recent research has shown that each monocyte subpopulation has distinct functions, e.g. classical and intermediate monocytes were shown to have high phagocytic capacities, whereas non-classical monocytes only had a limited phagocytic activity ${ }^{132}$. Characterizing the monocyte's functional phenotype using our HCA platform could help to determine how monocyte origin affects their functional profile, and whether monocytes from AMI patient are more prone to differentiate into functionally distinct macrophages than healthy patients. This could also help us to reveal and interfere with relevant mechanistic pathways involved in the differentiation of monocytes to functionally diverse macrophages. 


\section{Concluding remarks}

In this thesis, we have developed a ready-to-use, high-content analysis platform able to detect macrophage functional heterogeneity in the context of CVD inflammation. This platform is constantly being improved and expanded by including other relevant macrophage functions, and by incorporating functionalities of other cell types relevant to atherosclerosis. In addition, we have proven that this platform can be deployed in different settings, such as the development of a reference map of macrophage functional activation, or in detection of AMI-linked macrophage functional and transcriptional signatures, opening new avenues for therapeutic research.

Macrophages transcriptional plasticity is now widely acknowledged, which has refashioned the previous oversimplified M1/M2 activation view. Using high content cell imaging, we demonstrated that macrophage transcriptional diversity has direct repercussions at the functional level. Furthermore, we revealed specific gene expression patterns linked to unique functions. This allowed us to build a unique function-based macrophage atlas. This atlas could, in the future, be used to directly predict macrophage functional activity in responses to drugs based on gene expression profile, and thus rapidly study drug efficacy.

Aside from their important role in atherosclerosis development and progression, macrophages are also key players in AMI repair. Exposure of monocyte-derived macrophages to AMI systemic environment appears to affect macrophage functions and this is also reflected in the transcriptional patterns. Furthermore, we successfully detected specific transcriptional programs associated with certain macrophage functions and poor prognosis.

Lastly, using our platform, we studied the functional implication of newly discovered biomarkers for the development of obesity-related CVD. Studying the causal relationship of biomarkers with CVD inflammation could help at discovering new therapeutic targets. 


\section{References}

1. Nagenborg, J., Goossens, P., Biessen, E. A. L. \& Donners, M. M. P. C. Heterogeneity of atherosclerotic plaque macrophage origin, phenotype and functions: Implications for treatment. Eur. J. Pharmacol. 816, 14-24 (2017).

2. Gombozhapova, A. et al. Macrophage activation and polarization in post-infarction cardiac remodeling. J. Biomed. Sci. 24, 1-11 (2017).

3. Maguire, E. M., Pearce, S. W. A. \& Xiao, Q. Foam cell formation: A new target for fighting atherosclerosis and cardiovascular disease. Vascul. Pharmacol. 112, 54-71 (2019).

4. Chistiakov, D. A., Bobryshev, Y. V. \& Orekhov, A. N. Macrophage-mediated cholesterol handling in atherosclerosis. J. Cell. Mol. Med. 20, 17-28 (2016).

5. Babaev, V. R. et al. Reduced Atherosclerotic Lesions in Mice Deficient for Total or Macrophage-Specific Expression of Scavenger Receptor-A. Arterioscler. Thromb. Vasc. Biol. 20, 2593-2599 (2000).

6. Febbraio, M. et al. Targeted disruption of the class B scavenger receptor CD36 protects against atherosclerotic lesion development in mice. J. Clin. Invest. 105, 1049-56 (2000).

7. Zhou, L. et al. Compound K Attenuates the Development of Atherosclerosis in ApoE-/- Mice via LXR $\alpha$ Activation. Int. J. Mol. Sci. 17, 1054 (2016).

8. Lee, S.-M., Moon, J., Cho, Y., Chung, J. H. \& Shin, M.-J. Quercetin up-regulates expressions of peroxisome proliferator-activated receptor $\psi$, liver $X$ receptor $\alpha$, and ATP binding cassette transporter A1 genes and increases cholesterol efflux in human macrophage cell line. Nutr. Res. 33, 136-143 (2013).

9. Joseph, S. B. et al. Synthetic LXR ligand inhibits the development of atherosclerosis in mice. Proc. Natl. Acad. Sci. 99, 7604-7609 (2002).

10. Ku, C. S., Park, Y., Coleman, S. L. \& Lee, J. Unsaturated fatty acids repress expression of ATP binding cassette transporter A1 and G1 in RAW 264.7 macrophages. J. Nutr. Biochem. 23, 1271-1276 (2012).

11. Yu, X. H. et al. Interleukin-18 and interleukin-12 together downregulate ATP-binding cassette transporter $\mathrm{A} 1$ expression through the interleukin-18R/nuclear factor-KB signaling pathway in THP-1 macrophage-derived foam cells. Circ. J. 76, 1780-1791 (2012).

12. Madamanchi, N. R. \& Runge, M. S. Mitochondrial Dysfunction in Atherosclerosis. Circ. Res. 100, 460-473 (2007).

13. Forrester, S. J. \& Griendling, K. K. Mitochondrial Respiration and Atherosclerosis. Arterioscler. Thromb. Vasc. Biol. 37, 2229 (2017).

14. $\mathrm{Yu}, \mathrm{E}$. P. K. et al. Mitochondrial respiration is reduced in atherosclerosis, promoting necrotic core formation and reducing relative fibrous cap thickness. Arterioscler. Thromb. Vasc. Biol. 37, 2322-2332 (2017).

15. Mouton, A. J. et al. Mapping macrophage polarization over the myocardial infarction time continuum. Basic Res. Cardiol. 113, (2018).

16. Nowak, W. N., Deng, J., Ruan, X. Z. \& Xu, Q. Reactive oxygen species generation and atherosclerosis. Arterioscler. Thromb. Vasc. Biol. 37, e41-e52 (2017).

17. Ekstrand, M. et al. Imaging of intracellular and extracellular ROS levels in atherosclerotic mouse aortas ex vivo: Effects of lipid lowering by diet or 
atorvastatin. PLoS One 10, (2015).

18. Xu, Q. et al. NADPH Oxidases Are Essential for Macrophage Differentiation. J. Biol. Chem. 291, 20030-20041 (2016).

19. Xiao, L. et al. Quercetin attenuates high fat diet-induced atherosclerosis in apolipoprotein E knockout mice: A critical role of NADPH oxidase. Food Chem. Toxicol. 105, 22-33 (2017).

20. Wang, Y., Wang, G. Z., Rabinovitch, P. S. \& Tabas, I. Macrophage mitochondrial oxidative stress promotes atherosclerosis and nuclear factor-kB-mediated inflammation in macrophages. Circ. Res. 114, 421-433 (2014).

21. Moris, D. et al. The role of reactive oxygen species in the pathophysiology of cardiovascular diseases and the clinical significance of myocardial redox. Ann. Transl. Med. 6, (2017).

22. Zhao, W., Zhao, D., Yan, R. \& Sun, Y. Cardiac oxidative stress and remodeling following infarction: role of NADPH oxidase. Cardiovasc. Pathol. 18, 156-166 (2009).

23. Tedgui, A. \& Mallat, Z. Cytokines in Atherosclerosis: Pathogenic and Regulatory Pathways. Physiol. Rev. 86, 515-581 (2006).

24. Ohta, H. et al. Disruption of tumor necrosis factor- $\alpha$ gene diminishes the development of atherosclerosis in ApoE-deficient mice. Atherosclerosis 180, 11-17 (2005).

25. Gupta, S., Tall, A. R. \& Schindler, C. IFN-gamma potentiates atherosclerosis in ApoE knock-out mice. Find the latest version : 99, 2752-2761 (1997).

26. Cardilo-Reis, L. et al. Interleukin-13 protects from atherosclerosis and modulates plaque composition by skewing the macrophage phenotype. EMBO Mol. Med. 4, 1072-1086 (2012).

27. Han, X., Kitamoto, S., Wang, H. \& Boisvert, W. A. Interleukin-10 overexpression in macrophages suppresses atherosclerosis in hyperlipidemic mice. FASEB J. 24, 28692880 (2010).

28. Ma, Y., Mouton, A. J. \& Lindsey, M. L. Cardiac macrophage biology in the steadystate heart, the aging heart, and following myocardial infarction. Translational Research 191, 15-28 (2018).

29. Jung, M. et al. IL-10 improves cardiac remodeling after myocardial infarction by stimulating M2 macrophage polarization and fibroblast activation. Basic Res. Cardiol. 112, 33 (2017).

30. Karasawa, T. \& Takahashi, M. Role of NLRP3 Inflammasomes in Atherosclerosis. J. Atheroscler. Thromb. 24, 443-451 (2017).

31. Duewell, P. et al. NLRP3 inflammasomes are required for atherogenesis and activated by cholesterol crystals. Nature 464, 1357-1361 (2010).

32. Duewell, P. et al. NLRP3 inflammasomes are required for atherogenesis and activated by cholesterol crystals. Nature 464, 1357-1361 (2010).

33. Kawaguchi, M. et al. Inflammasome activation of cardiac fibroblasts is essential for myocardial ischemia/reperfusion injury. Circulation 123, 594-604 (2011).

34. Hansson, G. K., Libby, P. \& Tabas, I. Inflammation and plaque vulnerability. J. Intern. Med. 278, 483-93 (2015).

35. Gonzalez, L. \& Trigatti, B. L. Macrophage Apoptosis and Necrotic Core Development in Atherosclerosis: A Rapidly Advancing Field with Clinical Relevance to Imaging and 
Therapy. Can. J. Cardiol. 33, 303-312 (2017).

36. Seimon, T. \& Tabas, I. Mechanisms and consequences of macrophage apoptosis in atherosclerosis. J. Lipid Res. 50 Suppl, S382-7 (2009).

37. Halvorsen, B. et al. Atherosclerotic Plaque Stability-What Determines the Fate of a Plaque? Prog. Cardiovasc. Dis. 51, 183-194 (2008).

38. Schrijvers, D., Demeyer, G., Herman, A. \& Martinet, W. Phagocytosis in atherosclerosis: Molecular mechanisms and implications for plaque progression and stability. Cardiovasc. Res. 73, 470-480 (2007).

39. Björkerud, S. \& Björkerud, B. Apoptosis is abundant in human atherosclerotic lesions, especially in inflammatory cells (macrophages and T cells), and may contribute to the accumulation of gruel and plaque instability. Am. J. Pathol. 149, 367-80 (1996).

40. Otsuka, F. et al. Natural progression of atherosclerosis from pathologic intimal thickening to late fibroatheroma in human coronary arteries: A pathology study. Atherosclerosis 241, 772-782 (2015).

41. Ait-Oufella, H. et al. Defective mer receptor tyrosine kinase signaling in bone marrow cells promotes apoptotic cell accumulation and accelerates atherosclerosis. Arterioscler. Thromb. Vasc. Biol. 28, 1429-31 (2008).

42. Yancey, P. G. et al. Macrophage LRP-1 controls plaque cellularity by regulating efferocytosis and Akt activation. Arterioscler. Thromb. Vasc. Biol. 30, 787-95 (2010).

43. Wan, E. et al. Enhanced efferocytosis of apoptotic cardiomyocytes through myeloidepithelial-reproductive tyrosine kinase links acute inflammation resolution to cardiac repair after infarction. Circ. Res. 113, 1004-1012 (2013).

44. Qiao, J. H., Mishra, V., Fishbein, M. C., Sinha, S. K. \& Rajavashisth, T. B. Multinucleated giant cells in atherosclerotic plaques of human carotid arteries: Identification of osteoclast-like cells and their specific proteins in artery wall. Exp. Mol. Pathol. 99, 654-662 (2015).

45. Hafiane, A. \& Genest, J. HDL-mediated cellular cholesterol efflux assay method. Ann. Clin. Lab. Sci. 45, 659-668 (2015).

46. Choi, S.-H. et al. SYK regulates macrophage MHC-II expression via activation of autophagy in response to oxidized LDL. Autophagy 11, 785-795 (2015).

47. Liao, X. et al. Macrophage Autophagy Plays a Protective Role in Advanced Atherosclerosis. Cell Metab. 15, 545-553 (2012).

48. Fleetwood, A. J. et al. Degradation, and Adhesion Three-Dimensional Invasion, Matrix Central Regulator of Macrophage Urokinase Plasminogen Activator Is a. J. Imm (2019). doi:10.4049/jimmunol.1302864

49. DeLeon-Pennell, K. Y., Meschiari, C. A., Jung, M. \& Lindsey, M. L. Matrix Metalloproteinases in Myocardial Infarction and Heart Failure. in Progress in Molecular Biology and Translational Science 147, 75-100 (Elsevier B.V., 2017).

50. Marsch, E. et al. Reversal of hypoxia in murine atherosclerosis prevents necrotic core expansion by enhancing efferocytosis. Arterioscler. Thromb. Vasc. Biol. 34, 2545-53 (2014).

51. Aarup, A. et al. Hypoxia-inducible factor-1 $\alpha$ expression in macrophages promotes development of atherosclerosis. Arterioscler. Thromb. Vasc. Biol. 36, 1782-1790 (2016). 
52. Murray, P. J. et al. Macrophage Activation and Polarization: Nomenclature and Experimental Guidelines. Immunity 41, 14-20 (2014).

53. Chistiakov, D. A. et al. Macrophage phenotypic plasticity in atherosclerosis: The associated features and the peculiarities of the expression of inflammatory genes. Int. J. Cardiol. 184, 436-445 (2015).

54. Stöger, J. L. et al. Distribution of macrophage polarization markers in human atherosclerosis. Atherosclerosis 225, 461-468 (2012).

55. Chinetti-Gbaguidi, G. et al. Human atherosclerotic plaque alternative macrophages display low cholesterol handling but high phagocytosis because of distinct activities of the PPARY and LXR $\alpha$ pathways. Circ. Res. 108, 985-95 (2011).

56. Boyle, J. J. Heme and haemoglobin direct macrophage Mhem phenotype and counter foam cell formation in areas of intraplaque haemorrhage. Curr. Opin. Lipidol. 23, 453-461 (2012).

57. Kadl, A. et al. Identification of a novel macrophage phenotype that develops in response to atherogenic phospholipids via Nrf2. Circ. Res. 107, 737-46 (2010).

58. Shapouri-Moghaddam, A. et al. Macrophage plasticity, polarization, and function in health and disease. J. Cell. Physiol. 233, 6425-6440 (2018).

59. Saccani, A. et al. p50 Nuclear Factor-KB Overexpression in Tumor-Associated Macrophages Inhibits M1 Inflammatory Responses and Antitumor Resistance. Cancer Res. 66, 11342-11440 (2006).

60. Guiducci, C., Vicari, A. P., Sangaletti, S., Trinchieri, G. \& Colombo, P. Redirecting In vivo Elicited Tumor Infiltrating Macrophages and Dendritic Cells towards Tumor Rejection. Cancer Res. 65, 3437-3446 (2005).

61. Ginhoux, F., Schultze, J. L., Murray, P. J., Ochando, J. \& Biswas, S. K. New insights into the multidimensional concept of macrophage ontogeny, activation and function. Nat. Immunol. 17, 34-40 (2016).

62. Davies, L. C. \& Taylor, P. R. Tissue-resident macrophages: then and now. Immunology 144, 541-548 (2015).

63. Ginhoux, F. \& Guilliams, M. Tissue-Resident Macrophage Ontogeny and Homeostasis. Immunity 44, 439-449 (2016).

64. Ginhoux, F. \& Jung, S. Monocytes and macrophages: developmental pathways and tissue homeostasis. Nat. Rev. Immunol. 14, 392-404 (2014).

65. Scott, C. L. \& Guilliams, M. The role of Kupffer cells in hepatic iron and lipid metabolism. Journal of Hepatology 69, 1197-1199 (2018).

66. Leuschner, F. \& Nahrendorf, M. Novel functions of macrophages in the heart: insights into electrical conduction, stress, and diastolic dysfunction. Eur. Heart J. ehz159, (2019).

67. Libby, P. Inflammation in atherosclerosis. Arterioscler. Thromb. Vasc. Biol. 32, 204551 (2012).

68. Lhoták, Š. et al. Characterization of Proliferating Lesion-Resident Cells During All Stages of Atherosclerotic Growth. J. Am. Heart Assoc. 5, (2016).

69. Robbins, C. S. et al. Local proliferation dominates lesional macrophage accumulation in atherosclerosis. Nat. Med. 19, 1166-1172 (2013).

70. Epelman, S. et al. Embryonic and adult-derived resident cardiac macrophages are maintained through distinct mechanisms at steady state and during inflammation. 
Immunity 40, 91-104 (2014).

71. Psaltis, P. J. et al. Identification of a monocyte-predisposed hierarchy of hematopoietic progenitor cells in the adventitia of postnatal murine aorta. Circulation 125, 592-603 (2012).

72. Psaltis, P. J. et al. Characterization of a resident population of adventitial macrophage progenitor cells in postnatal vasculature. Circ. Res. 115, 364-375 (2014).

73. Dick, S. A., Zaman, R. \& Epelman, S. Using High-Dimensional Approaches to Probe Monocytes and Macrophages in Cardiovascular Disease. Front. Immunol. 10, (2019).

74. Gosselin, D. et al. An environment-dependent transcriptional network specifies human microglia identity. Science 356, eaal3222 (2017).

75. Lee, C. Z. W., Kozaki, T. \& Ginhoux, F. Studying tissue macrophages in vitro: are iPSCderived cells the answer? Nat. Rev. Immunol. 18, 716-725 (2018).

76. Zhuang, L. et al. Pure populations of murine macrophages from cultured embryonic stem cells. Application to studies of chemotaxis and apoptotic cell clearance. J. Immunol. Methods 385, 1-14 (2012).

77. Takata, K. et al. Induced-Pluripotent-Stem-Cell-Derived Primitive Macrophages Provide a Platform for Modeling Tissue-Resident Macrophage Differentiation and Function. Immunity 47, 183-198.e6 (2017).

78. Klimchenko, O. et al. Monocytic cells derived from human embryonic stem cells and fetal liver share common differentiation pathways and homeostatic functions. Blood 117, 3065-75 (2011).

79. Abud, E. M. et al. iPSC-Derived Human Microglia-like Cells to Study Neurological Diseases. Neuron 94, 278-293.e9 (2017).

80. Corkum, C. P. et al. Immune cell subsets and their gene expression profiles from human PBMC isolated by Vacutainer Cell Preparation Tube (CPT ${ }^{\mathrm{TM}}$ ) and standard density gradient. BMC Immunol. 16, 48 (2015).

81. Bosshart, H. \& Heinzelmann, M. THP-1 cells as a model for human monocytes. Ann. Transl. Med. 4, 4-7 (2016).

82. Qin, Z. The use of THP-1 cells as a model for mimicking the function and regulation of monocytes and macrophages in the vasculature. Atherosclerosis 221, 2-11 (2012).

83. Sharif, O., Bolshakov, V. N., Raines, S., Newham, P. \& Perkins, N. D. Transcriptional profiling of the LPS induced NF-KB response in macrophages. BMC Immunol. 8, 1 (2007).

84. Spiller, K. L. et al. Differential gene expression in human, murine, and cell linederived macrophages upon polarization. Exp. Cell Res. 347, 1-13 (2016).

85. Tedesco, S. et al. Convenience versus Biological Significance: Are PMADifferentiated THP-1 Cells a Reliable Substitute for Blood-Derived Macrophages When Studying in Vitro Polarization? Front. Pharmacol. 9, 71 (2018).

86. Leist, M. \& Hartung, T. Inflammatory findings on species extrapolations: humans are definitely no 70-kg mice. Arch. Toxicol. 87, 563-567 (2013).

87. Pasterkamp, G. et al. Human Validation of Genes Associated With a Murine Atherosclerotic Phenotype. Arterioscler. Thromb. Vasc. Biol. 36, 1240-1246 (2016).

88. Gaztanaga, J. et al. A phase 2 randomized, double-blind, placebo-controlled study 
of the effect of VIA-2291, a 5-lipoxygenase inhibitor, on vascular inflammation in patients after an acute coronary syndrome. Atherosclerosis 240, 53-60 (2015).

89. Poole, J. et al. Effect of Progenitor Cell Mobilization With Granulocyte-Macrophage Colony-Stimulating Factor in Patients With Peripheral Artery Disease. JAMA 310, 2631 (2013).

90. Nohria, A. et al. The effect of salsalate therapy on endothelial function in a broad range of subjects. J. Am. Heart Assoc. 3, e000609 (2014).

91. Tannenbaum, J. \& Bennett, B. T. Russell and Burch's 3Rs then and now: The need for clarity in definition and purpose. J. Am. Assoc. Lab. Anim. Sci. 54, 120-132 (2015).

92. Mattiazzi Usaj, M. et al. High-Content Screening for Quantitative Cell Biology. Trends Cell Biol. 26, 598-611 (2016).

93. Domschke, G. et al. Systematic RNA-interference in primary human monocytederived macrophages: A high-throughput platform to study foam cell formation. Sci. Rep. 8, 10516 (2018).

94. Gao, J. et al. Identification of Upregulators of Human ATP-Binding Cassette Transporter A1 via High-Throughput Screening of a Synthetic and Natural Compound Library. J. Biomol. Screen. 13, 648-656 (2008).

95. Honarnejad, K. et al. Development and Implementation of a High-Throughput Compound Screening Assay for Targeting Disrupted ER Calcium Homeostasis in Alzheimer's Disease. PLoS One 8, e80645 (2013).

96. Shami, A., Gonçalves, I. \& Hultgardh-Nilsson, A. Collagen and related extracellular matrix proteins in atherosclerotic plaque development. Curr. Opin. Lipidol. 25, 394399 (2014).

97. Hughes, C. J. R. \& Jacobs, J. R. Dissecting the role of the extracellular matrix in heart disease: Lessons from the Drosophila genetic model. Veterinary Sciences 4, (2017).

98. Linton, M. F. et al. The Role of Lipids and Lipoproteins in Atherosclerosis. Science (80-. ). 111, (1950).

99. Bennett, M. R., Sinha, S. \& Owens, G. K. Vascular Smooth Muscle Cells in Atherosclerosis. Circ. Res. 118, 692-702 (2016).

100. Bennett, M. R., Evan, G. I. \& Schwartz, S. M. Apoptosis of human vascular smooth muscle cells derived from normal vessels and coronary atherosclerotic plaques. J. Clin. Invest. 95, 2266-74 (1995).

101. Bennett, M. R., Sinha, S. \& Owens, G. K. Vascular Smooth Muscle Cells in Atherosclerosis. Circ. Res. 118, 692-702 (2016).

102. Hutcheson, J. D. et al. Genesis and growth of extracellular-vesicle-derived microcalcification in atherosclerotic plaques. Nat. Mater. 15, 335-43 (2016).

103. Howes, A. L., Richardson, R. D., Finlay, D. \& Vuori, K. 3-Dimensional Culture Systems for Anti-Cancer Compound Profiling and High-Throughput Screening Reveal Increases in EGFR Inhibitor-Mediated Cytotoxicity Compared to Monolayer Culture Systems. PLoS One 9, e108283 (2014).

104. Sahu, N. et al. Cotargeting of MEK and PDGFR/STAT3 Pathways to Treat Pancreatic Ductal Adenocarcinoma. Mol. Cancer Ther. 16, 1729-1738 (2017).

105. Mansour, A. A. et al. An in vivo model of functional and vascularized human brain organoids. Nat. Biotechnol. 36, 432-441 (2018). 
106. Munro, D. A. D. \& Davies, J. A. Vascularizing the Kidney in the Embryo and Organoid: Questioning Assumptions about Renal Vasculogenesis. J. Am. Soc. Nephrol. 29, 1593-1595 (2018).

107. Tuveson, D. \& Clevers, H. Cancer modeling meets human organoid technology. Science (80-. ). 364, 952-955 (2019).

108. Hoang, P., Wang, J., Conklin, B. R., Healy, K. E. \& Ma, Z. Generation of spatialpatterned early-developing cardiac organoids using human pluripotent stem cells. Nat. Protoc. 13, 723-737 (2018).

109. Long, C. et al. Correction of diverse muscular dystrophy mutations in human engineered heart muscle by single-site genome editing. Sci. Adv. 4, 1-12 (2018).

110. Zhang, Y. S. et al. Bioprinting 3D microfibrous scaffolds for engineering endothelialized myocardium and heart-on-a-chip. Biomaterials 110, 45-59 (2016).

111. Wimmer, R. A. et al. Human blood vessel organoids as a model of diabetic vasculopathy. Nature 565, 505-510 (2019).

112. Bogorad, M. I. et al. Review: In vitro microvessel models. Lab Chip 15, 4242-4255 (2015).

113. van Duinen, V. et al. Perfused 3D angiogenic sprouting in a high-throughput in vitro platform. Angiogenesis 22, 157-165 (2019).

114. Poussin, C. et al. 3D human microvessel-on-a-chip model for studying monocyte-toendothelium adhesion under flow - application in systems toxicology_suppl. ALTEX 1-18 (2019). doi:10.14573/altex.1811301s

115. Leong, D. P. et al. Reducing the Global Burden of Cardiovascular Disease, Part 2. Prevention and Treatment of Cardiovascular Disease. Circ. Res. 121, 695-710 (2017).

116. Ridker, P. M., Hennekens, C. H., Buring, J. E. \& Rifai, N. C-Reactive Protein and Other Markers of Inflammation in the Prediction of Cardiovascular Disease in Women. $N$. Engl. J. Med. 342, 836-843 (2000).

117. Stoner, L. et al. Inflammatory biomarkers for predicting cardiovascular disease. Clin. Biochem. 46, 1353-1371 (2013).

118. Ridker, P. M. et al. Antiinflammatory Therapy with Canakinumab for Atherosclerotic Disease. N. Engl. J. Med. 377, 1119-1131 (2017).

119. Clarke, R. et al. Plasma cytokines and risk of coronary heart disease in the PROCARDIS study. Open Hear. 5, e000807 (2018).

120. Pahwa, R., Adams-Huet, B. \& Jialal, I. The effect of increasing body mass index on cardio-metabolic risk and biomarkers of oxidative stress and inflammation in nascent metabolic syndrome. J. Diabetes Complications 31, 810-813 (2017).

121. Danaei, G. Metabolic mediators of the effects of body-mass index, overweight, and obesity on coronary heart disease and stroke: A pooled analysis of 97 prospective cohorts with 1.8 million participants. Lancet 383, 970-983 (2014).

122. Frühbeck, G., Kiortsis, D. N. \& Catalán, V. Precision medicine: diagnosis and management of obesity. Lancet Diabetes Endocrinol. 6, 164-166 (2018).

123. Locke, A. E. et al. Genetic studies of body mass index yield new insights for obesity biology. Nature 518, 197-206 (2015).

124. Deloukas, P. et al. Large-scale association analysis identifies new risk loci for coronary artery disease. Nat. Genet. 45, 25-33 (2013). 
125. Fan, Y. et al. Comprehensive Metabolomic Characterization of Coronary Artery Diseases. J. Am. Coll. Cardiol. 68, 1281-1293 (2016).

126. Dutta, P. et al. Myocardial infarction accelerates atherosclerosis. Nature 487, 325329 (2012).

127. Dresel, H. A. et al. Observations on leukocytes from patients with severe familial hypercholesterolemia. Arteriosclerosis 6, 259-64

128. Rahman, M. S., Murphy, A. J. \& Woollard, K. J. Effects of dyslipidaemia on monocyte production and function in cardiovascular disease. Nat. Rev. Cardiol. 14, 387-400 (2017).

129. Weber, C. et al. Role and analysis of monocyte subsets in cardiovascular disease. Thromb. Haemost. 116, 626-637 (2016).

130. Berg, K. E. et al. Elevated CD14++CD16-monocytes predict cardiovascular events. Circ. Cardiovasc. Genet. 5, 122-131 (2012).

131. Rogacev, K. S. et al. CD14++CD16+ Monocytes Independently Predict Cardiovascular Events. J. Am. Coll. Cardiol. 60, 1512-1520 (2012).

132. SHANTSILA, E. et al. Immunophenotypic characterization of human monocyte subsets: possible implications for cardiovascular disease pathophysiology. J. Thromb. Haemost. 9, 1056-1066 (2011). 




\section{Chapter 7}

Summary | Samenvatting | Résumé 



\section{Summary}

Cardiovascular diseases, mainly driven by atherosclerosis, are the leading cause of death in the world. Atherosclerosis is a chronic inflammatory and lipid-driven vascular disease, where inflammatory cells, lipids and fibrous tissue progressively accumulate in the inner wall of the arteries, forming an atherosclerotic plaque that can eventually rupture. This might restrict blood flow and cause myocardial infarction and/or stroke. Macrophages are instrumental in a variety of cardiovascular diseases, as they not only are the most abundant immune cell type in atherosclerosis, but also play a central role in ischemia-reperfusion injury and healing in the heart. Moreover, they are known to contribute to the low-grade inflammation typical of cardiometabolic diseases. The transcriptional heterogeneity and plasticity of macrophages have widely been demonstrated. However, to date, evidence of functional plasticity and its link to transcriptional activity is still missing. Having a detailed description of macrophage functional heterogeneity could help to understand their exact role under pathological condition. Therefore, in this dissertation, we examined the functional diversity of macrophages in the context of cardiovascular inflammation, such as atherosclerosis, acute myocardial infarction and cardiometabolic disease, and their potential role as disease sensors.

In chapter 2, we built a high-throughput platform able to detect key functions of macrophages in the context of cardiovascular inflammation. We developed and downscaled functional assays, all based on fluorescent probes, to detect a total of 19 functions, i.e. phagocytosis and apoptosis. We were able to show that macrophage transcriptional plasticity is directly translated to functional heterogeneity. Additionally, we generated a function-based atlas of human monocyte derived macrophage responses to a variety of established stimuli using our in vitro platform. The functional activation map can serve as a reference for future research on macrophage heterogeneity, but also to position diseaseassociated changes in functional pattern.

Next to their importance in atherosclerosis, macrophages are also key players of acute myocardial repair. Chapter 3 investigated the use of our novel highthroughput platform to study the impact of systemic status of patients that suffered an acute myocardial infarction on macrophages. We discovered that, after exposure to acute myocardial infarction patient serum, macrophages exert specific functions, reflecting their activation state and cellular stress level. Moreover, RNA 
sequencing analysis revealed specific genes highly correlating with acute myocardial infarction phenotype and clinical progression of the patient. Our results thus show that serum of patients with and acute myocardial infarction reprograms macrophage functionality, and this could help to understand how diseasecompromised functions can have direct consequences on disease prognosis. This opens the way for new therapies to correct adverse functional changes.

In chapter 4, we described the use of the platform to examine functionality of macrophages after depleting an anti-apoptotic protein, $\mathrm{Mcl}-1$, in a mouse model of atherosclerosis. Using our high-throughput platform, we showed that, macrophages lacking $\mathrm{Mcl}-1$ showed a clear phenotype of increased lipid uptake capacity and apoptosis, which aligns with the phenotypic effects we observed in mice with $\mathrm{Mcl}-1$ myeloid deficiency. Furthermore, we developed a novel assay for the platform to study the formation of giant cells, a hallmark of macrophages lacking $\mathrm{Mcl}-1$ in our study.

In chapter 5, we studied the causal relationship of novel obesity-related CVD biomarkers and macrophage functions using our high-throughput platform. Obesity is one of the main risk factors of CVD, as it is linked to abnormal blood lipid profiles, and conventional classifiers for CVD are not accurate enough in risk prediction. Therefore, we performed lipidomics on two independent obese cohorts and discovered a new lipid signature, able to accurately predict disease outcome. We measured the functional profile of macrophages after exposure to these novel biomarkers and identified phenotypic changes, such as phagocytosis, hinting to a causal involvement in the disease process and rendering them potential therapeutic target for obesity-related CVD.

Finally, chapter 6 addressed the main findings of this thesis and discusses their implications and future perspectives. This dissertation suggested that the novel platform able detect measure macrophage functional plasticity could, in the future, help to study the implication of macrophages in atherosclerosis and drug development.

Altogether, this thesis provided novel insights into the functional diversity of macrophages in cardiovascular disease inflammation, such as atherosclerosis, acute myocardial infarction and cardiometabolic diseases using a ready-to-use high-content analysis platform. 


\section{Samenvatting}

Cardiovasculaire aandoeningen, voornamelijk het gevolg van aderverkalking, zijn de belangrijkste doodsoorzaak wereldwijd. Aderverkalking is een chronische ontsteking van de vaatwand, waarbij ontstekingscellen, vetten en fibreus materiaal zich opstapelen in de binnenste laag van een bloedvat. Dit leidt tot de vorming van een atherosclerotische plaque die uiteindelijk kan scheuren, wat de bloeddoorstroming kan beperken en een hartinfarct en/of beroerte kan veroorzaken. Macrofagen zijn van belang bij verschillende cardiovasculaire aandoeningen; niet alleen zijn ze het meest voorkomende celtype bij aderverkalking, ze spelen ook een centrale rol bij ischemia-reperfusie schade en herstelprocessen in het hart. Daarenboven is bekend dat ze bijdragen aan de laaggradige ontsteking kenmerkend voor cardiometabole aandoeningen. De transcriptionele verscheidenheid en de plasticiteit van macrofagen zijn uitvoerig aangetoond. Tot op vandaag is er echter geen bewijs voor een functionele plasticiteit en de daarbijhorende brug naar transcriptionele activiteit. Een gedetailleerde beschrijving van de functionele verscheidenheid van een macrofaag zou zijn precieze rol in ziekteprocessen kunnen verduidelijken. Om die reden hebben we in deze verhandeling de functionele diversiteit van macrofagen in de context van cardiovasculaire ontstekingsziekten, zoals aderverkalking, hartinfarct en cardiometabole aandoeningen, onderzocht, alsmede hun mogelijk gebruik als ziekte-sensoren.

In hoofdstuk 2 bouwden we een high-throughput platform dat sleutelfuncties van macrofagen in een cardiovasculaire ontstekingscontext kan detecteren. We ontwikkelden en miniaturiseerden functionele testen, gebaseerd op fluorescente detectiemoleculen, zodat in totaal 19 functies, bijvoorbeeld fagocytose en apoptose, gemeten konden worden. We konden aantonen dat de transcriptionele plasticiteit in een macrofaag rechtstreeks relateert aan zijn functionele verscheidenheid. Daarnaast genereerden we met behulp van ons in vitro platform een op functie gebaseerde atlas van de reactiepatronen van humane monocytafgeleide macrofagen op een diverse set gekende stimuli. De functionele activatiekaart kan dienst doen als referentie voor toekomstig onderzoek naar macrofaag heterogeniteit, en ook als basis om ziekte-gerelateerde veranderingen in het functionele patroon op te positioneren.

Naast hun belangrijke rol in aderverkalking zijn macrofagen ook kritische spelers in het herstellen van het beschadigde hart na infarct. Hoofdstuk $\mathbf{3}$ onderzocht of ons 
nieuwe high-throughput platform geschikt was om de impact van de systemische omgeving van hartinfarctpatienten op macrofagen te bestuderen. We ontdekten dat macrofagen, na blootstelling aan serum van hartinfarctpatienten, specifieke functies vervulden die overeenkwamen met hun activatiestatus en cellulaire stressniveau. Daarenboven identificeerde RNA sequencing analyse bepaalde genen die heel sterk correleerden met het hartinfarct fenotype en met de klinische prognose van de patient. Onze resultaten laten zien dat het bloed van hartinfarctpatienten macrofagen programmeert tot het vervullen van andere functies. Ze kunnen bijdragen aan een beter begrip van hoe bepaalde functies die door ziekte worden gecompromitteerd onmiddellijke gevolgen kunnen hebben voor het verdere ziekteverloop. Dit zet de deur open naar nieuwe behandelingen die de ongewenste functionele veranderingen tegengaan.

In hoofdstuk 4 beschrijven we gebruik van het platform om macrofaag functionaliteit te onderzoeken nadat een anti-apoptotisch eiwit, Mcl-1, werd verwijderd in een muizenmodel van aderverkalking. Met behulp van het highthroughput platform bewezen we dat macrofagen die Mcl-1 misten een duidelijk verhoogde vetopname capaciteit en verhoogde celdood vertoonden, gelijkaardig aan het fenotype geobserveerd in muizen met $\mathrm{Mcl}-1$ deficientie in myeloide cellen. Daarnaast ontwikkelden we een nieuwe functionele test die aan het platform werd toegevoegd: de vorming van veelkernige reuzencellen, een in het oog springende eigenschap van de $\mathrm{Mcl}-1$ deficiente macrofagen in deze studie.

In hoofdstuk 5 bestudeerden we het oorzakelijk verband tussen nieuwe biomarkers voor overgewicht-gerelateerde cardiovasculaire aandoeningen en macrofaag functies met behulp van ons high-throughput platform. Overgewicht is een van de belangrijkste risicofactoren voor cardiovasculaire ziekten omdat het samenhangt met abnormale lipidenprofielen in het bloed. Standaard beslismodellen zijn hier niet voldoende accuraat in het voorspellen van cardiovasculair risico. Om die reden hebben we lipidomics uitgevoerd in twee onafhankelijke cohorten van mensen met overgewicht. We ontdekten een nieuwe lipidensignatuur die met grote precisie voorspelde hoe de ziekte verder verliep. We maten het functionele profiel van macrofagen na blootstelling aan deze nieuwe biomarkers en identificeerden fenotypische veranderingen, bijvoorbeeld in fagocytose, wat er mogelijks op wijst dat deze biomarkers oorzakelijk betrokken zijn in het ziekteproces en dus kandidaten kunnen zijn in het behandelen van overgewicht-gerelateerde cardiovasculaire aandoeningen.

Page | 206 
Hoofdstuk 6 tenslotte keek terug op de belangrijkste bevindingen van deze thesis en bespreekt hun implicaties en toekomstperspectieven. Deze verhandeling suggereerde dat het nieuwe platform dat de functionele plasticiteit van macrofagen in kaart kan brengen in de toekomst zou kunnen worden ingezet om de betrokkenheid van macrofagen in aderverkalking en medicijnontwikkeling te bestuderen.

Samenvattend verschaft deze thesis nieuwe inzichten in de functionele diversiteit van macrofagen in cardiovasculaire aandoeningen, zoals aderverkalking, hartinfarct en cardiometabole ziekten, door gebruik te maken van een operationeel highcontent analyse platform. 


\section{Résumé}

Les maladies cardiovasculaires, souvent causées par des plaques d'athérome, sont la principale cause de décès dans le monde. L'athérosclérose est une maladie vasculaire inflammatoire chronique dans laquelle des cellules inflammatoires, des lipides et des tissus fibreux s'accumulent progressivement dans la paroi interne des artères, formant une plaque d'athérome qui risque de finalement se rompre. Le flux sanguin est alors restreint et peut causer un infarctus du myocarde et/ou un accident vasculaire cérébral. Les macrophages ont un rôle déterminant dans plusieurs maladies vasculaires, car ils constituent non seulement le type de cellules immunitaires le plus abondant dans les plaques d'athérome, mais ont aussi un rôle central dans les lésions d'ischémie-reperfusion et la régénération des tissus cardiaques. Ils sont également connus pour contribuer à la légère inflammation caractéristique des maladies cardiométaboliques. L'hétérogénéité transcriptionnelle et la plasticité des macrophages ont été largement démontrées. Cependant, à ce jour, aucune preuve de plasticité fonctionnelle liée à leur activité de transcription n'a été prouvée. L'accès à une description détaillée de l'hétérogénéité fonctionnelle des macrophages pourrait aider à mieux comprendre leur rôle précis dans le développement de maladies cardiométaboliques. Par conséquent, dans cette thèse, nous avons étudié la diversité fonctionnelle des macrophages dans le contexte des maladies cardiovasculaires, telle que l'athérosclérose, l'infarctus aigu du myocarde et les maladies cardiométaboliques.

Dans le chapitre 2, nous avons développé une plateforme à haut débit capable de détecter certaines fonctions clés des macrophages dans le contexte de l'inflammation cardiovasculaire. Nous avons mis au point des tests fonctionnels, tous basés sur des sondes fluorescentes, afin de détecter un total de 19 fonctions, telles que la phagocytose ou l'apoptose. Nous avons démontré que la plasticité transcriptionnelle des macrophages est directement traduite en hétérogénéité fonctionnelle. De plus, en utilisant notre plateforme in vitro, nous avons généré un atlas de fonctionnalités de macrophages, dérivés de monocytes humains, qui répertorie leur réponse à une variété de stimuli. Ce spectre d'activation fonctionnelle pourra servir de référence pour des recherches futures sur l'hétérogénéité des macrophages, mais également pour classer les changements de fonction associés à certaines maladies dans notre atlas.

En plus de leur importance dans l'athérosclérose, les macrophages sont également des acteurs clés de la cicatrisation cardiaque à la suite d'un infarctus aigu du Page | 208 
myocarde. Dans le chapitre 3 nous avons utilisé notre nouvelle plateforme à haut débit pour étudier l'impact de l'état systémique des patients ayant subi infarctus du myocarde aigu sur les macrophages. Nous avons découvert qu'après être avoir été exposés au sérum de patients souffrant d'un infarctus aigu du myocarde, les macrophages exerçaient des fonctions spécifiques reflétant leur état d'activation et leur niveau de stress cellulaire. De plus, l'analyse du séquençage de l'ARN a révélé des gènes spécifiques étroitement corrélés au phénotype d'infarctus aigu du myocarde et à l'évolution clinique du patient. Nos résultats montrent donc que le sérum des patients atteints d'un infarctus aigu du myocarde reprogramme la fonctionnalité des macrophages. Cela pourrait aider à comprendre comment les dysfonctions cellulaires liées à certaines maladies peuvent avoir des conséquences directes sur le pronostic de la maladie et aider à développer de nouvelles solutions thérapeutiques pour rétablir les fonctions cellulaires.

Dans le chapitre 4, nous avons décrit l'utilisation de cette plateforme pour analyser la fonctionnalité des macrophages suite à la déplétion d'une protéine antiapoptotique, $\mathrm{Mcl}-1$, dans un modèle murin d'athérosclérose. En utilisant notre plateforme à haut débit, nous avons démontré que les macrophages dépourvus de Mcl-1 présentaient un phénotype précis d'augmentation de la capacité d'absorption des lipides et d'apoptose, ce qui correspond aux effets phénotypiques observés chez les souris présentant un déficit myéloïde en $\mathrm{Mcl}-1$. De plus, nous avons développé un nouveau test pour la plateforme permettant d'étudier la formation de cellules géantes, caractéristique des macrophages dépourvus de $\mathrm{Mcl}$ 1 dans notre étude.

Dans le chapitre 5, nous avons étudiés la relation de cause à effet entre nouveaux marqueurs biologiques pour le développement de maladies cardiovasculaires et macrophages chez les obèses, en utilisant notre plateforme à haut débit. L'obésité est l'un des principaux facteurs de risque des maladies cardiovasculaires, car elle est liée à des profiles lipidiques sanguins anormaux, et les marqueurs classiques des maladies cardiovasculaires ne permettent pas une prédiction du risque suffisamment précise. Par conséquent, nous avons effectué une analyse lipidomique sur deux cohortes indépendantes obèses et avons découvert une nouvelle signature lipidique, capable de prédire avec précision l'évolution de la maladie. Nous avons mesuré le profil fonctionnel des macrophages après exposition à ces nouveaux marqueurs biologiques et identifié des modifications 
phénotypiques, telles que la phagocytose, suggérant une implication causale dans le processus de la maladie.

Enfin, le chapitre 6 a traité des principales conclusions de cette thèse et discuté de leurs implications et perspectives. Cette thèse suggère que la nouvelle plateforme capable de détecter et mesurer la plasticité fonctionnelle des macrophages pourrait, à l'avenir, aider l'étude de l'implication des macrophages dans les maladies cardiovasculaires et le développement de médicaments.

En conclusion, cette thèse a fourni de nouvelles informations sur la diversité fonctionnelle des macrophages dans le contexte de l'inflammation vasculaire liées au pathologies cardiovasculaires, telles que l'athérosclérose, l'infarctus aigu du myocarde et les maladies cardiométaboliques en utilisant une plateforme d'analyse à haut débit prête à l'emploi. 




\section{Chapter 8}

Valorization 

Valorization, defined as a "process that aims at enhancing societal impact"1 ${ }^{1}$, is an important aspect of (academic) research. It is crucial for scientists to make the knowledge acquired during a PhD available and accessible to society both by transferring the results to potential stakeholders (e.g. pharmaceutical companies or other research centers) and if opportune, by translating them into possible news products that society could benefit from. In this chapter, we will present how the work described in this thesis has and will be transferred to society and how it, in the future, could help to reduce the socio-economic burden of cardiovascular disease.

\section{Cardiovascular disease}

Cardiovascular disease (CVD), mainly driven by atherosclerosis, is still the leading cause of death in the world ${ }^{2}$. In 2016, almost 18 million people died from CVDs globally, mostly attributable to coronary artery disease and stroke ${ }^{3}$. CVD has become an obvious economic burden, as the European Heart Network has estimated the total CVD-related cost to be $€ 210$ billion per year ${ }^{2}$. The main costs generated from CVD are related to healthcare of CVD patients (healthcare, medication, hospitalization), but also indirect costs, such as patient work productivity loss and intangible costs, e.g. costs of pain and suffering, are substantial. This highlights the need to rapidly discover new therapies or strategies to cure and study CVD. CVD research centers on two major topics: (1) investigations on mechanistic pathways involved in the pathophysiology of CVD; (2) translational studies aimed at CVD diagnosis, prevention and intervention, often based on findings from the basic science studies. In this thesis, we aimed to cover both areas of research, with chapter $\mathbf{3}$ and $\mathbf{5}$ focusing on prediction and prevention of CVD, and chapter $\mathbf{2}$ to 4 mainly focusing on understanding functional pathways involved in CVD inflammation.

As described above, valorization can be accomplished via two main tracks: "societal transfer of results" and "economical transfer". We have achieved the former by presenting the main results described in this thesis at (inter)national conferences. In addition, making scientific knowledge accessible to everyone is another key aspect of societal transfer. During my PhD, I was selected to give a Ted-talk at the PhD-student course organized by the Dutch Heart Foundation in 2017, improving my communication skills to present scientific research to a non-scientific audience. We further intend at disseminating the acquired knowledge to cardiovascular 
patients by giving lectures via the Harteraad (https://www.harteraad.nl/). Moreover, we aim at publishing the main results of this thesis in peer-reviewed, preferably open access, scientific journals; in fact chapter $\mathbf{4}$ has already been published in an open-access journal, and chapter $\mathbf{5}$ is under review at European Heart Journal. Datasets will be deposited in repositories that are publicly available, such as GEO. The published results could then be used as starting point or reference for the scientific community in future research. As to the second track, the translation of results into potential diagnostic or therapeutic strategies to detect and treat CVD, we aim at conducting an active Intellectual Property IP protection strategy to allow successful knowledge exploitation of the projects described in this thesis. Together with carefully selected external partners, such as biotech companies, we will develop a cost-effective utilization strategy of, for example, our MacroScreen platform or our predictive lipid-signature. The below paragraphs will expand the different valorization opportunities of the main results of this thesis.

\section{Bringing the predictive lipid signature to the market}

In chapter 5, we have profiled circulating lipids in two independent obese patient cohorts and built a prediction model of future CVD. Obesity is a well-known risk factor for CVD; it accounts for approximately $30 \%$ of the cases ${ }^{4}$. This is explained by the "bi-angular relationship" between CVD and obesity; obesity is both directly and indirectly linked to CVD due to the abnormal blood lipid profile and to its relation to other important risk factors of CVD, such as hypertension and diabetes, respectively. However, current risk factors, such as cholesterol levels, blood pressure or glucose levels, lack predictive power for the development of CVD in the obese population to be useful for individual risk assessment. The lipid-signature described in chapter 5, has unprecedented predictive power for future CVD and could be a valuable tool for early detection of high-risk obese patients, motivating them to lifestyle changes, instead of costly life-long medication, such as statins, or pricey surgical operations, thereby reducing the economic burden of CVD.

Current risk prediction is performed by calculating risk scores, based on many clinical parameters. Ideally, our multi-lipid CVD risk signature could be translated into a fast and accurate in vitro diagnostic (IVD) test for plasma samples of obese patients, which then would be used in the clinics to further help in individual CVD prediction. However, translating these findings to an accurate IVD test requires further study to prove the diagnostic value of our prediction model. First, future 
studies will have to reproduce and validate these findings in even larger cohorts, as patient numbers still were rather limited for both our discovery $(n=78)$ and validation cohort $(n=200)$. Second, current lipid profiling is performed using mass spectrometry. This technique requires specialized infrastructure and is expensive and time-consuming, making it not feasible for point-of-care testing. Therefore, further studies aim at developing an IVD assay, which could for example rely on aptamer technology, to detect our lipid signature. Aptamers arrays are spotted with single strand DNA or RNA (ssDNA/ssRNA), that have a unique tertiary structure able to specifically bind to a single lipid ${ }^{5}$ and have already showed their potential for biomarker discovery ${ }^{6}$. Together with specialized companies, such as Novaptech or Eurogentec, which have experience with production of aptamer-based arrays for diagnostic purposes, we will develop and validate a diagnostic product at different location sites and on a high number of biological samples. This easy-to-use diagnostic tool could directly be used by general practitioners and in the hospital, and lead to early identification of high-risk CVD patients, early individualized intervention and CVD prevention. Next to this, this diagnostic tool will help monitor medical treatment efficacy and will be used as an outcome measurement for clinical trials and intervention studies.

\section{Potential therapeutic solutions}

Current medication for CVD involves lipid lowering therapy, including statins ${ }^{7}$, and antihypertensive treatment. Despite their effectiveness with a $20 \%$ reduction in CVD risk, lipid lowering therapies are unable to prevent future cardiovascular events in a significant number of patients ${ }^{8}$. More recently, intervention in IL-1 $\beta$ signaling with a monoclonal antibody on top of statin treatment, in subjects with low grade inflammation led to a supplementary reduction of $14 \%$ in CVD incidence. However, this was accompanied by increased infection numbers and, importantly, no difference in overall mortality was observed after IL-1 $\beta$ antibody treatment. This emphasizes the need to discover new therapeutic targets to decrease CVD risk and develop new diagnosis tools to enable detection of high-risk profile at a reversible stage of the disease.

In chapter 5, we discovered an 18-lipid signature predicting the incidence of CV events in the obese population. Using our MacroScreen platform, we could show that some of our lipid predictors were affecting key functions of macrophages, the main immune cell type implicated in atherosclerosis, hinting at a possible causal 
relationship. Moreover, these lipids were enriched in unstable, as compared to stable human atherosclerotic plaques. Future research aims at studying the implication of these lipids in disease development and progression, by interacting with their synthesis in vivo for example. This could potentially lead to the discovery of new key players in atherosclerosis related CVD and, subsequently, open new avenues for therapeutic solutions. As statins fail at reducing the risk in a majority of patients, despite their profound effect on cholesterol and, indirectly, on other lipids levels ${ }^{10}$, novel drugs should be generated. To target specific lipids, one could think of generating molecules interacting with their synthesis pathway by inhibiting a key enzyme, for example.

Another potential target for future intervention was unveiled in Chapter 4, where we investigated the impact of a deficiency of $\mathrm{Mcl}-1$, an anti-apoptotic protein, on atherosclerosis. We were able to convincingly show that $\mathrm{Mcl}-1$ is essential for survival of macrophages, as well as neutrophils. Additionally, Mcl-1 was implicated in macrophage lipid uptake and subsequent macrophage fusion capacity, resulting in the formation of multinucleated giant cells (MGCs). Evidence for the presence of MGCs in human atherosclerotic plaques is scarce; and the description of a clear role in the pathogenesis of disease is lacking. One study described MGCs to express high level of cathepsins, enabling the rupture of the elastic lamina and facilitating the migration of smooth muscle cells during atherosclerosis ${ }^{11}$. Clearly, more research is needed to understand the implication of MGCs in atherosclerosis and their exact role in disease development and progression. Second, small molecules targeting Mcl-1 already exist, as $\mathrm{Mcl}-1$ is an interesting target to treat cancer, due its high expression in tumor cells and role in cell survival ${ }^{12,13}$. However, as we showed, targeting $\mathrm{Mcl}-1$ in an animal model of atherosclerosis led to severe neutropenia, and had no effect on atherosclerotic lesion size. Therefore, targeting Mcl-1 will most probably not lead to successful therapeutic strategies; yet, this could be used as a model of neutropenia or giant-cell enriched atherosclerosis to further investigate MGCs implication in atherosclerosis.

\section{Novel human centered validation strategies in CVD research}

Funding for cardiovascular disease research is sizable ${ }^{14}$. Between 2010 and 2012, funding for CVD research (both academic and in private company setting) amounted around $€ 876$ million in Europe ${ }^{14}$. CVD research is nowadays mainly performed on animal models, which are expensive, and time consuming and do 
not, in every aspect, represent human disease. Therefore, building a humanized test platform to capture cardiovascular inflammation, such as atherosclerosis and AMI, in vitro (chapter 2 to 5 ) could help reducing the costs of CVD fundamental research and drug development. First, chapter $\mathbf{2}$ showed that macrophages are functionally reprogrammed after exposure to various stimuli, such as several cytokines or fatty acids. This led to the identification of a macrophage activation functional map, which could serve as reference for further studies. Second, chapter 3 investigated the functional responses of macrophages after exposure to AMI patient serum. We observed that macrophages functionally respond to AMI systemic environment and these functionalities were also linked to poor prognosis, four months after the infarct, showing the potential utility of this platform as a fast and cheap drug screening platform. One could think of assessing the effect of compound libraries on key functions of macrophages related to AMI systemic environment, and subsequently select the most interesting target for further analysis. Importantly, our platform will never serve a diagnostic purpose, as it is too time-consuming and labor intensive for clinical use.

Altogether, this demonstrates that our platform has great potential to quickly study the implication of macrophages in CVD inflammation and to screen for modulators of critical macrophage functions for drug development purposes. The platform is ready-to-use, however future research aims at improving its physiological complexity, as it is currently based on two-dimensional monolayers of cells and this lacks the cell-cell interaction and 3-dimension aspects of the human body.

\section{Conclusion}

In conclusion, the work presented in this thesis aimed to tackle the socio-economic burden of CVD at several levels. We have developed a new tool, able to characterize macrophage functions in the context of CVD inflammation. This tool could, in the future, help reduce the use of animal models and improve the translational problem linked to animal studies. Furthermore, we have identified a predictive lipid signature for the development of obesity related CVD, which shows promise for stratifying obese individuals with increase CVD risk and may also have therapeutic potential. Lastly, we have investigated the impact of Mcl-1 in atherosclerosis, and its implication in giant cell formation opening new avenues to manipulate MGC formation in atherosclerosis, and potentially other diseases where MGCs play a role 


\section{References}

1. van Drooge, L. \& de Jong, S. Valorisation: researchers already do much more than they realise | Rathenau Instituut. Available at: https://www.rathenau.nl/en/knowledge-policy/valorisation-researchers-alreadydo-much-more-they-realise. (Accessed: 30th September 2019)

2. (EHN), E. H. N. European Cardiovascular Disease Statistics 2017 edition. (2017).

3. WHO. Cardiovascular diseases (CVDs). (2017). Available at: https://www.who.int/news-room/fact-sheets/detail/cardiovascular-diseases(cvds). (Accessed: 2nd October 2019)

4. WHO $\mid$ Obesity. WHO (2016). Available at: https://www.who.int/topics/obesity/en/.

5. Klapak, D., Broadfoot, S., Penner, G., Singh, A. \& Inapuri, E. Development of novel aptamers for low-density lipoprotein particle quantification. PLoS One 13, e0205460 (2018).

6. Chang, Y. M., Donovan, M. J. \& Tan, W. Using aptamers for cancer biomarker discovery. J. Nucleic Acids 2013, 817350 (2013).

7. Cupido, A. J., Reeskamp, L. F. \& Kastelein, J. J. P. Novel lipid modifying drugs to lower LDL cholesterol. Curr. Opin. Lipidol. 28, 367-373 (2017).

8. Fruchart, J.-C. et al. The Residual Risk Reduction Initiative: A Call to Action to Reduce Residual Vascular Risk in Patients with Dyslipidemia. Am. J. Cardiol. 102, $1 \mathrm{~K}-34 \mathrm{~K}$ (2008).

9. Ridker, P. M. et al. Antiinflammatory Therapy with Canakinumab for Atherosclerotic Disease. N. Engl. J. Med. 377, 1119-1131 (2017).

10. Meikle, P. J. et al. Statin action favors normalization of the plasma lipidome in the atherogenic mixed dyslipidemia of MetS: Potential relevance to statin-associated dysglycemia. J. Lipid Res. 56, 2381-2392 (2015).

11. Samokhin, A. O. et al. Cholate-containing high-fat diet induces the formation of multinucleated giant cells in atherosclerotic plaques of apolipoprotein E-/-mice. Arterioscler. Thromb. Vasc. Biol. 30, 1166-1173 (2010).

12. Kotschy, A. et al. The MCL1 inhibitor $\mathbf{5 6 3 8 4 5}$ is tolerable and effective in diverse cancer models. Nature 538, 477-482 (2016).

13. Xiang, W., Yang, C. Y. \& Bai, L. MCL-1 inhibition in cancer treatment. Onco. Targets. Ther. 11, 7301-7314 (2018).

14. Sankyo, D., Zeneca, A. \& Bayer, S.-A. Funding cardiovascular research in Europe. doi:10.1093/eurheartj/ehy817 


Appendices List of abbreviations 



$\begin{array}{ll}\text { 2D } & \text { 2-dimensional } \\ \text { BD } & \text { 3-dimensional } \\ \text { AMI } & \text { Acute myocardial infarction } \\ \text { AT } & \text { Adipose tissue } \\ \text { ASC } & \text { Apoptosis-associated speck like } \\ \text { AUC } & \text { area under the curve } \\ \text { ABCA1 } & \text { ATP binding cassette A1 } \\ \text { B-cell } & \text { B lymphocyte } \\ \text { BP } & \text { blood pressure } \\ \text { BMI } & \text { Body mass index } \\ \text { BMDM } & \text { Bone marrow derived macrophage } \\ \text { BMT } & \text { Bone marrow transplantation } \\ \text { CRP } & \text { C reactive protein } \\ \text { CCA } & \text { Canonical correlation analysis } \\ \text { CVD } & \text { Cardiovascular disease } \\ \text { CEA } & \text { Carotid endarterectomy } \\ \text { CER } & \text { Ceramide } \\ \text { CCL } & \text { Chemokine (C-C motif) ligand } \\ \text { CXCL } & \text { Chemokine (C-X-C motif) ligand } \\ \text { CXCR } & \text { Chemokine (C-X-C motif) receptor } \\ \text { CE } & \text { Cholesteryl ester } \\ \text { CD } & \text { Cluster of differentiation } \\ \text { CODAM } & \text { Cohort on Diabetes and Atherosclerosis Maastricht } \\ \text { CAD } & \text { Coronary artery disease } \\ \text { CHD } & \text { Coronary heart disease } \\ \text { CCM } & \text { Correlation coefficient matrix } \\ \text { DC } & \text { dendritic cell } \\ \text { DM } & \text { diabetes mellitus } \\ \text { DAG } & \text { Diacylglycerol } \\ \text { EC } & \text { Endothelial cells } \\ \text { FH } & \text { Familial hypercholesterolemia } \\ \text { FCS } & \text { Fetal calf serum } \\ \text { FRS } & \text { Framingham study } \\ \text { GO } & \text { Gene ontology } \\ \text { GWAS } & \text { Genome wide association study } \\ \text { GC } & \text { Glucocorticoids } \\ \text { GM-CSF } & \text { Granulocyte macrophage colony stimulating factor } \\ \text { HE } & \text { Hematoxylin and eosin } \\ & \\ & \end{array}$




\begin{tabular}{ll} 
HCA & high content analysis \\
HDL & High-density lipoprotein \\
iMacs & Iduced pluripotent stem cells derived macrophages \\
IC & Immune complexe \\
iPSC & Induced pluripotent stem cells \\
IFN $\beta$ & Interferion- $\beta$ \\
IFNg & Interferon-g \\
IL & Interleukin \\
KO & Knock-out \\
LA & Lauric acid \\
LiA & Linoleic acid \\
LPS & Lipopolysaccharide \\
LR & Logistic regression \\
LDL & Low-density lipoprotein \\
LDLR & Low-density lipoprotein receptor \\
LPC & Lysophosphaditycholine \\
LPA & Lysophosphatidic acid \\
M-CSF & Macrophage colony stimulating factor \\
MMP & Metalloprotease \\
mtDNA & Mitochondrial DNA \\
MAG & Monoacylglycerol \\
MCP-1 & Monocyte chemoattractant protein 1 \\
MDM & Monocyte-derived macrophage \\
MGC & Multinucleated giant cell \\
Mcl-1 & Myeloid cell leukemia 1 \\
MI & Myocardial infarction \\
NK & Natural killer cell \\
NET & Neutrophil extracellular trap \\
NMOC & Non-mitochondrial oxygen consumption \\
NLR & Nucleotide-binding oligomerization domain-like receptors \\
ORO & Oil Red O \\
OA & Oleic acid \\
oxLDL & oxidized low-density lipoprotein \\
PA & Palmitic acid \\
P3C & Pam3CSK4 \\
PLS-DA & Partial least square discriminant analysis \\
PAMP & Pathogen associated molecular pattern \\
PBMC & Peripheral blood mononuclear cells \\
& \\
\hline
\end{tabular}




\begin{tabular}{|c|c|}
\hline PBS & Phosphate buffered saline \\
\hline PC & Phosphatidylcholine \\
\hline PE & Phosphatidylethanolamine \\
\hline PMN & Polymorphonuclear leukocyte \\
\hline PCA & Principal componenet analysis \\
\hline PCSK9 & Proprotein converstase subtilisin/kexin type 9 \\
\hline PGE2 & Prostaglandin E2 \\
\hline RF & Random forest \\
\hline ROS & Reactive oxygen species \\
\hline qPCR & Real time polymerase chain reaction \\
\hline ROC & Receiver operator characteristic \\
\hline RPMI & Roswell park memorial institute medium \\
\hline SMC & Smooth muscle cell \\
\hline SM & Sphingomyelin \\
\hline SD & Standard deviation \\
\hline SEM & Standard error of the mean \\
\hline sLPS & Standard LPS \\
\hline SA & Stearic acid \\
\hline SHIP & Study of Health in Pomerania \\
\hline SVM & Support vector machine \\
\hline T-cell & T lymphocyte \\
\hline TUNEL & Terminal deoxytransferase dUTP nick-end labeling \\
\hline $3 D$ & Three dimensions \\
\hline TPP & TNF+PGE2+P3C \\
\hline $\mathrm{TC}$ & Total cholesterol \\
\hline TAG & Triacylglycerol \\
\hline TG & Triglycerides \\
\hline TAM & Tumor associated medium \\
\hline TNF- $\alpha$ & Tumor necrosis factor $\alpha$ \\
\hline $2 \mathrm{D}$ & Two dimensions \\
\hline T2DM & Type 2 diabetes mellitus \\
\hline upLPS & Ultra-pure LPS \\
\hline VCAM & Vascular cell adhesion molecule \\
\hline vSMC & Vascular smooth muscle cell \\
\hline VLDL & very-low density lipoprotein \\
\hline WGCNA & Weighted gene co-expression network analysis \\
\hline WTD & Western type diet \\
\hline WBC & White blood cells \\
\hline
\end{tabular}


Appendices

WT

Wild type

Page | 228 




\section{Appendices}

Acknowledgements | Remerciements 

Ça y est, 4 ans plus tard, j'y suis enfin! Time has flown by and I want to thank many people for their contribution, help, guidance and love throughout these 4 years!

Obviously, the first one to thank is Prof. Dr. Biessen! Erik, you have been the best mentor I could have wished for! I still remember my first day at Pathology, as if it was yesterday! I was waiting in the hallway, in front of your UNS40 office and you never showed up... Thinking about it now, it does not surprise me at all! You have taught me so much in the last four years and I am grateful to you for many reasons. First, you have allowed me to develop personally and professionally, by giving me the opportunity to (quickly) be independent on several (challenging) projects. You have never doubted about my abilities and supported me in all the directions I was taking. Our countless number of meetings have inspired me, and I was always impressed by how much you know about... everything (even though sometimes I had no idea what you were talking about... Oops). As we agreed on many times, my PhD journey has been a bumpy road, very bumpy at times, but having you as promoter kept me motivated throughout! Thank you for that!

The second ones to thank are of course Dr. Temmerman and Dr. Sluimer. Lieve and Judith, my two "doctor mamas"! Where to start? Lieve, you have found me in the hallway waiting for Erik, on my first day! And from that moment on, you never let me go! you have taught me everything about the HCA, lab work, macrophages, and many more topics (maybe not about organizational skills though... hihi) and we've spent a lovely four years working together. We were forming the Belgian HCA team, training others, performing tons of experiments together, answering questions with the exact same answers at the exact same time (great minds think alike!). We have worked hard on five projects together, and your scientific input, optimism and rationality have greatly helped me to move forward! Judith... In the first six months of $\mathrm{my} \mathrm{PhD}$, I was waiting for Erik to name a co-promoter and I have to admit that I was secretly hoping it would be you! Lucky me, you were the one and even though your evil look and frank honesty were a bit scary at first, being part of the "Eggplant team" or "teamplayers family" was one of the best things that happened during my $\mathrm{PhD}$. You are a driven and inspiring scientist; your help and input were greatly appreciated. Next to the scientific part, you are a wonderful person, who listened and comforted me in hard times! Thank you for all this!

I would also like to thank all the members of my assessment committee Prof. Schurgers, Prof. Kersten, Prof. Lutgens, Dr. van den Akker and Dr. Coort for taking the time to read and assess my thesis. 
Prof. Dr. Zur Hausen, thank you for having me in your department in the last four years and the countless compliments about my (very French) first name!

Thank you to STW and all the members of the user committee. Dr. Schalkwijk, thank you for the interactive discussions during the STW meetings. Dr. Mengerink, thank you for teaching me all about mass spectrometry.

Thank you to all the co-authors for their contribution to each chapter of this thesis

My par(ty)anymphs... Lauren and Kim! Shister and Kiki, the Kilamas... WHAT A JOURNEY TOGETHER! Let's start with Lauren... haha I'm laughing just by thinking of our story. We met on the $3^{\text {rd }}$ of December 2015 and I (don't) remember it well! It involved alcohol (Alcohooool, alcohoooooool), as everything we did from that day on! You rapidly became my buddy! We did EVERYTHING together, day and night drinking (or 24h long drinking!), traveling to Paris, Switzerland and New Jersey, organizing cool events for I'MCARIM, watching millions (or almost) of movies at Pathé, dancing like crazy at VBML with our socks (DOBBY IS A FREE ELF!). You have made my time in Maastricht amazing and unforgettable and I am very lucky to have you in my life!! My second paranymph, Kiki, as I once said, the only regret I have is that you did not start your PhD at the same time as me and that I only got to spend three years with you! But those three years were... epic! From the shy little Kim who began at Pathology, you became the confident and sometimes stubborn Kiki that I know. You were the mother of the KILAMA triangle, trying to guide both Lauren and me to the least stupid direction... From colleagues to roommates and best friend, you also taught me how to party well. You were always there for me, in good and bad times and I am so thankful for that! THANK YOU BOTH!

Taghi, I have met you right after I started my PhD and we directly became friends. You have taught me everything about machine learning, programming (ish), prediction modelling, missing values, etc... Without you, the lipid project wouldn't have been possible! Also, thank you for your support in hard times! Jan (Jean, Jeanette and so on), thanks for the parties, the macrophage stories, the bread-icebreaking questions and the 7am running session! It was a pleasure working with you, and I wish you all the best in the future! Jenny, the sweetest of all! Promise me one thing, you will always be that kind, smart and sexy woman I know! You rock girl, it was a pleasure having you around during my PhD. I wish you all the best in the future, and with your future husband Renzo! Dr. Jasper, thank you for all the thesis-writing tips, great parties and good fun in the lab! I hope your patients will be as fun as the pathology team! Enjoy your new life and let's keep in touch! Olivia, I am so happy that you have found love and happiness here in Maastricht! You Page | 234 
deserve it, girl! Thank you for always listening to me and good luck with the end of your PhD! Adele, a hell of a good student who turned into a brilliant PhD candidate! Good luck with the monocyte project and take good care of the HCA! Han, thank you for all the graphs you generated for me! No matter the day or the time you were always there to help, and most of the nice graphs in this thesis come from you! Good luck with finishing your PhD! To all the "old" PhD students, Elke, Thomas, Bart, Kosta, Anke, Marchy, thank you for introducing me to the lab and to the PhD life! To all the other ones, Renée, Ruud, Chang, Valeria, Danielle, Greg, John, Francesca, thank you for contributing from close or from far to this thesis and good luck with the end of your PhD trajectory!

Erwin, thank you for helping me with the HCA and developing the inflammasome assay! Your help and availability were always greatly appreciated! Mat, thank you for teaching me everything about cell culture, the HCA and the lab! Gregorio, Anique, Clairy, Jacques, Sylvia and Jack, thank you all for your contribution to this thesis!

Marion, thank you for the very long hours in front of the microscope to quantify the giant cells! Thank you for forcing me to speak Dutch to you, you were a great teacher! And of course, thank you for the good fun during all the parties! Andy, thank you for your input during my labmeetings, the good fun during the parties and promise me one thing: keep on drinking beer the way I taught you, you do it so well! Marjo, thank you for all the career advices and your input on my projects! Pieter, starting a debate with you was never a good idea; you know too much about everything! Thank you for all the macrophage tips and vive la Wallonie! Suzan, thank you for the all the meetings with the HCA team and good luck with the healthy aging project!

Frank, thank you for tolerating me through sober and drunk times! It was always fun to meet for movies, pubquizzes, borrels, etc and good luck with your PhD! Aurore, ma petite baguette, la seule petite frouze de mon entourage hollandais ! Merci pour tous les bons moments et pour toutes ces sessions de golfs endiablées ! Je te souhaite tout le meilleur dans ta vie professionnelle, comme privée et n'oublie pas de me rendre la coupe du monde un de ces 4 ! Geert, my party buddy! How many drunk nights have we spent together? Wow, too many! We've organized so many great events together and thank you for ADE, it was so cool! Lara, thank you for the sangria nights, the PhD-complaining-discussions, the tail-wiggling evenings and Carnival! Paula, thank you for all the tequilas! Andrea, thank you for all the parties (and stealing all the coins during the CARIM course week events)! 
Beaaaaaaa, thank you for your positivity and good vibes! Mitchell, Mimi, you're my oldest friend in Maastricht! From Senior training buddies, to PhD buddies! Thank you for your friendship, and good luck in Marseille! Huge thanks to all the members of my master crew, Nachito, Camilo, Jojo, Teo, Zizi and Dr. Hebels! We've done some nice trips together and you made my years as a master student nicer!

Thank you to all the members of I'MCARIM, Tate and Kim, and the members of the EPC for the great years as a CARIM PhD representative!

Merci à tous mes nouveaux collègues de chez Diagenode pour leur accueil et leur bonne humeur au quotidien!

Julie, Kim, Sophie et Elvire. Mes amies de toujours! Merci de m'avoir soutenue, écoutée, réconfortée durant toutes ces années! Ma maman avait raison, vous êtes et resterez mes meilleures amies à vie! Vous êtes des amours, et je vous remercie d'être vous et de m'avoir toujours acceptée et supportée malgré mon sale caractère! Mes cousines, Lorie et Eloise, merci à vous deux, vous êtes les sœurs que je n'ai jamais eues!

Florent, que dire... Avoir un meilleur grand-frère serait difficile ! Tu as toujours été là pour m'écouter, me conseiller, t'intéresser à mon travail, ma vie, m'épauler, me protéger et surtout me montrer que tu es fière de moi. Merci pour ta présence, ta gentillesse, et ton amour (et tes bisous magiques, ou pas haha !). Et évidemment, merci à Bubu, pour tous ces chouettes moments au Pérou (et pas que !). Lorrain et Laura, merci pour les noëls et soupers de famille arrosés ! Je vous souhaite beaucoup de bonheur et vivement votre mariage !

Mamouche, merci de ton soutien et de ton amour. Ces petits moments à nous deux à parler de ma thèse (et pas que) sont très précieux pour moi.

Mon Caillou, ta présence, ton humour, ta générosité et ta gentillesse me comblent de bonheur depuis maintenant plus d'un an. Je nous souhaite encore de longues et belles années, au coté de notre Mousse national. Merci pour tout ! Merci aussi à tous les membres de ta gentille famille (Pierre \& Dominique, Antoine \& Chabou, Loulou \& Doudou, Sara et Martine, Mamy Annette) pour leur accueil et gentillesse au quotidien! Un immense merci à Clément et Alex, pour tous les bons moments passés à 4 ! Vous êtes super et je me réjouis déjà pour nos sessions de golfs endiablées en été !

Papa et Maman... mon petit papou et ma petite mamoune, merci d'avoir toujours été là pour moi. Merci de m'avoir donné la possibilité de faire ces études, de Page | 236 
m'avoir soutenue et de m'avoir poussée à me dépasser. Merci aussi de me guider au quotidien, cette thèse n'aurait pas été possible sans vous ! Merci aussi à Véronique, de t'occuper si bien de mon petit papa, de ta gentillesse, et de toujours nous concocter de fabuleux petits plats qui nous font passer des merveilleux moments en famille.

Bonne maman, ma petite bonne-maman. Toi et moi c'est très spécial et un simple merci ne suffirait pas. Voilà maintenant plus de 10 ans que notre relation est fusionnelle et attendrissante. Je ne remplacerai mes moments avec toi pour rien au monde. Merci de ta confiance, ton amour inconditionnel, ton optimisme et ta bonne-humeur qui me rendent tellement heureuse !

Ma dernière pensée va tout naturellement à mon petit parrain...

HUGE THANK YOU TO YOU ALL, UN IMMENSE MERCI A VOUS TOUS!

Margaux 



\section{Appendices}

Curriculum Vitae 



\section{Personal information}

Name: Margaux Anne Charlotte Fontaine

Date of birth: 03 December 1990

Place of birth: Liège, Belgium

Nationality: Belgian

Education

09/2015 - 11/2019 PhD training in biomedical sciences

Dept. Of Pathology, Maastricht University Medical Center

The Netherlands

09/2012-06/2014 Biomedical Sciences (MSc)

Maastricht University

The Netherlands

09/2009-06/2012 Biotechnology (Bsc) - Magna Cum Laude

La Haute Ecole de la Province de Liège

Belgium

\section{Research/Work experience}

11/2019 - now R\&D Project Manager

Diagenode Diagnostics

Liège, Belgium

09/2015 - 11/2019 PhD training in biomedical sciences

Dept. Of Pathology, Maastricht University Medical Center

The Netherlands

Promoter: Prof. Dr. Erik. AL Biessen

co-promoter: Dr. Judith C Sluimer and Dr. Lieve

Temmerman

The Macroscreen Platform: Capturing Cardiovascular

Disease Inflammation In Vitro

10/2013-06/2014 MSc Senior practical training

Dept. Of Cardiology, Maastricht University, The

Netherlands

Title: A Deeper Look Into the Heart during Sepsis in the

Mouse

02/2013-07/2013 MSc Junior practical training

Dept. Of Neurology, Maastricht University, The

Netherlands 
09/2011-01/2012

Title: Inflammatory Reactivity in the Spleen and the Brain after Social Defeat Stress in Mice

Bachelor practical training

Dept. Of Oncology, Janssen Pharmaceutica, Beerse, Belgium

Title: Identification and Characterization of Cell Lines

Expressing a Specific Tyrosine Kinase and Development of Cellular Assays for Screening Small Compounds

Additional Activity

$04 / 2019$

2016-2019

2015-2019
International ESM-EVBO 2019 conference

Organizer of the Young Investigator Program

PhD Academy Maastricht

Social Committee member

PhD representative committee "I'MCARIM"

Chair of the committee

Publications

Low human and murine Mcl-1 expression leads to a pro-apoptotic plaque phenotype enriched in giant-cells.

MAC Fontaine, MM Westra, I Bot, H Jin, AJPM Franssen, M Bot, SCA de Jager, I Dzhagalov, Y-W He, BJM van Vlijmen, MJJ Gijbels, CP Reutelingsperger, TJC van Berkel, JC Sluimer, L Temmerman, EAL Biessen

Scientific Reports, 2019

A Novel Plaque Enriched Long Non-coding RNA in Macrophage Phagocytosis Regulation (PELATON)

J Hung, JP Scanlon, AD Mahmoud, J Rodor, M Ballantyne, MAC Fontaine, L Temmerman, J Kaczynski, K Connor, R Bhushan, EAL. Biessen, DE Newby, JC Sluimer, AH Baker

ATVB, 2019

Cardiovascular event prediction by machine learning: identification of a bloodbased lipid signature to stratify obese subjects

MAC Fontaine, T Aliyev, R Sikkens, MMJ van Greevenbroek, CJH van der Kallen, CG Schalkwijk, CDA Stehouwer, J Dehairs, R Derua, E Waelkens, M Nauck' E Hammer, U Völker, A Henneman, M Dörr, H Völzke, S Zylla, JC Sluimer, Y Mengerink, L Temmerman, EAL Biessen.

Submitted

Page | 242 
Towards a function-based model of macrophage plasticity: the MacroScreen platform

MAC Fontaine, H Jin H, T Ulas, J Schultze, J Huckriede, M Rousch, E Wijnands,JC Sluimer,L Temmerman, EAL Biessen

In Preparation

The systemic acute myocardial infarction environment reprograms human macrophages

MAC Fontaine, $\mathrm{H}$ Jin, M Gagliardi, M Rousch, E Wijnands, G Andersen, Bente Halvorsen, EAL Biessen, L Temmerman

In Preparation

Awards and selected talks

May $2019 \quad$ European Atherosclerosis Society (EAS) Meeting 2019. Maastricht, the Netherlands

Selected e-poster presentation: "Barcoding the lipidome in the obese:

who's at increased risk for the development of cardiovascular disease?"

April 2019 ESM-EVBO2019 conference. Maastricht, the Netherlands

Selected oral presentation: "Barcoding the lipidome in the obese:

who's at increased risk for the development of cardiovascular disease?"

Nov. 2018 Best poster prize

CARIM symposium day, Maastricht, The Netherlands

Nov. 2018 Best poster prize

Pathology research day, Valkenburg, The Netherlands

Oct. $2018 \quad$ Poster prize

PhD Training course, Dutch Heart Foundation, Papendal, The Netherlands

April $2018 \quad 24^{\text {th }}$ Annual Scandinavian Atherosclerosis Conference, Humlabaek, Denmark

Selected oral presentation: "Barcoding the adipokines in the obese:

Who's at risk for the development of cardiovascular disease?" 
Nov. $2017 \quad 1^{\text {st }}$ oral presentation prize

Pathology research day, Valkenburg, The Netherlands

Nov. 2017 Netherlands Vascular Biology meeting, Biezenmortel, the Netherlands

Selected oral presentation: "Barcoding the adipokines in the obese:

Who's at risk for the development of cardiovascular disease?"

Oct. 2017 Poster prize

PhD Training course, Dutch Heart Foundation, Papendal, The Netherlands

Oct. 2017 Audience prize oral presentation

PhD Training course, Dutch Heart Foundation, Papendal, The Netherlands 